\title{
Near-Field Hydrology Data Package for the Immobilized Low-Activity Waste 2001 Performance Assessment
}

\author{
P. D. Meyer \\ R. J. Serne
}

December 1999

Prepared for the U.S. Department of Energy under Contract DE-AC06-76RLO 1830

Pacific Northwest National Laboratory

Richland, Washington 


\section{DISCLAIMER}

This report was prepared as an account of work sponsored by an agency of the United States Government. Neither the United States Government nor any agency thereof, nor any of their employees, make any warranty, express or implied, or assumes any legal liability or responsibility for the accuracy, completeness, or usefulness of any information, apparatus, product, or process disclosed, or represents that its use would not infringe privately owned rights. Reference herein to any specific commercial product, process, or service by trade name, trademark, manufacturer, or otherwise does not necessarily constitute or imply its endorsement, recommendation, or favoring by the United States Government or any agency thereof. The views and opinions of authors expressed herein do not necessarily state or reflect those of the United States Government or any agency thereof. 


\section{DISCLAIMER}

Portions of this document may be illegible in electronic image products. Images are produced from the best available original document. 


\section{Summary}

Lockheed Martin Hanford Company (LMHC) is designing and assessing the performance of disposal facilities to receive radioactive wastes that are currently stored in single- and double-shell tanks at the Hanford Site. The preferred method for disposing of the portion that is classified as immobilized lowactivity waste (ILAW) is to vitrify the waste and place the product in near-surface, shallow land burial facilities. The LMHC project to assess the performance of these disposal facilities is the Hanford ILAW Performance Assessment (PA) Activity. The goal of this project is to provide a reasonable expectation that the disposal of the waste is protective of the general public, groundwater resources, air resources, surface water resources, and inadvertent intruders. Achieving this goal will require prediction of contaminant migration from the facilities. This migration is expected to occur primarily via the movement of water through the facilities and the consequent transport of dissolved contaminants in the pore water of the vadose zone.

Pacific Northwest National Laboratory (PNNL) assists LMHC in its performance assessment activities. One of PNNL's tasks is to provide estimates of the physical, hydraulic, and transport properties of the materials comprising the disposal facilities and the disturbed region around them. These materials are referred to as the near-field materials. Their properties are expressed as parameters of constitutive models used in simulations of subsurface flow and transport. In addition to the best-estimate parameter values, information on uncertainty in the parameter values and estimates of the changes in parameter values over time are required to complete the PA. These parameter estimates and information are contained in this report, the Near-Field Hydrology Data Package. 


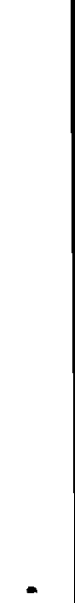




\section{Acknowledgments}

Technical reviews of this report were provided by Dr. John R. Nimmo of the U.S. Geological Survey, Dr. Bridget R. Scanlon of the Texas Bureau of Economic Geology, and Dr. Gary P. Streile of Pacific

Northwest National Laboratory. These reviews contributed significantly to the technical soundness and timely completion of this report. 


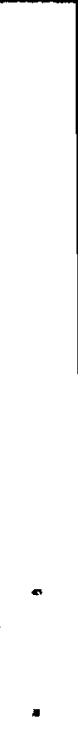




\section{Contents}

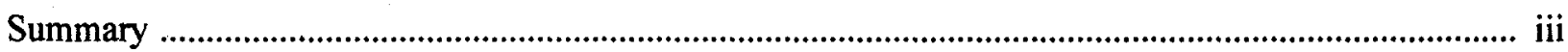

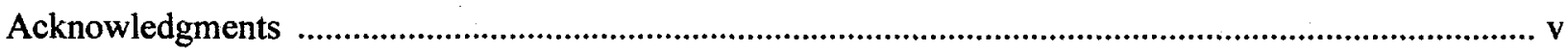

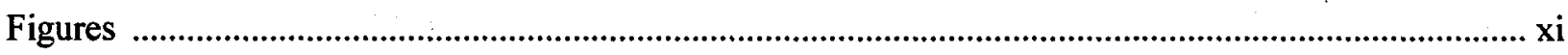

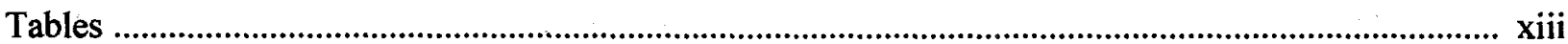

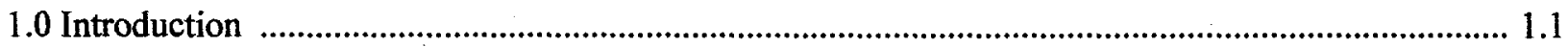

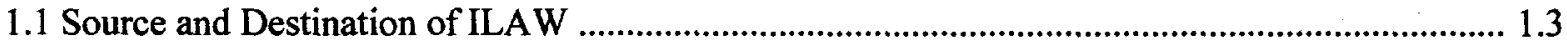

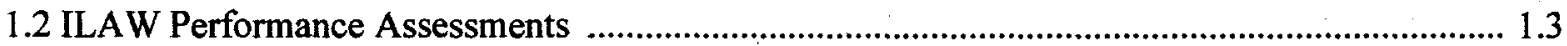

2.0 Facility Design and Description of Near-Field Materials ........................................................... 2.1

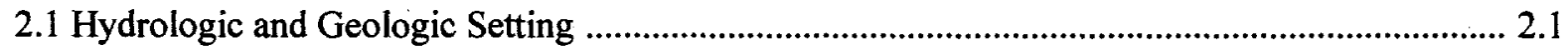

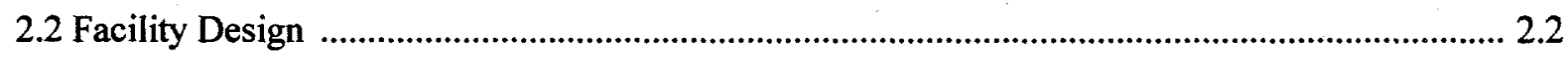

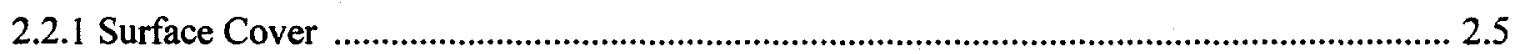

2.2.1.1 Layer 1: Silt Loam Soil with Gravel ................................................................... 2.5

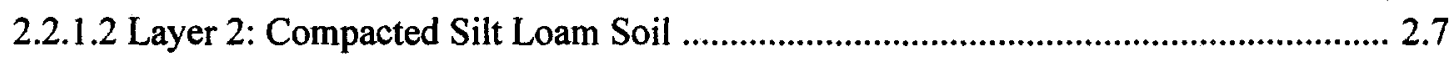

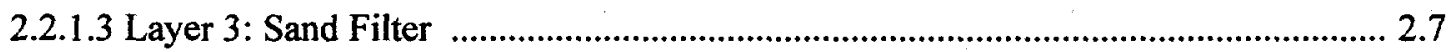

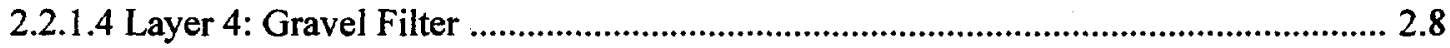

2.2.1.5 Layer 5: Gravel Lateral Drainage Layer ............................................................... 2.8

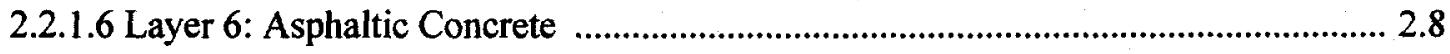

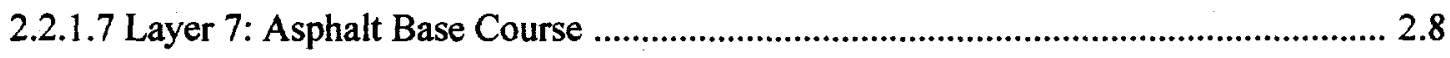

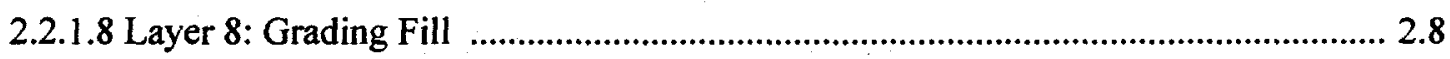

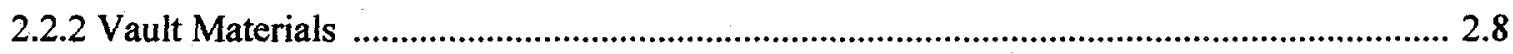

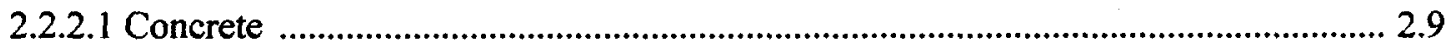

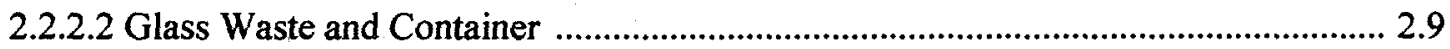

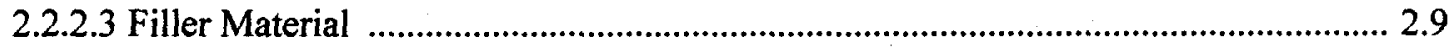

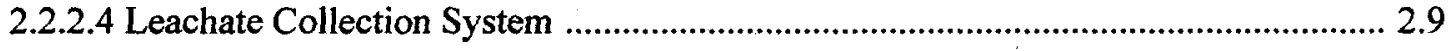

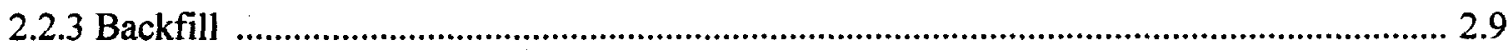

2.2.4 Water Conditioning Layer .................................................................................... 2.10

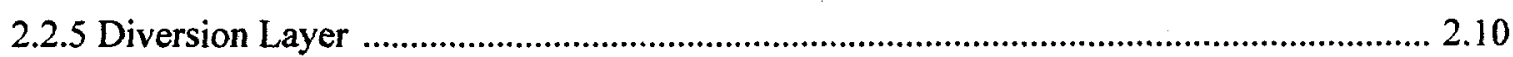

3.0 Required Properties and Parameters of Near-Field Materials ................................................... 3.1

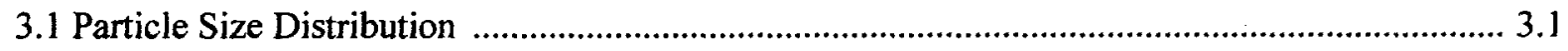

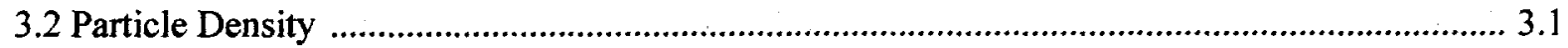

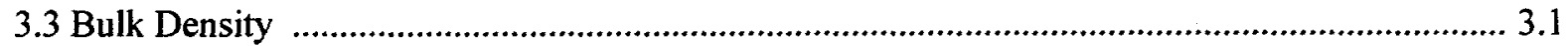

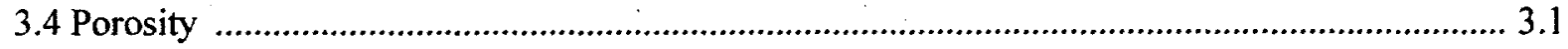

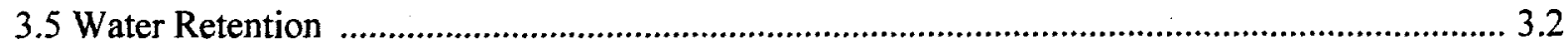

vii 


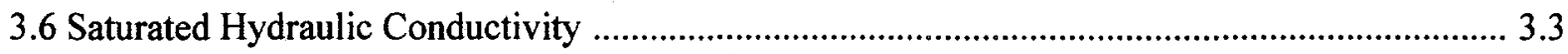

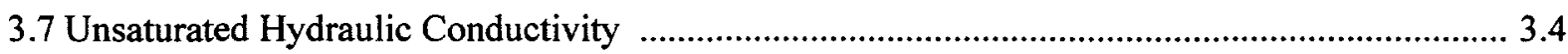

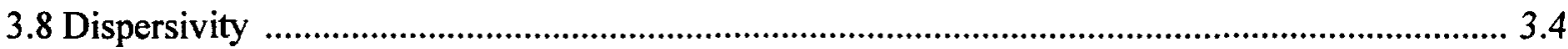

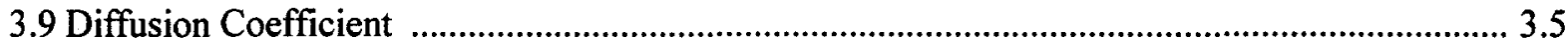

4.0 Best-Estimate Values for Hydraulic Parameters of Near-Field Materials ........................................ 4.1

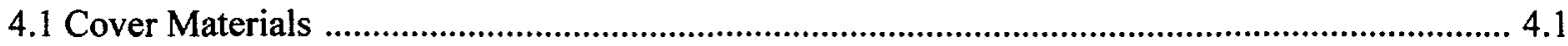

4.1.1 Silt Loam-Gravel Admix ................................................................................................. 4.1

4.1.2 Compacted Silt Loam ................................................................................................. 4.2

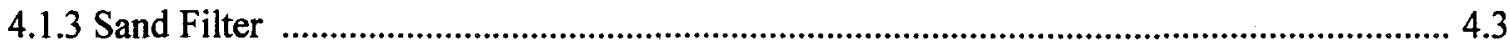

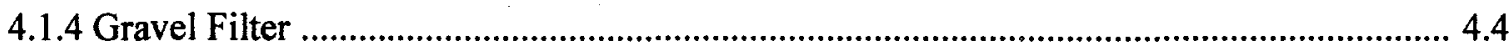

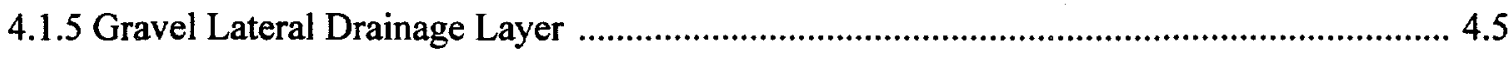

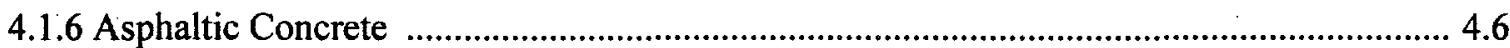

4.1.7 Asphalt Base Course and Grading Fill .............................................................................. 4.6

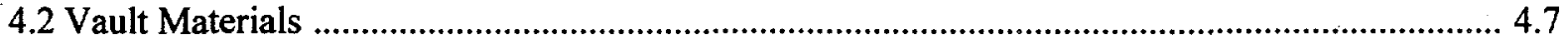

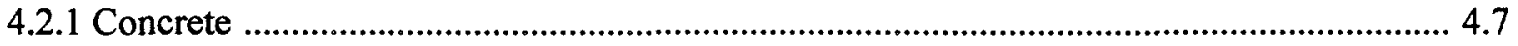

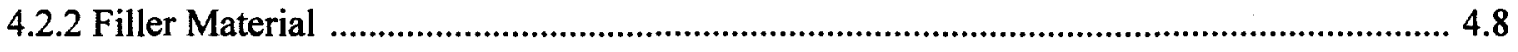

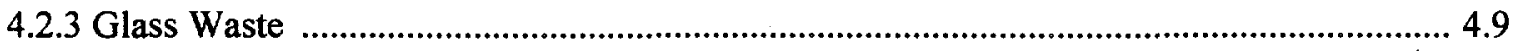

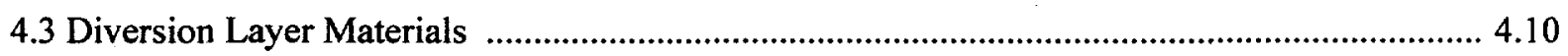

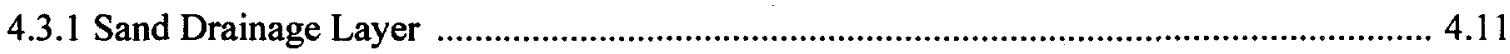

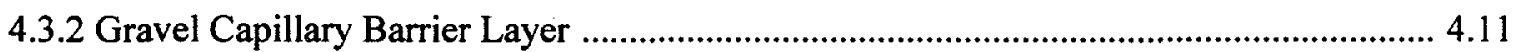

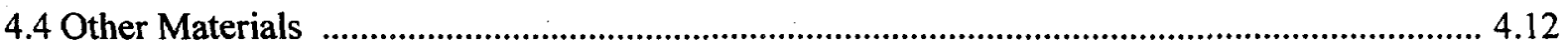

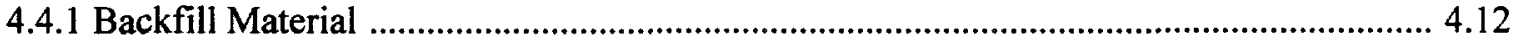

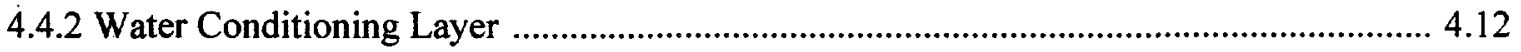

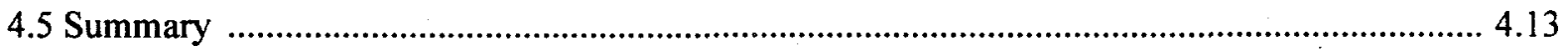

5.0 Best-Estimate Values for Transport Parameters of Near-Field Materials ....................................... 5.1

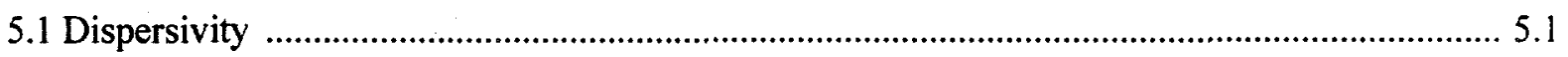

5.2 Apparent Diffusion Coefficients through Concrete ......................................................... 5.2

5.2.1 Conceptual Model of Diffusion through Cement ............................................................. 5.2

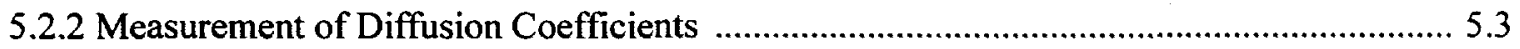

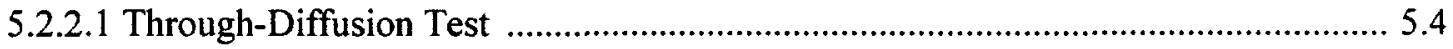

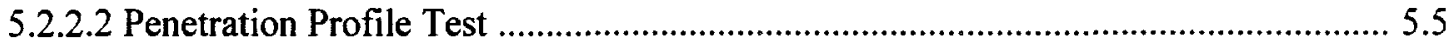

5.2.3 Best-Estimate Diffusion Coefficients .................................................................................. 5.6

5.3 Apparent Diffusion Coefficients in Backfill and Glass Waste ............................................ 5.11

6.0 Uncertainty and Other Issues Affecting Parameter Values ............................................................ 6.1 


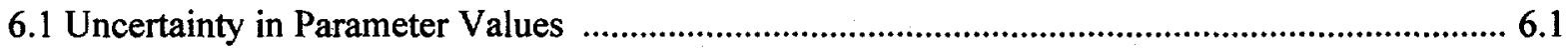

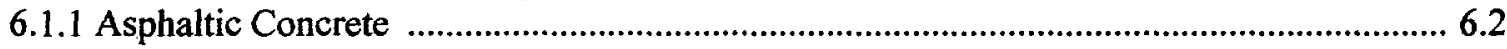

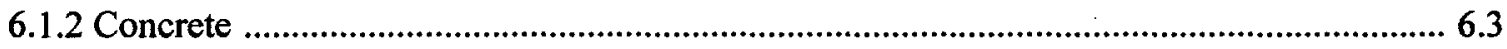

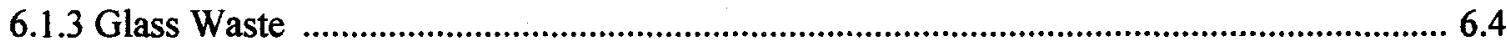

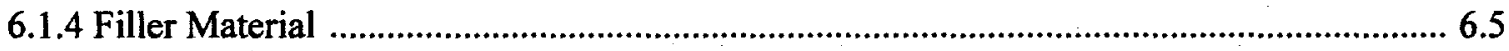

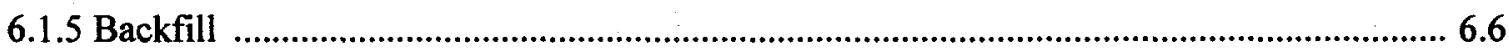

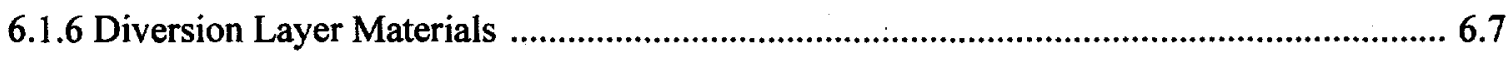

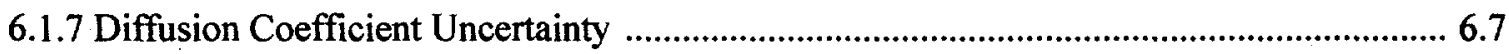

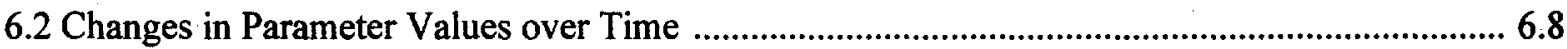

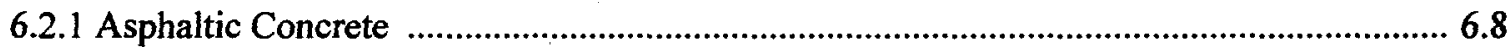

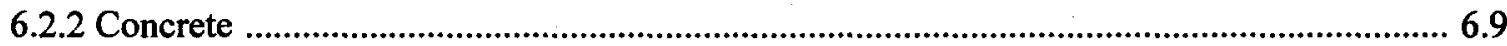

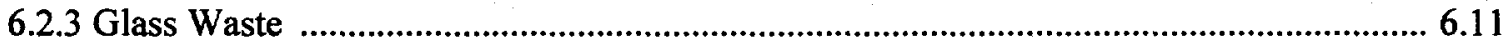

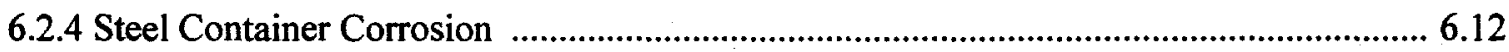

6.2.5 Backfill and Filler Material between Waste Packages .................................................. 6.13

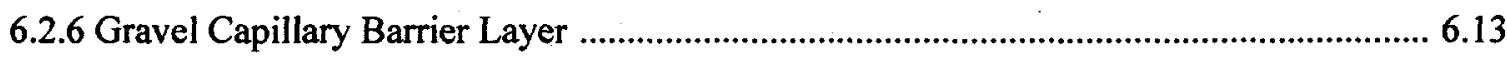

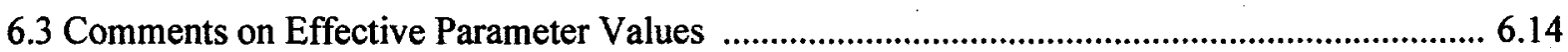

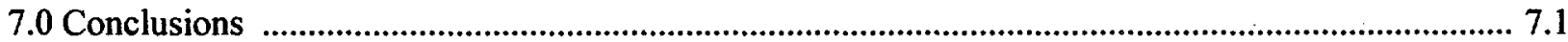

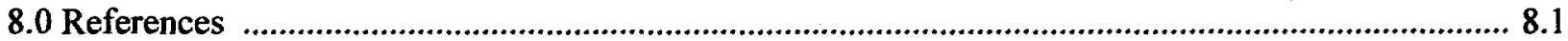

Appendix A: Quality Assurance and Safety ….................................................................................. A.1 


\section{Figures}

1.1 Location of the Hanford Site in Washington State ....................................................................... 1.1

1.2 Hanford Site Map Illustrating the Locations of Major Facility Areas, Public Roads, Rivers, and the Future Site Boundary

1.3 Location of the ILAW Disposal Facilities within the Hanford Site 200 East Area: Existing Disposal Facility and New ILAW Disposal Facility

2.1 Detailed Geologic Logs for Boreholes B8501, B8502, and 299-E17-21 from the Southwest Corner of the New ILAW Disposal Site

2.2 Schematic Cross-Section of an Excavation Trench and Vault at the New ILAW Disposal Facility

2.3 Schematic Profile of the Modified RCRA Subtitle C Barrier Currently Intended for Use on the ILAW Disposal Facilities

4.1 Water Retention and Hydraulic Conductivity Functions for Near-Field Materials Using the Best-Estimate Parameters 


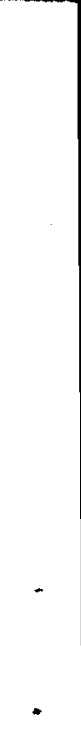




\section{Tables}

4.1 Best-Estimate Parameter Values for Silt Loam-Gravel Admixture .......................................... 4.2

4.2 Best-Estimate Parameter Values for Compacted Silt Loam ...................................................... 4.3

4.3 Best-Estimate Parameter Values for Sand Filter ...................................................................... 4.4

4.4 Particle Size Distribution for Sand Filter .......................................................................... 4.4

4.5 Best-Estimate Parameter Values for Gravel Filter ....................................................................... 4.4

4.6 Particle Size Distribution for Gravel Filter ............................................................................. 4.5

4.7 Best-Estimate Parameter Values for Gravel Drainage Layer ....................................................... 4.5

4.8 Particle Size Distribution for Gravel Drainage Layer ............................................................... 4.5

4.9 Best-Estimate Parameter Values for Asphaltic Concrete ........................................................... 4.6

4.10 Best-Estimate Parameter Values for Asphalt Base Course ....................................................... 4.7

4.11 Best-Estimate Parameter Values for Grading Fill .............................................................. 4.7

4.12 Best-Estimate Parameter Values for Concrete ....................................................................... 4.8

4.13 Best-Estimate Parameter Values for Filler Material ....................................................................... 4.9

4.14 Best-Estimate Parameter Values for Glass Waste ............................................................... 4.10

4.15 Best-Estimate Parameter Values for Sand Drainage Layer ................................................... 4.11

4.16 Best-Estimate Parameter Values for Gravel Capillary Barrier Layer ......................................... 4.11

4.17 Best-Estimate Parameter Values for Backfill ............................................................................ 4.12

4.18 Best-Estimate Parameter Values for Water Conditioning Layer ................................................ 4.13

4.19 Summary of Best-Estimate Parameter Values for Near-Field Materials ................................... 4.14

5.1 The Composition of ILAW Concrete Used in Diffusion Testing ................................................. 5.7

5.2 Best-Estimate Apparent Diffusion Coefficients for Constituents Migrating through Cement ..... 5.8

5.3 Best-Estimate Free-Water Diffusion Coefficients and Capacity Factors for Constituents Migrating through Concrete ........................................................................................... 5.10

6.1 Reasonable Bounding Values for Critical Asphaltic Concrete Parameters ................................ 6.3

6.2 Reasonable Bounding Values for Concrete Parameters ............................................................. 6.4

6.3 Reasonable Bounding Values for Glass Waste Parameters ....................................................... 6.5

6.4 Reasonable Bounding Values for Filler Material Parameters ................................................ 6.6

6.5 Reasonable Bounding Values for Backfill Parameters .............................................................. 6.6

6.6 Diversion Layer Parameters Used by Nichols and Meyer (1996) for their Poorest and

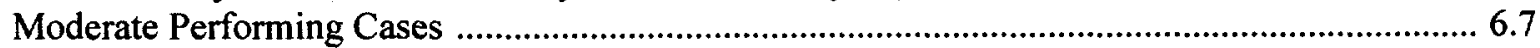

6.7 Assumed Particle Size Distribution for Fully Degraded Concrete ........................................... 6.10

6.8 Parameter Values for Fully Degraded Concrete ............................................................... 6.11

6.9 Representative Parameter Values for the Fully Corroded Steel Containers .............................. 6.13 


\subsection{Introduction}

The Hanford Site was established in 1944 as a U.S. Government nuclear materials production facility. During its history, site missions included nuclear reactor operation, storage and reprocessing of spent nuclear fuel, and management of radioactive and hazardous wastes. Today, activities on the site involve environmental restoration, energy-related research, and technology development. Fifty-five years of operations have resulted in the accumulation of significant quantities of radioactive and hazardous wastes as well as their intentional and unintentional release to the environment. Figure 1.1 shows the location of the Hanford Site within Washington State and the proximity of major population centers. Figure 1.2 shows the boundaries of the Hanford Site and the location of the major facilities. The 100 Areas are the sites of reactor facilities. The major processing facilities, waste storage facilities, and waste disposal areas are located in the 200 Areas.

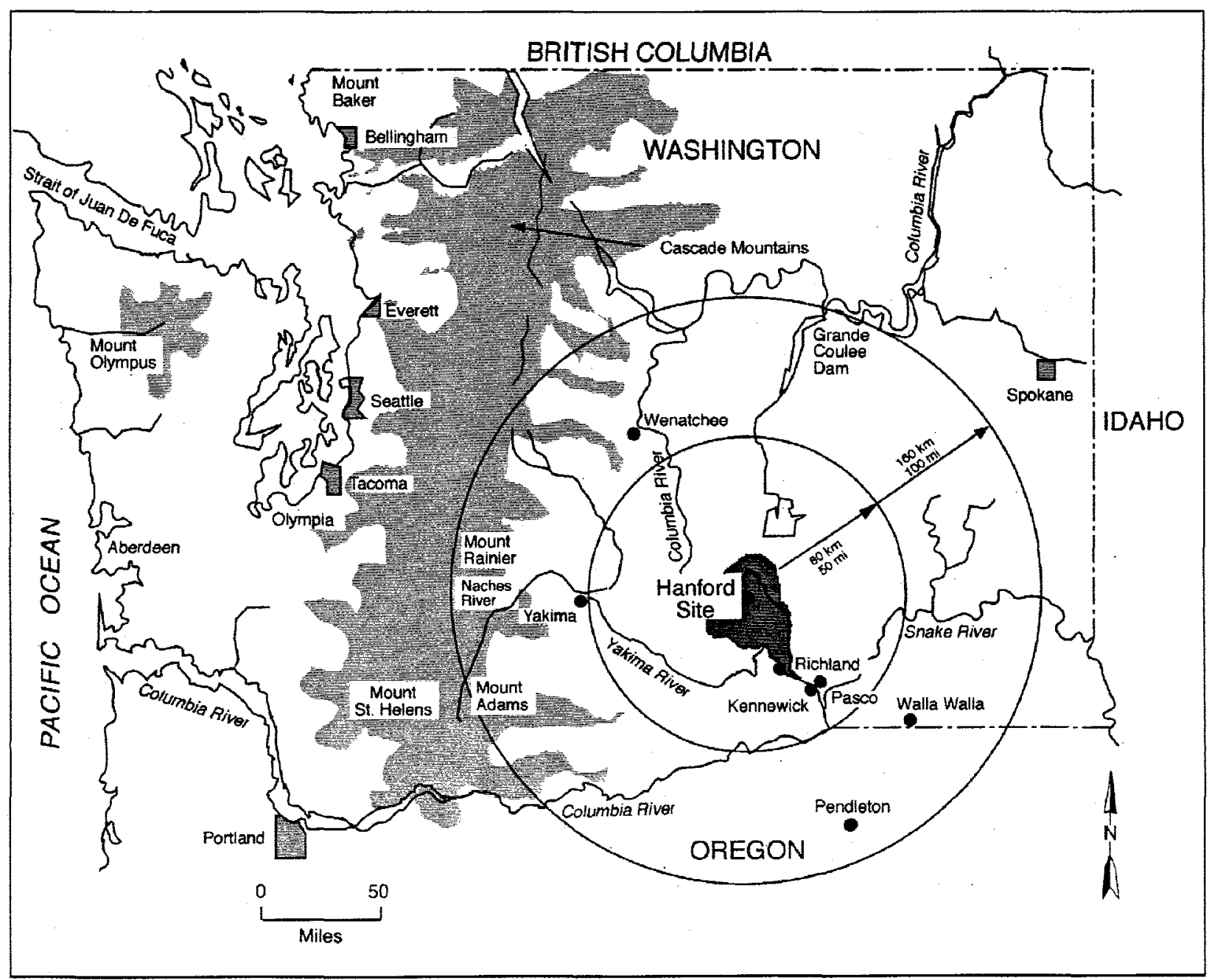

$\$ 9211085.21$

Figure 1.1. Location of the Hanford Site in Washington State 


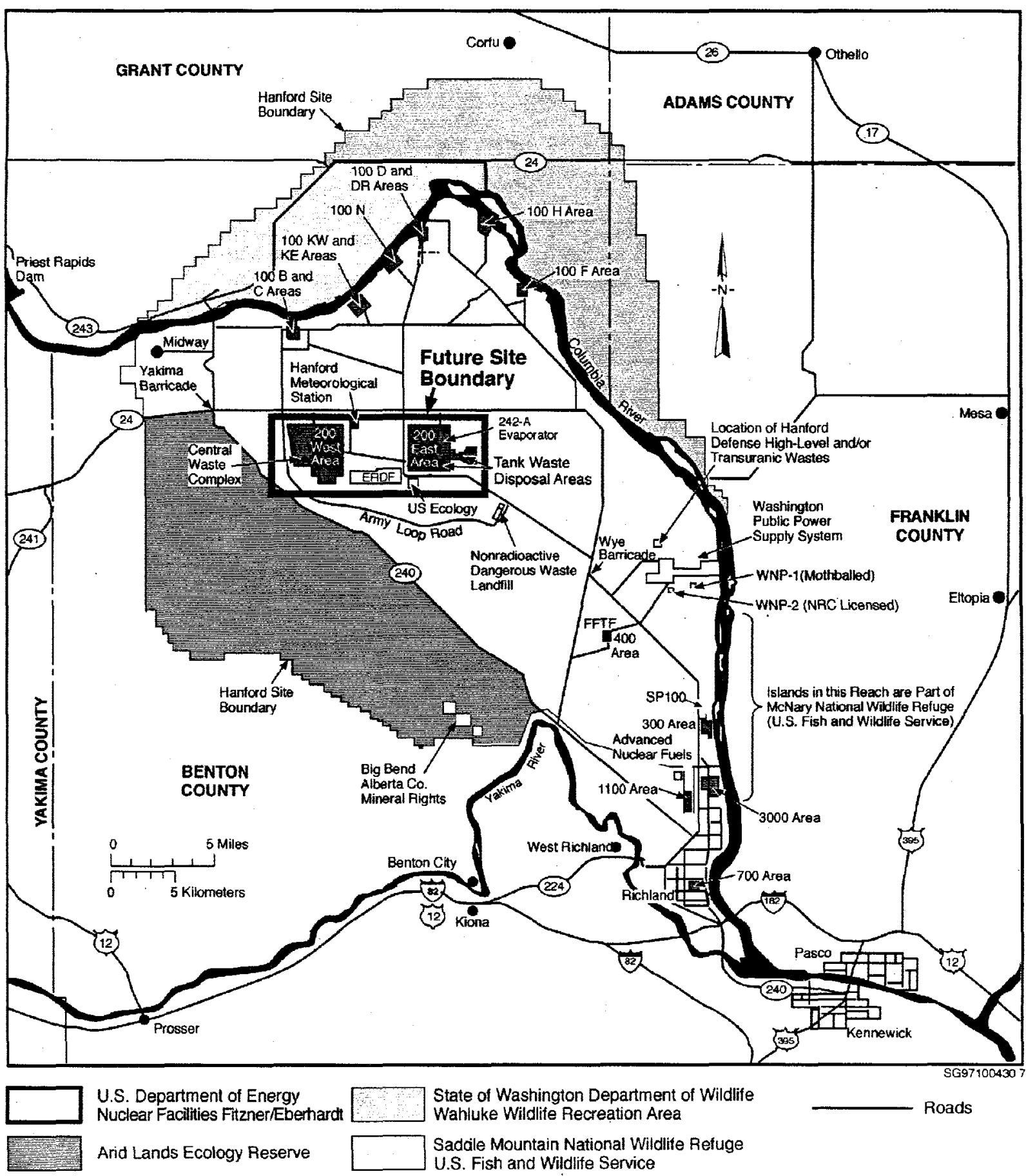

Figure 1.2. Hanford Site Map Illustrating the Locations of Major Facility Areas, Public Roads, Rivers, and the Future Site Boundary 


\subsection{Source and Destination of ILAW}

The legacy of the earlier Hanford missions consists of approximately $204,000 \mathrm{~m}^{3}$ of radioactive and mixed waste stored in 177 buried single- and double-shell tanks in the Hanford Site 200 Areas. Some of the more important radionuclides in these wastes are ${ }^{3} \mathrm{H},{ }^{79} \mathrm{Se},{ }^{90} \mathrm{Sr},{ }^{99} \mathrm{Tc},{ }^{129} \mathrm{I},{ }^{126} \mathrm{Sn}$, and ${ }^{137} \mathrm{Cs}$, as well as isotopes and progeny of uranium, plutonium, neptunium, and americium. The current plan for disposal of this waste calls for retrieval of the waste from the tanks, separation of the waste into high-level and lowactivity waste streams, and vitrification (incorporation in glass) of each waste stream. Vitrification is intended to immobilize the waste components within the glass matrix. The high-level waste stream will be relatively low in volume, but will contain most of the radionuclides. Vitrified high-level waste will be stored on the Hanford Site until shipped to a federally approved repository. The immobilized low-activity waste (ILAW) will contain the bulk of the material from the tanks, including most of the non-radioactive chemical constituents, but relatively few radionuclides. (This paragraph references information found in Mann, 1999b.)

Current plans for disposal of the ILAW call for the molten glass waste to be placed in steel containers. These containers will be stacked in underground vaults located in the 200 East Area. Existing vaults, constructed for the grouted tank waste disposal program, will be used for the initial production of ILAW. The location of these existing disposal facility vaults is shown in Figure 1.3. The bulk of the waste (approximately 96\%) will be placed in newly constructed vaults located to the southwest of the existing vaults, within the area marked ILAW on Figure 1.3 (Mann, 1999b; Burbank and Hohl, 1999). Protective surface covers will be constructed over the vaults prior to closure. Additional details on disposal facility design are given in Section 2.2.

\subsection{ILAW Performance Assessments}

Lockheed Martin Hanford Company (LMHC) is designing and assessing the performance of the disposal facilities to receive the ILAW. The LMHC project to assess the performance of these disposal facilities is called the Hanford ILAW Performance Assessment (PA) Activity, referred to as the ILAW PA within this report. An interim PA (Mann et al., 1997) and the 1998 ILAW PA (Mann et al., 1998) were the initial efforts to demonstrate the feasibility of safely disposing of ILAW at the Hanford Site. Because the ILAW PA project was in its early stages during the preparation of these PAs, the analyses were conducted using conceptual designs of the facilities and reasonable estimates of material properties without having site-specific and waste-form-specific information. The project has since collected a variety of information including geologic, geochemical, and hydraulic data from a borehole adjacent to the new ILAW disposal site, site-specific recharge data, and geochemical information on contaminant transport through the site sediments. In addition, hydraulic and geochemical information for the expected materials of the disposal facilities and data regarding the behavior of the expected waste form have been and continue to be collected. In addition, various facility design alternatives have been considered and a definitive conceptual design has been proposed for the new ILAW disposal facility. In preparation for a revision of the ILAW PA 


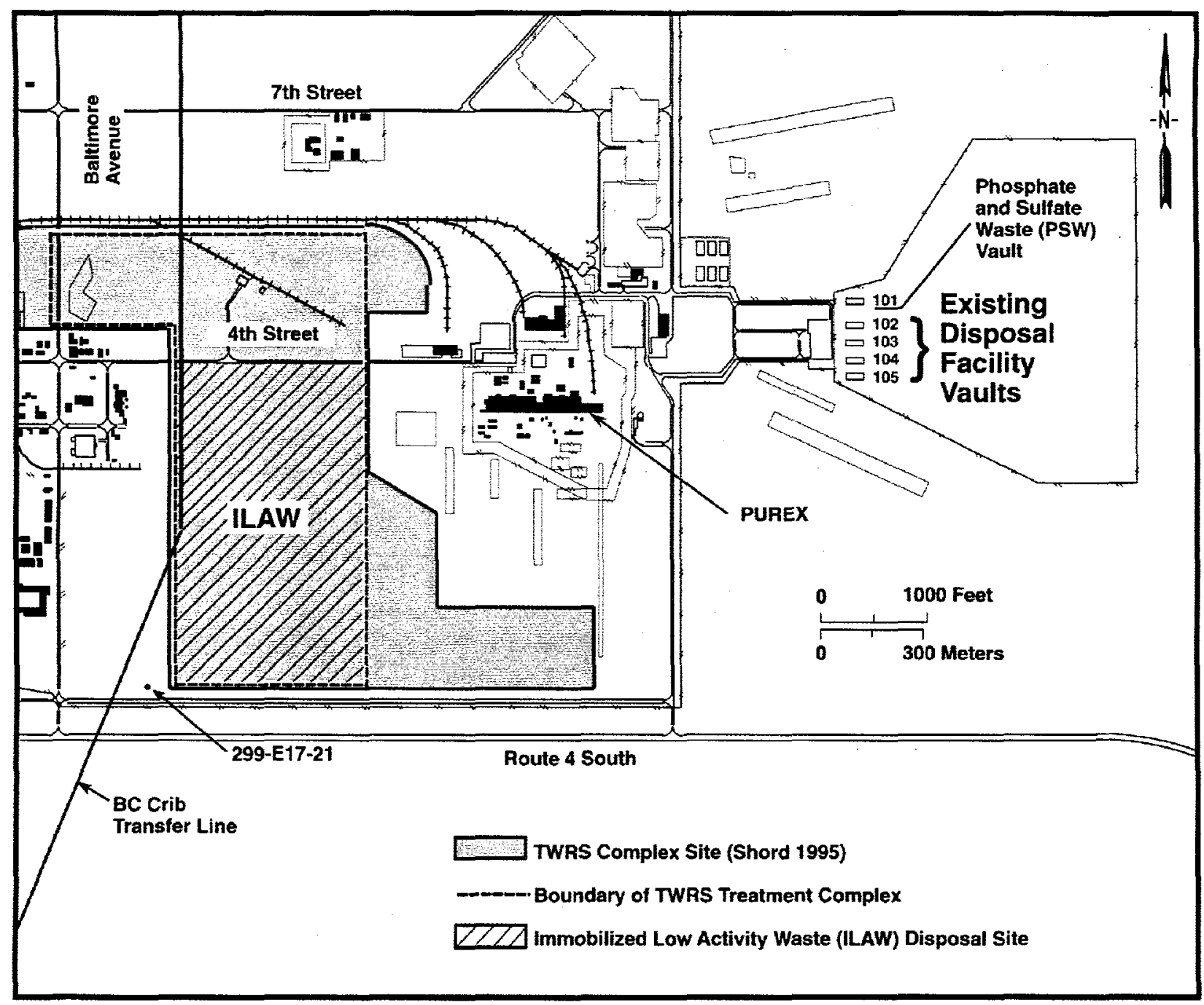

Figure 1.3. Location of the ILAW Disposal Facilities within the Hanford Site 200 East Area: Existing Disposal Facility and New ILAW Disposal Facility (labeled ILAW)

(the 2001 ILAW PA), a number of data packages are being prepared (LMHC, 1998). These data packages will bring together recently collected site-specific ILAW data as well as relevant data collected by other projects. This additional information will be used in the 2001 ILAW PA. These additional data packages include information on geology (Reidel and Horton, 1999), recharge (Fayer et al., 1999), flow and transport in the natural sediments (Khaleel, 1999), geochemistry (Kaplan and Serne, 1999), waste form release (McGrail et al., 1999), and facility design (Puigh, 1999). All data package reports will be included as appendices in the 2001 ILAW PA.

The goal of the PAs is to provide a reasonable expectation that the disposal of the waste is protective of the general public, groundwater resource, air resources, surface water resources, and inadvertent intrud- 
ers. Radiological performance objectives and dangerous material (hazardous chemical) performance goals to be used in the 2001 ILAW PA are described in Mann (1999a). The radiological performance objectives include dose limits for an all-pathways scenario and an inadvertent intruder scenario as well as concentration and dose limits in groundwater, surface water, and air. Performance objectives are evaluated for 1,000 and 10,000 years, but are calculated to the time of peak or 10,000 years, whichever is longer. Results from the 1998 ILAW PA (Mann et al., 1998) showed that long-lived radionuclides (e.g., uranium and its daughter products) may produce peak impacts at times significantly greater than 10,000 years after closure.

The specific scenarios to be considered in the 2001 ILAW PA are discussed in Mann (1999b). It is assumed that the main pathway by which exposure will occur involves water movement into and through the disposal facilities, dissolution of the waste, transport of contaminants through the vadose zone to the unconfined aquifer, transport in the aquifer to an extraction well, and human exposure via domestic use of the pumped water. Prediction of subsurface flow and contaminant transport via numerical simulation will be required to complete the 2001 PA. In addition to a base case simulation, sensitivity calculations will be performed to demonstrate that the design for the ILAW disposal achieves impacts that are as low as reasonably achievable (ALARA).

Pacific Northwest National Laboratory (PNNL) assists LMHC in its performance assessment activities. One of PNNL's tasks is to provide estimates of the physical, hydraulic, and transport properties of the materials comprising the disposal facilities and the disturbed region around them. These materials are referred to as the near-field materials. Their properties are expressed as parameters of constitutive models used in simulations of subsurface flow and transport. In addition to the best-estimate parameter values (to be used in the base case simulation), information on uncertainty in the parameter values and estimates of the changes in parameter values over time are required to satisfy the ALARA requirement of the PA. These parameter estimates and information are contained in this report, the Near-Field Hydrology Data Package. 


\subsection{Facility Design and Description of Near-Field Materials}

A brief summary of the hydrologic and geologic setting of the ILAW disposal facilities is presented in this section. This is followed by a detailed discussion of the current conceptual design of the disposal facilities and the near-field materials to be used in their construction.

\subsection{Hydrologic and Geologic Setting}

The Hanford Site is located in the semiarid Pasco Basin of the Columbia Plateau in southeastern Washington State, within the rain shadow of the Cascade Mountain Range. The Hanford Meteorological Station, located between the 200 East and 200 West Areas on the Hanford Site, has been collecting climatological data representative of the ILAW disposal sites since 1945 (Hoitink et al., 1999). Precipitation at the Hanford Meteorological Station has averaged $17.4 \mathrm{~cm} / \mathrm{yr}$. since 1946, with more than half of the annual precipitation occurring from November through February. Days with more than $1.3 \mathrm{~cm}$ of precipitation occur on average less than once each year. Rainfall intensities of $1.3 \mathrm{~cm} / \mathrm{hr}$. with a duration of one hour are expected to occur once every 10 years. Rainfall intensities of $2.5 \mathrm{~cm} / \mathrm{hr}$. with a one-hour duration are expected to occur once every 500 years. Monthly average snowfall ranges from $0.8 \mathrm{~cm}$ in March to 13.7 $\mathrm{cm}$ in December. The maximum recorded monthly snowfall is $60 \mathrm{~cm}$; the maximum recorded seasonal snowfall is $142 \mathrm{~cm}$. On average, snowfall accounts for about $38 \%$ of precipitation from December through February.

Average daily maximum temperature varies from $2{ }^{\circ} \mathrm{C}$ in late December and early January to $35^{\circ} \mathrm{C}$ in late July. On average, there are 52 days during the summer months with a maximum temperature greater than or equal to $32^{\circ} \mathrm{C}$ and 12 days with a maximum temperature greater than $38^{\circ} \mathrm{C}$. From mid-November through early March, minimum temperatures average less than or equal to $0^{\circ} \mathrm{C}$. The recorded maximum temperature is $45^{\circ} \mathrm{C}$; the recorded minimum is $-31^{\circ} \mathrm{C}$.

The Hanford Site is characterized as a shrub-steppe ecosystem that is adapted to the region's midlatitude, semiarid climate (Neitzel, 1998). Such ecosystems are typically dominated by a shrub overstory with a grass understory. Livestock grazing and agricultural production prior to government control of the Hanford Site contributed to colonization by non-native vegetation species that currently dominate portions of the landscape. In addition, summer range fires have tended to eliminate fire-intolerant species and have allowed more opportunistic and fire-resistant species a chance to become established. The dominant nonnative species on the site is cheatgrass.

Three soil types occur in the vicinity of the ILAW disposal sites. As described by Hajek (1966), these soils are: Burbank Loamy Sand, a coarse-textured soil usually about $40 \mathrm{~cm}$ thick, underlain by a subsoil with a gravel content ranging from 20 to 80 volume percent; Ephrata Sandy Loam, a medium-textured soil underlain by gravelly material; and Rupert Sand, generally characterized as a coarse sand developed under grass, sagebrush, and hopsage in coarse sandy alluvial deposits. 
The semiarid climate results in fairly low rates of groundwater recharge. Natural recharge rates across the Hanford Site are estimated to range from 0 to more than $10 \mathrm{~cm} / \mathrm{yr}$ depending on surface soils, vegetation, and topography (Fayer and Walters, 1995). Minimal recharge rates occur in fine-textured soils where deep-rooted plants prevail. Larger recharge rates are likely to occur in areas with coarse, gravelly surface sediments and little or no vegetation. Fayer et al. (1999) provides estimates of the recharge rates expected to occur on the ILAW disposal sites.

The ILAW disposal sites are located on the Cold Creek bar (commonly referred to as the 200 Areas Plateau), a geomorphic remnant of the cataclysmic floods of the Pleistocene epoch (the Missoula Floods). The stratigraphy in the area consists of basalt flows overlain by the Ringold Formation sediments, Hanford Formation sediments, and surficial deposits. The Ringold Formation consists of clay, silt, compacted mud, fine- to coarse-grained sand and granular to cobble gravel. The Hanford Formation, deposited by the Missoula Floods, consists of pebble-to-boulder sized gravel, fine- to coarse-grained sand, and silt. The finegrained sediments were deposited under slackwater and backflooded conditions. The surficial sediments consist of alluvial and eolian silt, sand, and gravel deposits that are generally less than $5 \mathrm{~m}$ thick. The southernmost $200 \mathrm{~m}$ of the new ILAW disposal site (see Figure 1.3) is covered with a stabilized sand dune that is as much as $8 \mathrm{~m}$ high (Fayer et al., 1999). Reidel and Horton (1999) provides detailed information on the available geologic information for the ILAW disposal sites (see also Reidel and Reynolds, 1998).

The ILAW disposal vaults will be constructed in excavations within the surficial and upper Hanford Formation sediments. Excavations are likely to be no more than 10 to $15 \mathrm{~m}$ deep. Three boreholes drilled near the southwest corner of the new ILAW disposal site in 1998 provide information on the nature of the sediments within the depth of the facility excavations (Reidel et al., 1998). Figure 2.1 contains the detailed geologic logs from the three boreholes for the upper $15 \mathrm{~m}(50 \mathrm{ft}$.). Note the generally coarse nature of the sediments and the presence of gravelly layers.

\subsection{Facility Design}

The existing disposal facility consists of concrete vaults constructed for the grouted waste disposal program (Kincaid et al., 1995). Use of these existing vaults for ILAW disposal will involve removal of the roofs from the vaults and subsequent placement of ILAW waste packages and filler material into the vaults. The vaults will then be sealed with new concrete roofs, and a modified RCRA C cover will be constructed to the original grade. The existing disposal facility vaults will hold about $4 \%$ of the anticipated volume of ILAW.

The new ILAW disposal facility will be constructed as described in PHMC (1998) (see also Puigh, 1999). The facility consists of a series of concrete vaults within which the waste packages will be placed. Each vault will be approximately $208 \mathrm{~m}$ long, $23 \mathrm{~m}$ wide, and $9 \mathrm{~m}$ deep and will be constructed within its own excavated trench. Construction of a new vault will take place as each vault is filled. A schematic cross-section of one of the new ILAW disposal facility vaults is shown in Figure 2.2 


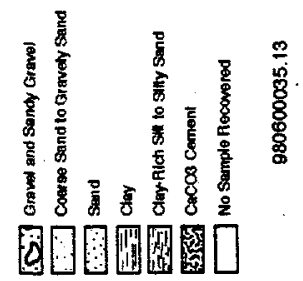

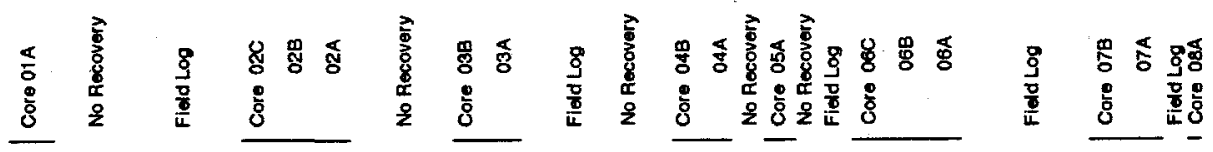
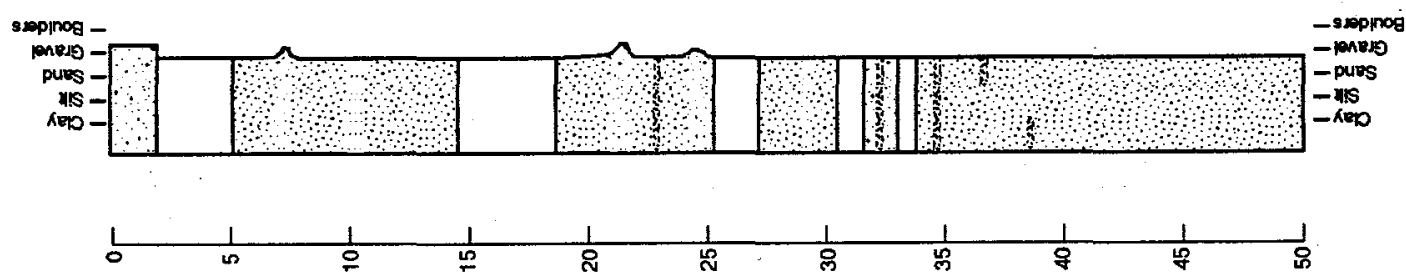

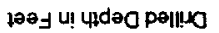

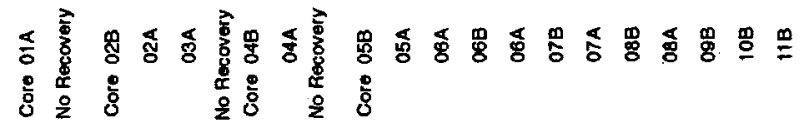
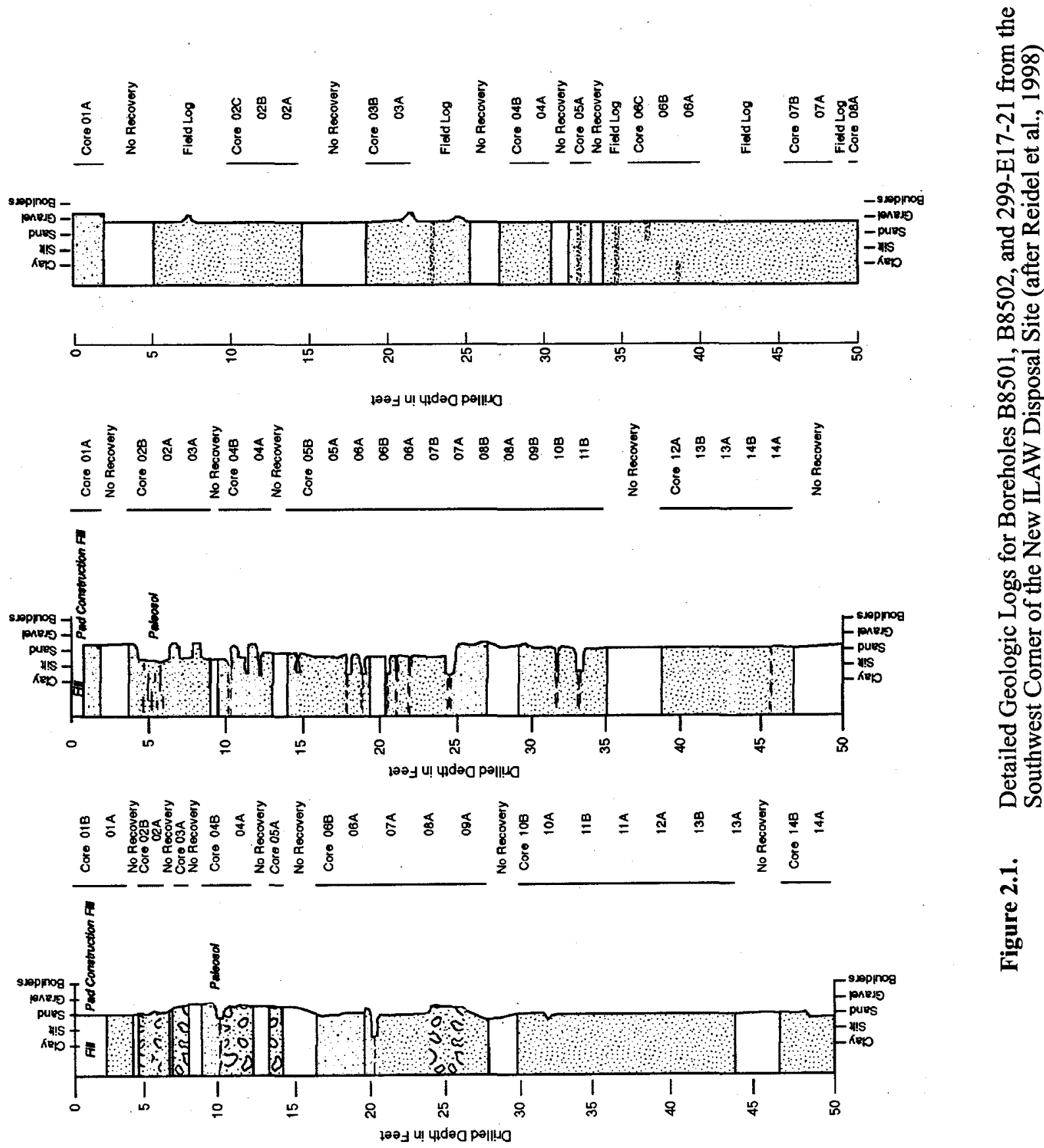

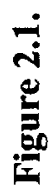




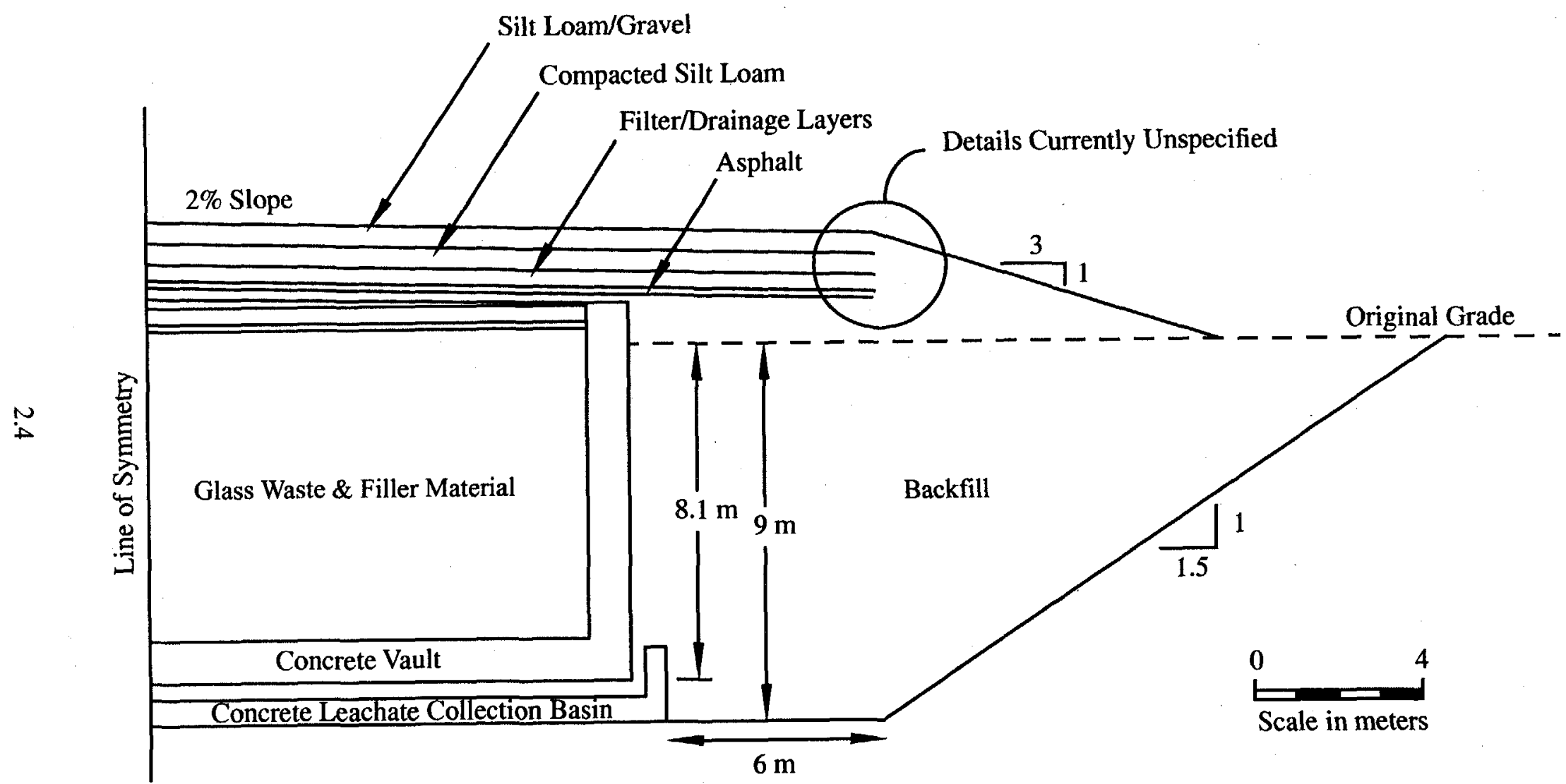

Figure 2.2. Schematic Cross-Section of an Excavation Trench and Vault at the New ILAW Disposal Facility 
For both ILAW facilities the waste packages consist of steel containers filled with the glass waste. The space in the vaults between waste packages will be filled with a porous material such as sand. The vaults will be covered with a controlled density fill (defined below) and a layer of concrete to produce a $2 \%$ slope. Backfill material will be used to fill in to the original grade. Prior to closure, a protective surface cover will be constructed over the vaults to provide a barrier to water. (Components of the cover will also serve as an inadvertent intruder barrier.) The current conceptual design for the new ILAW disposal facility calls for individual surface barriers to be constructed over each vault. Other design features such as a water conditioning layer and a water diversion layer are not currently specified, but may be included in the final facility design.

For the purposes of hydrologic modeling, the primary differences between the two facilities are as follows.

1. The geometry of the vaults differs.

2. The top of the existing disposal facility vaults are well below grade, whereas the top of the new disposal facility vaults will be approximately at the original grade.

3. High-strength concrete with an asphalt shell was used in the existing disposal facility vault. The type of concrete to be used in the new facility has not yet been specified, but it is anticipated to be a more conventional concrete, with no asphalt shell or coating.

Other than the type of concrete used and the asphalt shell, the near-field materials to be used at the existing disposal site and at the new ILAW disposal site are similar. Because no measurements have been made of the hydraulic properties for the concrete at the existing site, the discussion below of the near-field materials and the parameter values to be presented later in this report should be applied at both sites.

Each material currently specified or that may potentially be used in the ILAW disposal facility is discussed below.

\subsubsection{Surface Cover}

A Modified RCRA Subtitle C Barrier Design (DOE-RL, 1993) will be used as a surface cover for both the existing and the new disposal facilities. The components of this cover and their minimum thicknesses are shown in Figure 2.3. The combined minimum thickness of the cover is $1.7 \mathrm{~m}$. The thickness of individual components of the cover could be increased if needed to meet regulatory requirements. $A$ description of each component in the cover is given below, taken primarily from DOE-RL (1993). The ILAW facility cover is similar in design to the Hanford Prototype Barrier (DOE-RL, 1999; DOE-RL, 1993) and is expected to perform in a similar manner.

\subsubsection{Layer 1: Silt Loam Soil with Gravel}

This layer consists of $50 \mathrm{~cm}$ of sandy silt to silt loam soil from the McGee Ranch area on the Hanford Site with $15 \%$ pea gravel by weight. The design bulk density of this layer is about $1.46 \mathrm{~g} / \mathrm{cm}^{3}$. The 


\section{Modified RCRA Subtitle C Barrier}

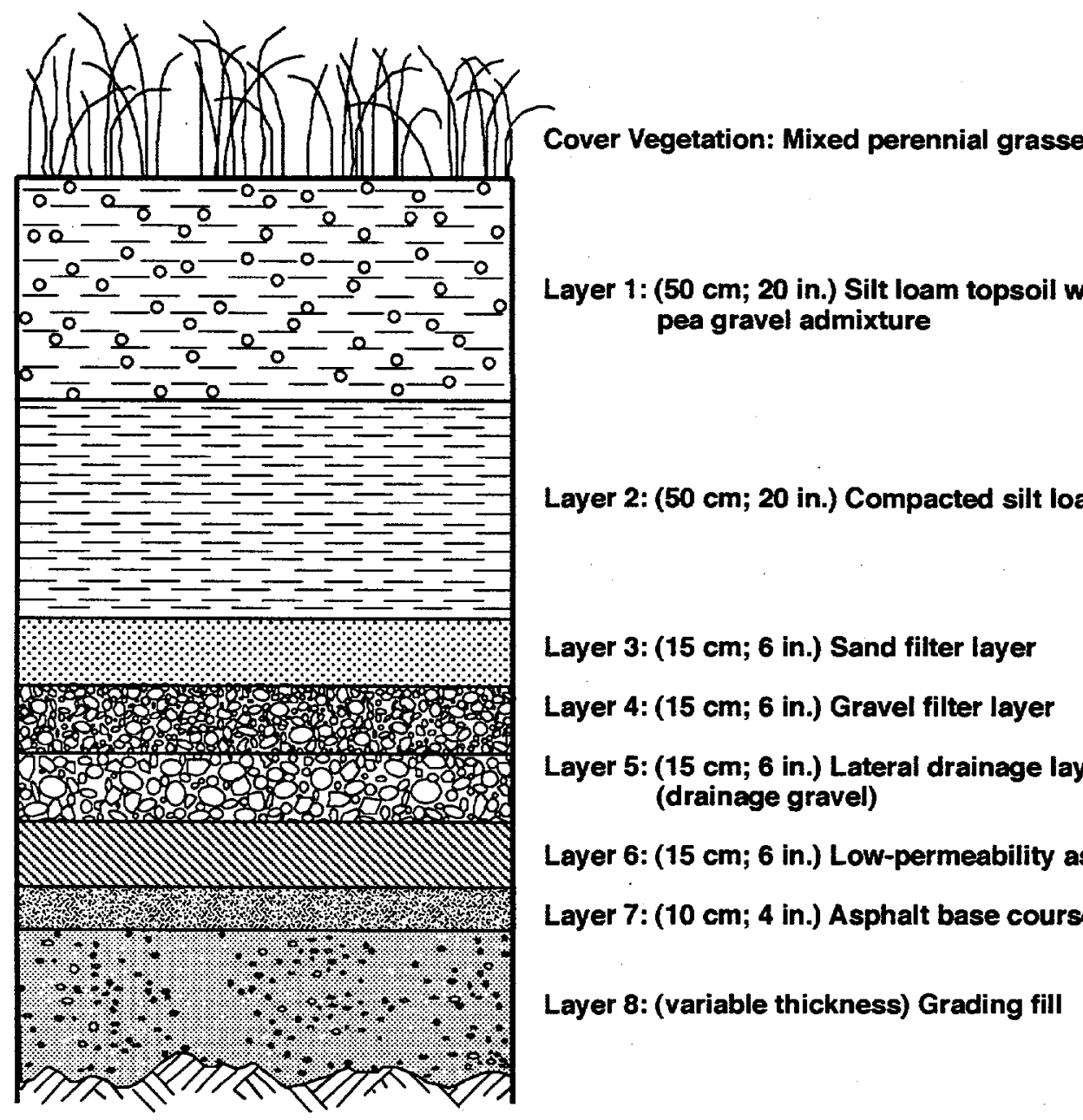

H9408029.2

Figure 2.3. Schematic Profile of the Modified RCRA Subtitle C Barrier Currently Intended for Use on the ILAW Disposal Facilities. Note, minimum total barrier thickness is $1.7 \mathrm{~m}$. 
surface slope is limited to a maximum of $2 \%$ (after allowances for settlement and subsidence). The purpose of Layer 1 is to support vegetation and provide maximum storage capacity for precipitation and snowmelt. A large storage capacity in conjunction with evapotranspiration from vegetation will tend to minimize percolation from the cover (recharge). The pea gravel provides resistance to erosion of the silt loam.

\subsubsection{Layer 2: Compacted Silt Loam Soil}

This layer consists of an additional $50 \mathrm{~cm}$ of soil from the McGee Ranch area, but without the addition of pea gravel. This layer will be compacted during construction to a design bulk density of about 1.76

$\mathrm{g} / \mathrm{cm}^{3}$. The purpose of Layer 2 is to provide water storage capacity for precipitation and snowmelt and support for vegetation. The purpose of the compaction is to reduce the hydraulic conductivity of the layer.

\subsubsection{Layer 3: Sand Filter}

This layer consists of $15 \mathrm{~cm}$ of graded sand that is intended to serve, in conjunction with Layer 4, as a filter, preventing the fine particles of Layer 2 from moving into the lateral drainage layer (Layer 6). Particle size requirements for the sand filter were taken from Cedergren (1989) [also cited in Ecology (1987) and EPA (1989)] and are as follows.

$$
\begin{array}{ll}
\text { Retention Criteria: } & \mathrm{D}_{15} \text { (Filter) } / \mathrm{D}_{85} \text { (Filtrate) }<4 \text { to } 5 \\
& \mathrm{D}_{50} \text { (Filter) } / \mathrm{D}_{50} \text { (Filtrate) }<25 \\
\text { Permeability Criterion: } & \mathrm{D}_{15} \text { (Filter) } / \mathrm{D}_{15} \text { (Filtrate) }>4 \text { to } 5
\end{array}
$$

The $\mathrm{D}$ values refer to the particle diameters on a particle size distribution curve (e.g., $\mathrm{D}_{15}$ is the particle diameter at which $15 \%$ of the particles are smaller). The filter material in this case is the sand; the filtrate material is the compacted silt loam. These filtration criteria were developed for applications in earth dams under saturated conditions. They are expected to be conservative for the unsaturated conditions of the ILAW surface cover.

The presence of the relatively coarse textured sand layer immediately beneath the fine textured silt loam will produce a capillary barrier effect at the interface. This effect arises because the unsaturated hydraulic conductivity of the sand will be significantly less than that of the silt loam for a large range of matric potential. Significant flow into the sand layer will not occur until the matric potential at the silt loam-sand interface becomes sufficiently large (close to zero) that water can move into the relatively large pores of the sand (Hillel, 1980). The capillary barrier will, in effect, increase the water storage capacity of the silt loam layers. Its ability to do so will depend on the hydraulic properties of the silt loam and sand materials. 


\subsubsection{Layer 4: Gravel Filter}

This layer consists of $15 \mathrm{~cm}$ of a graded gravel that functions, with Layer 3, as a filter, preventing the fine particles of Layer 2 from moving into the lateral drainage layer (Layer 6). Particle size requirements for this layer are identical to those of the sand filter (Layer 3), with the exception that the filter material in this case is the gravel and the filtrate material is the sand. No slope is specified for the sand and gravel filter layers. It is assumed that they will be constructed at a $2 \%$ slope (as drawn in Figure 2.2 ) to minimize required thickness of the surface cover.

\subsubsection{Layer 5: Gravel Lateral Drainage Layer}

This layer consists of $15 \mathrm{~cm}$ of screened gravel with a required saturated hydraulic conductivity of no less than $1.0 \mathrm{~cm} / \mathrm{s}$. This layer will be constructed at a $2 \%$ slope. Its purpose is to divert (to the edge of the cover) water that passes through the filter layers and reaches the asphalt layer (Layer 6).

\subsubsection{Layer 6: Asphaltic Concrete}

This layer consists of $15 \mathrm{~cm}$ of a durable asphaltic concrete mixture consisting of double-tar asphalt with added sand as binder material, conforming to WSDOT M41-10, Section 9-02.1(4), Grade AR-4000W (WDOT, 1991). The asphaltic concrete will potentially be coated with a spray-applied asphaltic material. This layer will be constructed at a $2 \%$ slope. The asphalt layer is intended to function as a low permeability layer and as an inadvertent intruder barrier. As a low permeability layer, analogous to the compacted soil component of a standard RCRA Subtitle $C$ barrier, the asphalt layer should be expected to have a maximum saturated hydraulic conductivity of $10^{-7} \mathrm{~cm} / \mathrm{s}$.

\subsubsection{Layer 7: Asphalt Base Course}

This layer serves as a stable base for placement of the asphalt and consists of $10 \mathrm{~cm}$ of screened, crushed surfacing material, with $100 \%$ passing the $32 \mathrm{~mm}$ sieve. The material must conform to WSDOT M 41-10, Section 9-03.9(3) (WDOT, 1991).

\subsubsection{Layer 8: Grading Fill}

This material consists of a well-graded, granular soil mixture, which may include as much as $20 \%$ by volume of cobbles measuring no more than $75 \mathrm{~mm}$ in the greatest dimension. This material will be used as needed to establish the base for construction of the other cover layers. Backfill material from excavation of the sites may serve as the grading fill.

\subsubsection{Vault Materials}

These materials include the vault itself as well as the materials of the waste packages and the filler material. 


\subsubsection{Concrete}

The vaults will be constructed of steel-reinforced concrete approximately $1.0 \mathrm{~m}$ thick on the bottom and sides. After placing the waste packages and the filler material in the vault, $0.45 \mathrm{~m}$ of controlled density fill will be used to fill the vault to the level of the side walls. (Controlled density fill is a mixture of Portland cement, fly ash, aggregate, water, and admixtures proportioned to provide a non-segregating, selfconsolidating, free-flowing, and excavatable material that will result in a hardened, dense, non-settling fill.) A steel-reinforced concrete layer 5 to $21 \mathrm{~cm}$ thick will be constructed on top of the controlled density fill to create a $2 \%$ sloped vault roof. No specifications have currently been given for the concrete or the controlled density fill.

\subsubsection{Glass Waste and Container}

The current design calls for molten glass waste to be poured into stainless steel containers. Although significant fracturing of the glass is anticipated, there have been no studies to determine the extent of the fracturing and the effect this will have on hydraulic properties of the glass.

\subsubsection{Filler Material}

Filler material may be used to fill the void space in the steel waste containers and will be used to fill the space in the vault between the waste containers. The inter-container filler is specified to be an inert material, such as graded sand. Crushed glass is also a possible filler material. Since the inter-container filler material will be poured into the vault from an overhead hopper, it must have a consistency that allows it to flow into the void spaces in the vault with little potential for bridging.

\subsubsection{Leachate Collection System}

A steel-reinforced concrete catch basin will be located beneath the vault to catch leachate. The catch basin will be sloped at $2 \%$ toward a trench in the center. The trench will be sloped toward each end of the basin. The interior of the catch basin walls must be no less than $25 \mathrm{~cm}$ outside of the exterior of the vault walls. Two 60 -mil, high-density polyethylene liners will be used within the catch basin, with a polypropylene geonet placed between the liners and a 60 mil geotextile above the upper liner. Gravel will be placed above the liners and beneath the vault to facilitate movement of water to the leachate detection riser pipes.

\subsubsection{Backfill}

It is anticipated that backfill around the vault will consist of excavation spoils, potentially screened to remove large cobbles (for use as grading fill immediately beneath the surface cover, for instance). As a result of the excavation, re-emplacement, and compaction, the backfill hydraulic properties are expected to differ from the properties of the naturally occurring sediments. The backfill is likely to be more homogeneous and isotropic. 


\subsubsection{Water Conditioning Layer}

A water conditioning layer consisting of quartz sand or crushed glass is being considered as a component of the facility. The intent of this layer is to increase the silica content of water that contacts the waste, thus reducing the dissolution of silica in the glass waste and decreasing the contaminant flux from the facility. The water conditioning layer would likely be located immediately above the concrete vault, or may even be used as the filler material within the vault. No specifications have been given for the material itself.

\subsubsection{Diversion Layer}

A diversion layer consisting of a sand and gravel capillary barrier may potentially be used in the final design of the facility covers. This diversion layer would be used as an alternative to, or in addition to, the asphalt low permeability layer. This layer would consist of a well-graded sand overlying a well-graded gravel. The diversion layer would likely be constructed at a $2 \%$ slope, corresponding to the other surface cover components.

The required hydraulic properties of the sand and gravel components of the diversion layer depend on the length of the layer and on the expected water flux reaching the layer. Appropriate hydraulic parameters could be determined using numerical modeling and matched to available materials. 


\subsection{Required Properties and Parameters of Near-Field Materials}

This section provides a brief description of the properties and parameters required to model unsaturated flow and nonreactive contaminant transport in the near-field environment of the ILAW disposal facilities. Additional parameters required to model reactive transport are discussed in Kaplan and Serne (1999) and McGrail et al. (1999).

\subsection{Particle Size Distribution}

The particle size distribution (PSD) is typically presented as the cumulative fraction by weight of particles whose mean diameter is less than a specific value. This physical property is useful for classifying soils (e.g., sand, silt loam), but is not typically used directly in modeling. Those particles greater than 2 $\mathrm{mm}$ in diameter are often removed from the sample before measuring the particle size distribution using standard methods (ASTM D422-63; Gee and Bauder, 1986). For ILAW PA purposes, however, the fraction greater than $2 \mathrm{~mm}$ should be included in the particle size distribution or recorded as a gravel percentage.

In the absence of a direct measurement of water retention (see Section 3.5), the particle size distribution can be used to estimate water retention by assuming the particle size distribution reflects the pore size distribution (Arya and Paris, 1981).

\subsection{Particle Density}

Particle density $\left(\rho_{\mathrm{p}}\right)$ is the mass of solids in a sample divided by the volume of the solids. It is typically used to calculate porosity. The fraction less than $2 \mathrm{~mm}$ may be used in the measurement of particle density (Blake and Hartge, 1986b).

\subsection{Bulk Density}

The dry bulk density $\left(\rho_{b}\right)$ is the mass of solids in a sample divided by the total (bulk) volume of the sample. The total volume includes the volume occupied by the solids, water (or other liquid), and air. Due to the potential for compaction during sampling, bulk density measured in the laboratory may vary from that measured in situ (Blake and Hartge, 1986a). Bulk density is used to calculate porosity and retardation coefficients. Some techniques for estimating water retention and hydraulic conductivity may also use the bulk density.

\subsection{Porosity}

Porosity $(\phi)$ is the volume of voids in a sample (the air- and liquid-filled volume) divided by the total volume of the sample. It is typically calculated using measured values of particle and dry bulk densities. 


$$
\phi=1-\rho_{\mathrm{b}} / \rho_{\mathrm{p}}
$$

The porosity can also be measured directly (Danielson and Sutherland, 1986).

\subsection{Water Retention}

Water retention $[\theta=f(\psi)]$ in a porous medium refers to the relationship between water content and matric potential. Volumetric water content $(\theta)$ is the volume of water in a sample divided by the total volume of the sample. The matric potential represents the capillary and adsorptive forces that attract and bind water to the soil matrix. (Matric potential is also referred to as soil water pressure or negative soil water tension.) A variety of methods are available to obtain water retention data (Klute, 1986; Rawlins and Campbell, 1986; Wierenga, et al., 1993). In some cases, laboratory measurements of water retention have been conducted on samples for which the gravel fraction (particle diameter $>2 \mathrm{~mm}$ ) has been removed. The water contents obtained on such samples should be corrected for the gravel content (Bouwer and Rice, 1983; Gardner, 1986) before estimating the parameters of a water retention model.

Water retention is typically represented in simulation codes using one of a number of water retention models that have been presented in the literature. In this report, the model proposed by van Genuchten (1980) is used:

$$
\mathrm{s}_{\mathrm{e}}(\psi)=\left[1+(\alpha \psi)^{\mathrm{n}}\right]^{-\mathrm{m}}
$$

where

$$
\begin{aligned}
\psi= & \text { matric potential } \\
S_{e}= & \text { effective saturation }=\frac{\theta-\theta_{\mathrm{r}}}{\theta_{\mathrm{s}}-\theta_{\mathrm{r}}}, 0 \leq S_{e} \leq 1 \\
\alpha= & \text { curve fitting parameter related to air entry pressure } \\
n, m= & \text { curve fitting parameters related to pore size distribution; the relationship, } m=1-1 / n, \text { is often } \\
& \text { assumed } \\
\theta_{r}= & \text { residual (or irreducible) water content } \\
\theta_{s}= & \text { saturated water content. }
\end{aligned}
$$

The saturated water content is often assumed to be equal to porosity. It has been observed in laboratory and field measurements, however, that soils often cannot be saturated to the full porosity. This effect is more pronounced in the field, presumably because of the greater variation in soil structure and the inability to carefully control wetting. For this reason, $\theta_{\mathrm{s}}$ is sometimes a fitted parameter, in which case it represents a field-saturated water content. Klute (1986) states that field-saturated water content is typically 80 to $90 \%$ of the porosity.

The residual water content is interpreted here as an empirical parameter and thus is generally a fitted parameter. This interpretation is a subject of debate (Nimmo, 1991; Luckner et al., 1991). At very low matric potentials (large negative values), the van Genuchten model may provide a poor representation of water 
retention. Alternative models have been proposed that improve the fit at low water contents (Rossi and Nimmo, 1994; Fayer and Simmons, 1995). Because water contents in the ILAW disposal facilities and the surrounding soils are expected to be low, accurate representation by the water retention model may be important. This is especially true if diffusion dominates the transport of contaminants and a water-contentdependent diffusion coefficient is used.

The remainder of the parameters in the van Genuchten water retention model are fitting parameters, estimated using measured or inferred water retention data.

There are many water retention models that could be used. Although the parameters in the van Genuchten model are related to the parameters used in other models, the transformation from one to the other is not always straightforward. Caution should be exercised in using the results presented in this report with water retention models other than the van Genuchten model.

Water retention in soils and sediment exhibits hysteresis: the observed water content at a given matric potential depends on whether the soil is being wetted or is drying. Models have been developed for describing this hysteresis, but the data on which the parameters of hysteresis can be estimated are often not available. Hysteresis is likely to be most important near the ground surface where water content changes with time will be the largest. In the deeper materials (below the cover), water content changes will be less significant and hysteresis effects are not anticipated to be significant.

\subsection{Saturated Hydraulic Conductivity}

Darcy's Law is used in models of subsurface flow to relate water flux to the potential gradient. Under saturated conditions, the proportionality constant in this relationship is the saturated hydraulic conductivity $\left(\mathrm{K}_{\mathrm{s}}\right)$. Measurements can be made using a variety of methods (Klute and Dirksen, 1986). Saturated hydraulic conductivity may exhibit anisotropy: a value that depends on the direction in which it is measured. Data on anisotropy are typically not available. Hydraulic conductivity anisotropy is not anticipated to be significant in any single near-field material. At a scale that encompasses multiple near-field materials that have contrasting properties, anisotropy should be considered.

Saturated hydraulic conductivity measurements are often made on small-scale laboratory samples. Because of the variability in natural materials, these small-scale measurements should not be interpreted as field-measured hydraulic conductivity values, which are typically larger. Values used in numerical models should represent the scale of the numerical grid size. The appropriate scaling methods for deriving model values of saturated hydraulic conductivity from laboratory measurements is currently a matter of scientific debate. Because the near-field materials will be relatively homogeneous, this scale issue is anticipated to be less important than for the naturally occurring sediments. 


\subsection{Unsaturated Hydraulic Conductivity}

Under unsaturated conditions, the water flux occurring through a porous material in response to a specified potential gradient is strongly dependent on the water content of the material. The unsaturated hydraulic conductivity $[K=f(\theta, \psi)]$ describes this dependence. Direct measurement of the unsaturated hydraulic conductivity as a function of water content is possible using a steady-state method (Klute and Dirksen, 1986) and centrifugal methods (Nimmo et al., 1987; Nimmo, 1990; Conca and Wright, 1992; Wright et al., 1994), but such data is often not available. More typically, the unsaturated hydraulic conductivity relationship is estimated using water retention and saturated hydraulic conductivity measurements and adopting a particular model (Mualem, 1986). Eching and Hopmans (1993) and Eching et al. (1994) present an alternative method of estimating unsaturated hydraulic conductivity using outflow measurements, but this method also requires adopting a specific model.

The unsaturated hydraulic conductivity model used in this report is the model derived by van Genuchten (1980) using the relationship of Mualem (1976). This model can be written either in terms of the water content or the matric potential.

$$
\begin{gathered}
\mathrm{K}\left(\mathrm{S}_{\mathrm{e}}\right)=\mathrm{K}_{\mathrm{s}} \sqrt{\mathrm{S}_{\mathrm{e}}}\left[1-\left(1-\mathrm{S}_{\mathrm{e}}^{\left.1 / \mathrm{m})^{\mathrm{m}}\right]^{2}}\right.\right. \\
\mathrm{K}(\Psi)=\mathrm{K}_{\mathrm{s}} \frac{\left\{1-(\alpha \psi)^{\mathrm{n}-1}\left[1+(\alpha \psi)^{\mathrm{n}}\right]^{-\mathrm{m}}\right\}^{2}}{\left[1+(\alpha \psi)^{\mathrm{n}}\right]^{0.5 m}}
\end{gathered}
$$

Parameters in these equations are as defined for the water retention model and can be estimated using both water retention and unsaturated hydraulic conductivity data when available. The factor of 0.5 in the exponent of the denominator of Equation 3.4 represents the pore interaction term. A value of 0.5 is typical.

Khaleel et al. (1995) found that the van Genuchten-Mualem model did not provide accurate estimates of unsaturated hydraulic conductivity for Hanford sediments at low water contents when these estimates were based solely on water retention data and a saturated hydraulic conductivity measurement. This condition may be explained by observing that the saturated hydraulic conductivity for these relatively coarse materials is dominated by large pores, whereas the unsaturated hydraulic conductivity appears to be dominated by small pores. Khaleel et al. (1995) recommended the use of at least one direct measurement of hydraulic conductivity at a low water content as a match point.

\subsection{Dispersivity}

Dispersivity $(\lambda)$, when multiplied by the pore water velocity, yields the mechanical dispersion coefficient, which relates the dispersive solute flux to the solute concentration gradient. Dispersivity is generally larger in the direction of flow than in transverse directions and it is also scale dependent. Khaleel 
(1999) provides a discussion of the issues related to scale-dependent dispersion. Because of the smaller scale and the relative homogeneity, this issue is likely to be less important for the near-field materials.

Field measurements of dispersivity are extremely rare and small-scale laboratory measurements have only marginal utility in estimating field values. In the absence of data, dispersivity values are often based on simple guidelines related to the size of the computation elements in numerical simulation codes.

\subsection{Diffusion Coefficient}

The diffusion coefficient is the proportionality factor in Fick's law that relates the diffusive transport flux to the gradient in solute concentration. Diffusion results in mass transport from regions of high solute concentration to regions of lower concentration and occurs as a result of the random thermal motion (Brownian motion) of molecules and atoms. Diffusive transport in a dilute water solution is quantified by the free-water diffusion coefficient, $\mathrm{D}_{\mathrm{f}}$. Several models have been proposed for calculating the diffusion coefficient of a dilute solute in water (Grathwohl, 1998). The viscosity of the solution, which depends strongly on temperature, affects $D_{f}$ most directly. For most simple aqueous species $D_{f}$ is about $10^{-5} \mathrm{~cm}^{2} / \mathrm{s}$ $\left(10^{-9} \mathrm{~m}^{2} / \mathrm{s}\right)$. Kemper (1986) provides a table of diffusion coefficients of common ions in water; values range from approximately $4.8 \times 10^{-6}$ to $1.6 \times 10^{-5} \mathrm{~cm}^{2} / \mathrm{s}$ at $15^{\circ} \mathrm{C}$.

In the constrained geometry of a porous medium, the diffusion coefficient is reduced compared to the diffusion coefficient in free aqueous solution. The intrinsic diffusion coefficient for a species within a saturated porous medium, $D_{i}$, can be expressed as

$$
\mathrm{D}_{\mathrm{i}}=\mathrm{D}_{\mathrm{f}} \phi \delta / \tau
$$

where

$$
\delta=\text { a constrictivity factor }
$$$$
1 / \tau=\mathbf{a} \text { tortuosity factor. }
$$

The intrinsic diffusion coefficient has also been referred to as the effective diffusion coefficient.

The constrictivity factor in Equation 3.5 represents a reduction in diffusion due to the constricted flow path caused by small pores and pore throats in the porous medium. The effect of constrictions on diffusion has been attributed to an increased viscocity in the vicinity of the pore walls (Grathwohl, 1998) and electrical interactions (Kemper, 1986). The tortuosity factor represents a reduction in diffusion due to the increased path length taken by solute molecules in traveling through the porous medium. The tortuosity factor is given by $1 / \tau=\left(L / L_{e}\right)^{2}$, where $L_{e}$ is the length of the tortuous path and $L$ is the straight-line path length (Porter et al. 1960).

In a saturated porous medium, the cross-sectional area available for diffusion in the aqueous phase is reduced by the volume fraction of the void space. This fraction will be the total porosity, $\phi$, if all porosity in the porous medium is interconnected and can thus contribute to contaminant diffusion. If there are pores that do not contribute to diffusion (such as dead end pores), the porosity appearing in Equation 3.5 will be less than the total porosity. 
In practice, it is difficult to directly measure or reliably estimate the constrictivity and tortuosity factors. As a result, the intrinsic diffusion coefficient is frequently modeled as a function of the porosity alone.

$$
\mathrm{D}_{\mathrm{i}}=\mathrm{D}_{\mathrm{f}} \phi^{\beta}
$$

In this equation, $\beta$ is an empirical parameter incorporating the tortuosity and constrictivity effects. The empirical form of this equation is attributed to Buckingham (1904) (although it was then proposed to describe the equivalent concept of effective diffusion of a vapor-phase species through the air-filled pore space of a porous medium). Millington (1959) derived a value of $\beta=4 / 3$. Grathwohl (1998) states that the expected range of $\beta$ for most natural porous media is 1.5 to 2.5 .

In unsaturated porous media, Equation 3.5 or 3.6 must be modified to account for the additional reduction in cross-sectional area available for diffusion as a result of the reduced volumetric water content. Millington (1959) derived a model for gas-phase diffusion in unsaturated porous media that has also been applied to aqueous-phase diffusion. [See also Millington and Quirk $(1959 ; 1961)$.] The Millington expression for the intrinsic diffusion coefficient in unsaturated porous media is

$$
\mathrm{D}_{\mathrm{i}}=\mathrm{D}_{\mathrm{f}} \theta^{10 / 3} / \phi^{2}
$$

This model assumes $\delta=1$ in Equation 3.5, replaces the porosity with the volumetric water content, and results in a tortuosity factor defined by $1 / \tau=\theta^{7 / 3} / \phi^{2}$. In the saturated case with $\theta=\phi$, Equation 3.7 reduces to Equation 3.6 with $\beta=4 / 3$.

Papendick and Campbell (1980), citing Brooks and Corey (1966), assumed a tortuosity factor in Equation 3.5 of $1 / \tau=c \theta^{2}$. With $\delta=1$ and the volumetric water content replacing the porosity, Equation 3.5 becomes

$$
D_{i}=c D_{f} \theta^{3}
$$

Campbell (1985) suggested that the empirical parameter ' $c$ ' in this relationship could be taken as a constant with a value of $\mathrm{c}=2.8$.

Kemper and Van Schaik (1966), Olsen et al. (1965), Olsen and Kemper (1968) and Porter et al. (1960) developed a model for diffusive transport in agricultural systems.

$$
D_{i}=a D_{f} \exp (b \theta)
$$

where $\quad a=$ an empirical constant based on particle size ( 0.003 is a representative value for sand)

$\mathrm{b}=$ an empirical constant based on particle size (10 is a representative value for sand).

The value of the diffusion coefficient can vary significantly depending on which of the empirical relationships (Equations 3.7 to 3.9 ) is used, particularly at low water contents. For example, $\log \left(\mathrm{D}_{\mathrm{i}}\right)$ is $\operatorname{lin}$ ear in $\theta$ using Equation 3.9, but is nonlinear for the other two models. Furthermore, Equations 3.7 and 3.8 are similar for porosities of 0.4 to $\mathbf{0 . 6}$, but can be significantly different for porosities outside this range, particularly porosities that are smaller than 0.3 . Fayer and Kincaid (1998) $)^{1}$ demonstrate the potential impact of using different diffusion relationships for a waste-form-alone simulation (no vault) of the new 
ILAW disposal facility. Predictions of dose were reduced by more than $80 \%$ when using Equation 3.7 as compared with using Equation 3.9. A discussion in Section 5.3 of available diffusion data suggests that the model of Kemper and Van Schaik (Equation 3.9) is inappropriate for use in the ILAW PA.

The chemical contributions to diffusion can potentially be quite varied (ion-exchange, specific adsorption, precipitation, and lattice substitution) as well as quite significant. If we assume a very simple chemical process, i.e., reversible surface adsorption having fast kinetics and a linear isotherm (adsorption is proportional to the concentration in solution via a fixed constant, $K_{d}$ ), then diffusion of a reactive contaminant can be characterized by an apparent diffusion coefficient, $\mathrm{D}_{\mathrm{a}}$ :

$$
\mathrm{D}_{\mathrm{a}}=\mathrm{D}_{\mathrm{i}} / \alpha^{\prime}=\mathrm{D}_{\mathrm{f}} \delta \phi /\left(\tau \alpha^{\prime}\right)
$$

using Equation 3.5 for the intrinsic diffusion coefficient. In this equation, $\alpha^{\prime}$ is the capacity factor or ratio of the moles of contaminant per unit volume of water-saturated solid, $\mathrm{C}_{\boldsymbol{s}}$, to the moles of contaminant per unit volume of liquid, $\mathrm{C}_{\mathrm{l}}$. The capacity factor is related to the distribution coefficient, $\mathrm{K}_{\mathrm{d}}$, by the equation

$$
\alpha^{\prime}=\phi+\rho_{b} K_{d}
$$

where $\rho_{b}$ is the dry bulk density of the porous media and $K_{d}$ is the amount of contaminant adsorbed per unit mass of porous solid divided by the amount of contaminant per unit volume of liquid. Also note that $\alpha^{\prime} / \phi$ is the familiar retardation factor used in transport modeling in water-saturated porous media:

$$
\alpha^{\prime} / \phi=\mathrm{R}=1+\rho_{\mathrm{b}} \mathrm{K}_{\mathrm{d}} / \phi
$$

For unsaturated porous media, it is appropriate to replace the porosity in Equations 3.10 to 3.12 with the volumetric water content.

Remember that these simple relationships are strictly valid only for reversible, linear adsorption reactions with fast kinetics. These conditions may not be met for many actual porous media-contaminantsolution interactions. Nevertheless such simplifying assumptions allow for some useful analysis such as performed in the ILAW PAs. In Equation 3.10 one can see that the term $D_{i}$ contains all the physical aspects of diffusional transport and the term $\alpha^{\prime}$ contains all the chemical aspects of diffusional transport. Because the distribution coefficient for different contaminants in various porous media can be substantially greater than $1 \mathrm{~cm}^{3} / \mathrm{g}$, the apparent diffusion coefficient may be significantly less than the value of the intrinsic diffusion coefficient.

1. Fayer, M.J. and C.T. Kincaid. 1998. Simulations to Guide Measurements of Near-Field Hydraulic Parameters. Letter Report to Fluor Daniel Hanford, Inc., September 30, 1998, Pacific Northwest National Laboratory, Richland, Washington. 


\subsection{Best-Estimate Values for Hydraulic Parameters of Near-Field Materials}

This section contains best-estimate values for the hydraulic parameters of the near-field materials to be used in performance assessment analyses of the ILAW disposal facilities. A description of the source of these values is included. In determining the best-estimate parameter values it has been assumed in most cases that the saturated volumetric water content is equal to the porosity. This assumption was made to avoid the application of an arbitrary factor to account for field saturation in such disparate materials as gravel and concrete. In those cases where a model was fit to water retention data the saturated water content was a fitted parameter and may be less than the porosity. Best-estimate values for transport parameters are discussed in Chapter 5. Information on parameter uncertainty and changes in parameter values over time is discussed in Chapter 6.

\subsection{Cover Materials}

\subsubsection{Silt Loam-Gravel Admix}

The silt loam component of this material is specified to come from the McGee Ranch area on the Hanford Site. Gee et al. (1989) obtained sixteen samples of this soil from the top meter of a site in the McGee Ranch area. Particle size analysis of the samples yield textures from loam to silt loam with the percentage of sand ranging from 32 to $44 \%$, silt from 42 to $59 \%$, and clay from 7 to $16 \%$. The average particle density of the samples was $2.72 \mathrm{~g} / \mathrm{cm}^{3}$. Samples were packed to a bulk density of $1.37 \mathrm{~g} / \mathrm{cm}^{3}$ and the saturated hydraulic conductivity and water retention (drying curve) were measured.

Gee et al. (1989) estimated hydraulic parameters of the van Genuchten-Mualem model for each McGee Ranch soil sample. In addition, they determined average parameters by simultaneously fitting data from all sixteen samples. Gee et al. (1989) reported that complete saturation was not achieved in the samples during the hydraulic conductivity measurements. Thus the saturated hydraulic conductivity was a fitted parameter in their study with the measured values used as match points. The average parameter values reported by Gee et al. (1989) for the McGee Ranch soil samples were as follows:

$$
\theta_{s}=0.496, \theta_{r}=0.0049, \alpha=0.0163 \mathrm{~cm}^{-1}, \mathrm{n}=1.372 \text {, and } \mathrm{K}_{\mathrm{s}}=9.9 \times 10^{-4} \mathrm{~cm} / \mathrm{s} \text {. }
$$

To adjust the silt loam parameters for a $15 \%$ by weight addition of pea gravel, the relationships of Bouwer and Rice (1983) were used. These relationships have been used previously for Hanford soils (e.g., Khaleel and Freeman, 1995). The water content was updated using the relationship

$$
\theta^{\mathrm{Mix}}=\left(1-\mathrm{F}_{\mathrm{g}}\right) \theta^{\mathrm{SiL}}
$$

where $\theta^{\mathrm{Mix}}$ is the volumetric water content of the silt loam-gravel admix, $\theta^{\mathrm{SiL}}$ is the volumetric water content of the silt loam, and $\mathrm{F}_{\mathrm{g}}$ is the volume fraction of gravel (the volume of gravel divided by the total volume of the silt loam-gravel admix). 
$\mathrm{F}_{\mathrm{g}}$ can be calculated by assuming that the addition of gravel to the silt loam soil does not increase the volume of voids in the sample (i.e., there is no porosity associated with the gravel). With a $1000 \mathrm{~g}$ sample of silt loam-gravel admix, for example, the volume of silt loam is the ratio of silt loam mass $(850 \mathrm{~g})$ to silt loam bulk density $\left(1.37 \mathrm{~g} / \mathrm{cm}^{3}\right)$, or $620.4 \mathrm{~cm}^{3}$. The volume of gravel is the ratio of gravel mass $(150 \mathrm{~g})$ to gravel particle density $\left(2.72 \mathrm{~g} / \mathrm{cm}^{3}\right)$, or $55.1 \mathrm{~cm}^{3}$. The gravel particle density used is the average density reported by Rockhold et al. (1993) for samples from a borehole adjacent to the existing disposal facility, and is comparable to the values measured for cores taken from a borehole adjacent to the new ILAW disposal site. ${ }^{1}$ Using the values above, the volume fraction of gravel in the silt loam-gravel admixture is $\mathrm{F}_{\mathrm{g}}=55.1 /(55.1+620.4)=0.0816$. The bulk density of the admixture is $1.48 \mathrm{~g} / \mathrm{cm}^{3}$.

The saturated hydraulic conductivity of the silt loam-gravel admixture is estimated using a relationship from Bouwer and Rice (1983).

$$
\mathrm{K}_{\mathrm{s}}^{\mathrm{Mix}}=\left(\mathrm{e}^{\mathrm{Mix}} / \mathrm{e}^{\mathrm{SiL}}\right) \mathrm{K}_{\mathrm{s}}^{\mathrm{SiL}}
$$

where $\mathrm{K}_{\mathrm{s}}{ }^{\mathrm{Mix}}$ is the saturated hydraulic conductivity of the silt loam-gravel admixture, $\mathrm{K}_{\mathrm{s}}^{\mathrm{SiL}}$ is the saturated hydraulic conductivity of the silt loam, and $\mathrm{e}^{\mathrm{Mix}}$ and $\mathrm{e}^{\mathrm{SiL}}$ are the void ratios of the admixture and silt loam soils, respectively. The void ratio is a function of the porosity, with $e=\phi /(1-\phi)$. Using the bulk and particle densities listed above and Equation 3.1 to calculate the porosities, the scaling factor for the saturated hydraulic conductivity is $\mathrm{e}^{\mathrm{Mix}} / \mathrm{e}^{\mathrm{SiL}}=0.850$.

Applying the scaling factors for the water content and hydraulic conductivity to the silt loam parameters listed above results in the best-estimate physical and hydraulic parameters for the silt loam-gravel admixture given in Table 4.1.

Table 4.1. Best-Estimate Parameter Values for Silt Loam-Gravel Admixture

\begin{tabular}{|c|c|c|c|c|c|c|}
\hline$\rho_{\mathbf{p}}\left(\mathbf{g} / \mathbf{c m}^{3}\right)$ & $\rho_{\mathbf{b}}\left(\mathbf{g} / \mathbf{c m}^{\mathbf{3}}\right)$ & $\theta_{\mathbf{s}}$ & $\theta_{\mathbf{r}}$ & $\alpha\left(\mathbf{c m}^{-1}\right)$ & $\mathbf{n}$ & $\mathbf{K}_{\mathbf{s}}(\mathbf{c m} / \mathbf{s})$ \\
\hline \hline 2.72 & 1.48 & 0.456 & 0.0045 & 0.0163 & 1.37 & $8.4 \times 10^{-4}$ \\
\hline
\end{tabular}

\subsubsection{Compacted Silt Loam}

This material is also specified to come from the McGee Ranch area on the Hanford Site. The silt loam parameters obtained by Gee et al. (1989) were adjusted to account for an increase in bulk density from $1.37 \mathrm{~g} / \mathrm{cm}^{3}$ used by Gee et al. (1989) in their measurements to a value of $1.76 \mathrm{~g} / \mathrm{cm}^{3}$ as specified in DOE-RL (1993). The effect of the compaction was estimated using the relationships of Arya and Paris (1981). Since the compaction will not affect the particle size distribution, the equations presented in Arya

1. Fayer, M.J., A.L. Ward, J.S. Ritter, and R.E. Clayton. 1998. "Physical and Hydraulic Measurements of FY 1998 Borehole Cores." Letter Report to Fluor Daniel Northwest, Inc., September 10, 1998, Pacific Northwest National Laboratory, Richland, Washington. 
and Paris (1981) can be used with the compacted bulk density to estimate the expected change in water content and soil matric potential as a result of the compaction. Water contents are expected to be reduced by a factor of $\left(\rho_{p}-\rho_{b c}\right) /\left(\rho_{p}-\rho_{b u}\right)$ where the $c$ and $u$ subscripts indicate the compacted and uncompacted bulk densities. Soil matric potentials will be increased by a factor of $\sqrt{e_{u} / e_{c}}$ where e indicates the void ratio of the uncompacted and compacted soils and is calculated as $e=\left(\rho_{p}-\rho_{b}\right) / \rho_{b}$.

Preliminary water content-matric potential pairs were generated using the silt loam parameters determined by Gee et al. (1989). The generated values were then adjusted for the effect of compaction using the factors given above, and the van Genuchten water retention function was fit to the adjusted water content-matric potential pairs. The resulting parameters for the compacted silt loam soil are given in Table 4.2. The saturated hydraulic conductivity in this table is the geometric mean of two measurements made by Wing (1993) on compacted silt loam soil from the McGee Ranch area. These samples were compacted to 1.70 and $1.75 \mathrm{~g} / \mathrm{cm}^{3}$. This hydraulic conductivity value is similar to the value of $1.4 \times 10^{-6} \mathrm{~cm} / \mathrm{s}$ reported by Skelly (1994) for measurements on compacted silt loam samples from the McGee Ranch area.

Table 4.2. Best-Estimate Parameter Values for Compacted Silt Loam

\begin{tabular}{|c|c|c|c|c|c|c|}
\hline$\rho_{\mathbf{p}}\left(\mathbf{g} / \mathbf{c m}^{\mathbf{3}}\right)$ & $\rho_{\mathbf{b}}\left(\mathbf{g} / \mathbf{c m}^{\mathbf{3}}\right)$ & $\theta_{\mathbf{s}}$ & $\theta_{\mathbf{r}}$ & $\alpha\left(\mathrm{cm}^{-1}\right)$ & $\mathbf{n}$ & $\mathbf{K}_{\mathbf{s}}(\mathbf{c m} / \mathbf{s})$ \\
\hline \hline 2.72 & 1.76 & 0.353 & 0.0035 & 0.0121 & 1.37 & $1.8 \times 10^{-6}$ \\
\hline
\end{tabular}

\subsubsection{Sand Filter}

Wing (1993) measured the physical properties and saturated hydraulic conductivity of a variety of materials used in the construction of a prototype Hanford Barrier on the Hanford Site. The design of this barrier is similar to the barrier design to be used in the ILAW disposal facilities. Wing (1993) report on the properties of two sand samples prepared from sediments gathered from the excavation spoil pile of the existing disposal facility. The sediments were sieved to provide two samples that bracketed a specified range in particle size distribution. Measurements were made on both the fine and coarse samples at two bulk densities, representing uncompacted and compacted conditions.

It is assumed here that the sand filter will be compacted during construction. The best-estimate parameter values for the sand filter are listed in Table 4.3. The particle density and bulk density are the average values of the compacted samples from Wing (1993). The porosity (and saturated water content) calculated from these two values is $\mathbf{0 . 3 1 8}$. The best-estimate saturated hydraulic conductivity is the geometric average of the compacted sand values reported by Wing (1993). Water retention parameters were estimated from the particle size distribution using the midpoint of the ranges specified in Wing (1993). The particle size distribution range specified in Wing (1993) and the distribution assumed here are shown in Table 4.4. The method of Arya and Paris (1981) was used to calculate water retention points from the particle size distribution. An average soil temperature of $20^{\circ} \mathrm{C}(\mathrm{PNL}, 1973)$ and a contact angle of zero were 
assumed in these calculations. The van Genuchten water retention function was fit to the calculated points to provide the parameter values for $\theta_{\mathrm{r}} \alpha$, and $\mathrm{n}$ shown in Table 4.3.

Table 4.3. Best-Estimate Parameter Values for Sand Filter

\begin{tabular}{|c|c|c|c|c|c|c|}
\hline$\rho_{\mathbf{p}}\left(\mathbf{g} / \mathbf{c m}^{3}\right)$ & $\rho_{\mathbf{b}}\left(\mathbf{g} / \mathbf{c m}^{3}\right)$ & $\theta_{\mathbf{s}}$ & $\theta_{\mathbf{r}}$ & $\alpha\left(\mathbf{c m}^{-1}\right)$ & $\mathbf{n}$ & $\mathbf{K}_{\mathbf{s}}(\mathbf{c m} / \mathbf{s})$ \\
\hline \hline 2.755 & 1.88 & 0.318 & 0.030 & 0.538 & 1.68 & $8.58 \times 10^{-5}$ \\
\hline
\end{tabular}

Table 4.4. Particle Size Distribution for Sand Filter: Specified Range from Wing (1993) and Midpoint Values Used to Estimate Water Retention Parameters

\begin{tabular}{|c|c|c|c|}
\hline \multirow{2}{*}{ U.S. Sieve Size/No. } & $\begin{array}{c}\text { Particle Diameter } \\
(\mathbf{m m})\end{array}$ & Range (Wing, 1993) & Midpoint \\
\cline { 3 - 4 } & 4.75 & 100 & 100 \\
\hline \hline No. 4 & 2.00 & $85-100$ & 92.5 \\
\hline No. 10 & 0.85 & $30-90$ & 60 \\
\hline No. 20 & 0.425 & $15-55$ & 35 \\
\hline No. 40 & 0.15 & $5-35$ & 20 \\
\hline No. 100 & 0.075 & $1-25$ & 12 \\
\hline No. 200 & & & \\
\hline
\end{tabular}

\subsubsection{Gravel Filter}

Best-estimate parameter values for the gravel filter material were calculated in a manner similar to the sand filter. Wing (1993) obtained 5/8 in. crushed basalt road top course and prepared two samples corresponding to the fine and coarse extremes of a specified particle size distribution. This material was also used in the prototype Hanford Barrier (Buckmaster, 1993). The average particle and bulk densities of compacted samples of the crushed basalt are given in Table 4.5. Porosity (and saturated water content) was calculated from these two values. The best-estimate saturated hydraulic conductivity is the geometric mean of the two sample values measured by Wing (1993). Water retention parameters were calculated using the method of Arya and Paris (1981) with the particle size distribution assumed to be the midpoint of the values specified in Wing (1993). Particle size distributions are shown in Table 4.6.

Table 4.5. Best-Estimate Parameter Values for Gravel Filter

\begin{tabular}{|c|c|c|c|c|c|c|}
\hline$\rho_{\mathbf{p}}\left(\mathrm{g} / \mathrm{cm}^{\mathbf{3}}\right)$ & $\rho_{\mathbf{b}}\left(\mathrm{g} / \mathrm{cm}^{\mathbf{3}}\right)$ & $\theta_{\mathbf{s}}$ & $\theta_{\mathbf{r}}$ & $\alpha\left(\mathrm{cm}^{-1}\right)$ & $\mathbf{n}$ & $\mathbf{K}_{\mathbf{s}}(\mathbf{c m} / \mathbf{s})$ \\
\hline \hline 2.725 & 1.935 & 0.290 & 0.026 & 8.10 & 1.78 & $1.39 \times 10^{-2}$ \\
\hline
\end{tabular}


Table 4.6. Particle Size Distribution for Gravel Filter: Specified Range from Wing (1993) and Midpoint Values Used to Estimate Water Retention Parameters

\begin{tabular}{|c|c|c|c|}
\hline \multirow[b]{2}{*}{ U.S. Sieve Size/No. } & \multirow{2}{*}{$\begin{array}{c}\text { Particle Diameter } \\
\text { (mm) }\end{array}$} & \multicolumn{2}{|c|}{ Percent Passing } \\
\hline & & Range (Wing, 1993) & Midpoint \\
\hline $5 / 8$ in. & 15.9 & 100 & 100 \\
\hline $1 / 4$ in. & 6.35 & $55-75$ & 65 \\
\hline No. 40 & 0.425 & $8-24$ & 16 \\
\hline No. 200 & 0.075 & $0-10$ & 5 \\
\hline
\end{tabular}

\subsubsection{Gravel Lateral Drainage Layer}

No measurements are available for the gravel drainage layer material. It was assumed that this layer would be composed of crushed basalt and could be compacted to the same bulk density as the gravel filter layer. The particle density, bulk density, and porosity (saturated water content) were thus assumed to be the same as those of the gravel filter. Water retention parameter values for the gravel drainage layer were based on particle size distribution requirements for the gravel drainage component of the prototype Hanford Barrier as given in Buckmaster (1993). As with the sand and gravel filters, the midpoint particle size distribution was assumed and the Arya and Paris (1981) method was used to calculate the parameters, which are given in Table 4.7. The particle size distribution range and midpoint are given in Table 4.8. Saturated hydraulic conductivity is an estimated value based on the minimum required conductivity $(1.0 \mathrm{~cm} / \mathrm{s})$ and the measurement (via the constant head method) of a gravel sample in Rockhold et al. (1993). This sample had a saturated hydraulic conductivity of $1.85 \mathrm{~cm} / \mathrm{s}$.

Table 4.7. Best-Estimate Parameter Values for Gravel Drainage Layer

\begin{tabular}{|c|c|c|c|c|c|c|}
\hline$\rho_{\mathbf{p}}\left(\mathrm{g} / \mathrm{cm}^{3}\right)$ & $\rho_{\mathbf{b}}\left(\mathrm{g} / \mathrm{cm}^{\mathbf{3}}\right)$ & $\theta_{\mathbf{s}}$ & $\theta_{\mathbf{r}}$ & $\alpha\left(\mathrm{cm}^{-1}\right)$ & $\mathbf{n}$ & $\mathbf{K}_{\mathbf{s}}(\mathbf{c m} / \mathbf{s})$ \\
\hline \hline 2.725 & 1.935 & 0.290 & 0.006 & 17.8 & 4.84 & 2.0 \\
\hline
\end{tabular}

Table 4.8. Particle Size Distribution for Gravel Drainage Layer: Specified Range from Buckmaster (1993) and Midpoint Values Used to Estimate Water Retention Parameters

\begin{tabular}{|c|c|c|c|}
\hline \multirow{2}{*}{ U.S. Sieve Size/No. } & Particle Diameter & \multicolumn{2}{|c|}{ Percent Passing } \\
\cline { 3 - 4 }$(\mathbf{m m})$ & Range (Buckmaster, 1993) & Midpoint \\
\hline \hline 1 in. & 25.4 & 100 & 100 \\
\hline $3 / 4$ in. & 19.0 & $80-100$ & 90 \\
\hline
\end{tabular}


Table 4.8. Particle Size Distribution for Gravel Drainage Layer: Specified Range from Buckmaster (1993) and Midpoint Values Used to Estimate Water Retention Parameters

\begin{tabular}{|c|c|c|c|}
\hline \multirow[b]{2}{*}{ U.S. Sieve Size/No. } & \multirow{2}{*}{$\begin{array}{c}\text { Particle Diameter } \\
(\mathbf{m m})\end{array}$} & \multicolumn{2}{|c|}{ Percent Passing } \\
\hline & & Range (Buckmaster, 1993) & Midpoint \\
\hline $3 / 8$ in. & 9.5 & $10-40$ & 25 \\
\hline No. 4 & 4.75 & $0-4$ & 2 \\
\hline No. 200 & 0.075 & 0.5 & 0.5 \\
\hline
\end{tabular}

\subsubsection{Asphaltic Concrete}

No water retention measurements on asphaltic concrete have been found in the literature. In estimating parameters for use in the Grouted Tank Waste Disposal PA (Kincaid et al., 1995), Rockhold et al. (1993) assumed that the asphalt layer was impermeable to liquid water and assigned a low conductivity $\left(10^{-20} \mathrm{~cm} / \mathrm{s}\right)$ to achieve this. Clemmer et al. (1992) analyzed several asphalt samples and estimated a porosity of $3 \%$ to $4 \%$ and a hydraulic conductivity of $2 \times 10^{-13} \mathrm{~cm} / \mathrm{s}$ based on measured $\mathrm{N}_{2}$ permeability. Hydraulic conductivity values reported in DOE-RL (1993) for asphaltic concrete are $10^{-10} \mathrm{~cm} / \mathrm{s}$ based on falling head measurements in the laboratory and $10^{-7}$ to $10^{-9} \mathrm{~cm} / \mathrm{s}$ for in-field values measured with a falling head permeameter (DOE-RL, 1994). These tests were carried out on materials used in the prototype Hanford Barrier. The spray-applied asphalt coating is expected to reduce the permeability of the asphaltic concrete layer. A polymer-modified asphalt coating from the Hanford Barrier prototype had measured hydraulic conductivity values of approximately $10^{-11} \mathrm{~cm} / \mathrm{s}$ (Freeman et al., 1994).

Best estimate parameter values for the asphaltic concrete are given in Table 4.9. The average particle density was assumed to be the same as that of the concrete (see Section 4.2.1). The bulk density was calculated from this assumed particle density and the saturated water content. Water retention parameters $\theta_{\mathrm{p}} \alpha$ and $\mathrm{n}$ are those assumed by Rockhold et al. (1993) and are not based on data. The saturated hydraulic conductivity assumes that a low permeability coating is applied to the asphaltic concrete.

Table 4.9. Best-Estimate Parameter Values for Asphaltic Concrete

\begin{tabular}{|c|c|c|c|c|c|c|}
\hline$\rho_{\mathbf{p}}\left(\mathbf{g} / \mathbf{c m}^{3}\right)$ & $\rho_{\mathbf{b}}\left(\mathbf{g} / \mathbf{c m}^{3}\right)$ & $\theta_{\mathbf{s}}$ & $\theta_{\mathbf{r}}$ & $\alpha\left(\mathrm{cm}^{-1}\right)$ & $\mathbf{n}$ & $\mathbf{K}_{\mathbf{s}}(\mathbf{c m} / \mathbf{s})$ \\
\hline \hline 2.63 & 2.52 & 0.04 & 0.000 & $1.0 \times 10^{-7}$ & 2.0 & $1.0 \times 10^{-11}$ \\
\hline
\end{tabular}

\subsubsection{Asphalt Base Course and Grading Fill}

The asphalt base course and grading fill components fulfill structural requirements of the disposal facility, but are unlikely to have a significant impact on water flow or contaminant transport. For this rea- 
son, they are assigned the hydraulic parameters of materials discussed in other sections. The best-estimate parameter values for the asphalt base course are the same as those of the gravel lateral drainage layer material (Section 4.1.5), which meets the maximum particle size requirement of the base course. These parameter values are repeated here in Table 4.10. The backfill material (Section 4.4.1) is likely to be suitable for use as grading fill. The parameter values of the backfill are thus assigned to the grading fill and given here in Table 4.11.

Table 4.10. Best-Estimate Parameter Values for Asphalt Base Course

\begin{tabular}{|c|c|c|c|c|c|c|}
\hline$\rho_{\mathbf{p}}\left(\mathbf{g} / \mathbf{c m}^{3}\right)$ & $\rho_{\mathbf{b}}\left(\mathrm{g} / \mathrm{cm}^{\mathbf{3}}\right)$ & $\theta_{\mathbf{s}}$ & $\theta_{\mathbf{r}}$ & $\alpha\left(\mathbf{c m}^{-1}\right)$ & $\mathbf{n}$ & $\mathbf{K}_{\mathbf{s}}(\mathbf{c m} / \mathbf{s})$ \\
\hline \hline 2.725 & 1.935 & 0.290 & 0.006 & 17.8 & 4.84 & 2.0 \\
\hline
\end{tabular}

Table 4.11. Best-Estimate Parameter Values for Grading Fill

\begin{tabular}{|c|c|c|c|c|c|c|}
\hline$\rho_{\mathbf{p}}\left(\mathbf{g} / \mathrm{cm}^{\mathbf{3}}\right)$ & $\rho_{\mathbf{b}}\left(\mathbf{g} / \mathrm{cm}^{\mathbf{3}}\right)$ & $\theta_{\mathbf{s}}$ & $\theta_{\mathbf{r}}$ & $\alpha\left(\mathrm{cm}^{-1}\right)$ & $\mathbf{n}$ & $\mathbf{K}_{\mathbf{s}}(\mathbf{c m} / \mathbf{s})$ \\
\hline \hline 1.89 & 2.76 & 0.316 & 0.049 & 0.035 & 1.72 & $1.91 \times 10^{-3}$ \\
\hline
\end{tabular}

\subsection{Vault Materials}

\subsubsection{Concrete}

The concrete for the new ILAW disposal facility has not yet been specified and the hydraulic properties of the concrete in existing disposal vaults have not been measured. To provide representative parameter values for the concrete components of the disposal facilities (i.e., the vault itself and the leachate collection system), a number of cores were obtained from the wall of a concrete munitions bunker near Gable Butte on the Hanford Site. This bunker, designated 213J, was built in the late 1940s. This vault was chosen for coring because of the available access to the interior of the vault and because the outer wall has been buried in Hanford sediments for 50 years under natural conditions similar to those expected in the ILAW disposal vaults. Seven cores were drilled from the interior of the vault, five of which were cored all the way to the soil interface on the exterior side of the vault wall (approximately $30.5 \mathrm{~cm}$, or 12 inches). Two of the cores were intact, one had a single clean fracture, and the others fractured when steel reinforcing bars were contacted. The cores were about $4.5 \mathrm{~cm}$ in diameter, a dimension chosen to allow collection of intact cores that could be used with minimal modification as samples in a centrifuge machine.

Two of the cores were selected for hydraulic property measurements. After removing a thin layer on the interior and exterior ends of the cores, three sections about $5.5 \mathrm{~cm}$ long were cut for samples. Two sections were from each end of the cores, and one section was from the middle. The samples were initially saturated with $\mathrm{CO}_{2}$ and then vacuum saturated for at least 72 hours with a synthetic Hanford vadose zone 
water. Bulk density was calculated from the dry weight and known bulk volume of each sample. Saturated water content was calculated from the difference between the dry and saturated sample weights and the known bulk volume of each sample. Particle density was calculated from the saturated water content and the bulk density.

Water retention and hydraulic conductivity were measured using centrifuge techniques. ${ }^{1,2}$ The parameters of the van Genuchten function, $\alpha$ and $\mathbf{n}$, were fit to the water retention data. Residual water content was assumed to be zero in the fitting procedure, which resulted in superior fits to the data. Hydraulic conductivity was sufficiently low that no unsaturated values could be obtained. Average values for the six concrete samples are given in Table 4.12 and should be used as the best-estimate values until further information about the concrete specifications of the ILAW vaults is known. Arithmetic averages are given except for $\alpha$ and $\mathrm{K}_{\mathrm{s}}$, which are the geometric averages. ${ }^{3}$

Table 4.12. Best-Estimate Parameter Values for Concrete

\begin{tabular}{|c|c|c|c|c|c|c|}
\hline$\rho_{\mathbf{p}}\left(\mathrm{g} / \mathrm{cm}^{3}\right)$ & $\rho_{\mathbf{b}}\left(\mathrm{g} / \mathrm{cm}^{3}\right)$ & $\theta_{\mathbf{s}}$ & $\theta_{\mathbf{r}}$ & $\alpha\left(\mathrm{cm}^{-1}\right)$ & $\mathbf{n}$ & $\mathbf{K}_{\mathbf{s}}(\mathbf{c m} / \mathbf{s})$ \\
\hline \hline 2.63 & 2.46 & 0.067 & 0.00 & $3.87 \times 10^{-5}$ & 1.29 & $1.33 \times 10^{-9}$ \\
\hline
\end{tabular}

\subsubsection{Filler Material}

The filler material to be used in the vault has not been specified. It is assumed here that a quartz sand will be used. This material provides the desired texture to fill the voids and will provide the additional benefit of serving as a water conditioning medium. The parameters given in this section should be used for both the filler material within the steel waste containers and for the filler material between the waste containers until additional specifications for these materials are available.

Kaplan et al. (1998) report measurements made on a coarse quartz sand sample that may be suitable as the filler material. [Kaplan et al. (1998) identify this sand as \#2095 Industrial Quartz, Unimin Corp., Emmett, Idaho. It has also been referred to as No. 8 sand.] In this material, particle size was greater than 2 $\mathrm{mm}$ for $3.4 \%$, between 1 and $2 \mathrm{~mm}$ for $87.5 \%$, and between 0.5 and $1 \mathrm{~mm}$ for $8.2 \%$. The particle density of this material was about $2.56 \mathrm{~g} / \mathrm{cm}^{3}$. It was packed to a bulk density of $1.56 \mathrm{~g} / \mathrm{cm}^{3}$ resulting in a porosity of

1. UFA Ventures, Inc. 1997. Procedure for Using the UFA to Measure the Matric Potential of a Core Sample. Technical Procedure: MPP1, Rev. 001.

2. Test Method for Determining Unsaturated and Saturated Hydraulic conductivity in Porous Media by Open-Flow Centrifugation. Currently under review by American Society for Testing and Materials D18.21 Subcommittee on Ground Water.

3. Meyer, P.D. 1999. Hydraulic Parameters of Aged Near-Field Materials of the Immobilized Low-Activity Waste Disposal Facility, Letter Report to Fluor Daniel Northwest, Inc., August 30, 1999, Pacific Northwest National Laboratory, Richland, Washington. 
0.39. Saturated hydraulic conductivity and water retention measurements were made. The van Genuchten function was fit to the water retention data reported by Kaplan et al. (1998). The resulting parameters for the quartz sand are:

$$
\theta_{\mathrm{S}}=0.39, \theta_{\mathrm{r}}=0.005, \alpha=0.014 \mathrm{~cm}^{-1}, \mathrm{n}=2.82 \text {, and } \mathrm{K}_{\mathrm{s}}=0.0712 \mathrm{~cm} / \mathrm{s} \text {. }
$$

Because the matric potential values used by Kaplan et al. (1998) in their water retention measurements do not adequately delineate the water retention curve, the resulting parameters are not reliable.

The same quartz sand material analyzed by Kaplan et al. (1998) was also evaluated more recently using the multistep outflow method of Eching et al. (1994). A sample of the sand was packed to a bulk density of $1.586 \mathrm{~g} / \mathrm{cm}^{3}$; average particle density was measured at $2.63 \mathrm{~g} / \mathrm{cm}^{3}$. This resulted in a porosity of 0.397. Estimated water retention and hydraulic conductivity parameter values from the multistep outflow experiment are given in Table 4.13. These values are the best-estimate parameter values for the filler material.

Table 4.13. Best-Estimate Parameter Values for Filler Material

\begin{tabular}{|c|c|c|c|c|c|c|}
\hline$\rho_{\mathbf{p}}\left(\mathbf{g} / \mathbf{c m}^{3}\right)$ & $\rho_{\mathbf{b}}\left(\mathbf{g} / \mathrm{cm}^{3}\right)$ & $\theta_{\mathbf{s}}$ & $\theta_{\mathbf{r}}$ & $\alpha\left(\mathrm{cm}^{-1}\right)$ & $\mathbf{n}$ & $\mathbf{K}_{\mathbf{s}}(\mathbf{c m} / \mathbf{s})$ \\
\hline \hline 2.63 & 1.59 & 0.397 & 0.005 & 0.106 & 4.26 & $3.79 \times 10^{-2}$ \\
\hline
\end{tabular}

\subsubsection{Glass Waste}

According to current plans, the glass waste will be poured into steel packages and allowed to cool. Significant fracturing is anticipated. It is assumed here that the fracturing will be sufficient to allow the glass waste to be treated as an effective porous medium, instead of a fractured medium, and thus the parameters are the same as for the other materials. All porosity in the glass will reside in the fractures (i.e., the glass matrix has no porosity). Total porosity is anticipated to be small - on the order of a few percent ${ }^{1}$. A porosity of $2 \%$ was assumed for the best estimate, given in Table 4.14 . Bulk density was calculated from the porosity and the measured particle density of ILAW glass (BP1 glass) ${ }^{1}$.

McGrail et al. (1998) report hydraulic measurements on crushed and sieved glass waste samples. Glass samples were crushed by hand and sieved to obtain particles between 0.15 and $0.212 \mathrm{~mm}$ (the size of fine sand). The sieved material was washed to remove fines smaller than $0.15 \mathrm{~mm}$. Although the process of crushing the glass will result in a porosity much higher than expected to occur in the disposal containers, these are the only known measurements of the hydraulic properties of the glass waste.

The glass samples prepared by McGrail et al. (1998) were packed to a porosity of approximately 0.55 . Water retention and unsaturated hydraulic conductivity were measured using centrifuge methods.

1. B.P. McGrail, July 1999, personal communication. 
Although the results reported in McGrail et al. (1998) were limited, they indicate that the material behaved similarly to a fairly well-graded loam or sandy loam soil with an air-entry matric potential less than $50 \mathrm{~cm}$. It is difficult, however, to draw conclusions about the best-estimate hydraulic parameters from these experimental results because of the dissimilarity between the expected glass waste form and these sample materials. Measurements on more representative materials are planned for FY 2000.

Assuming that the glass block will be sufficiently fractured to behave as an equivalent porous medium and with the additional assumption that the fracture apertures in the glass waste will have a relatively narrow distribution, it can be expected that the glass waste will behave like a well-sorted material. This suggests a value of $n$ greater than 2 or 3 . The value of $\alpha$ and $\mathrm{K}_{\mathrm{s}}$ will depend on the actual fracture apertures, which are unknown. If significant fracturing occurs, and yet the porosity remains small, this suggests that the fracture aperture will be small. For the best-estimate hydraulic parameters of the fractured glass waste it has been assumed that the glass waste will behave similarly to a coarse sand. Parameter values, given in Table 4.14, are based on these assumed characteristics of the glass and on representative parameters for a coarse sand.

Note that Fayer et al. (1997) and Fayer and Kincaid (1998) ${ }^{1}$ used properties of a clean gravel to represent the glass fractures in a dual porosity model of the new ILAW disposal facility. These properties were measured by Rockhold et al. (1993), with saturated and residual water contents reduced to reflect the low porosity of the fractured glass waste. Particle size in the sample measured by Rockhold et al. (1993) varied from 3.7 to $8 \mathrm{~mm}$. The parameters given in Table 4.14 reflect a small anticipated fracture aperture and thus smaller $\alpha$ and $\mathrm{K}_{\mathrm{s}}$ values. The best-estimate $\alpha$ and $\mathrm{n}$ values are comparable to the estimates obtained by Reitsma and Kueper (1994) from measurements made on a single fracture in a limestone rock sample.

Table 4.14. Best-Estimate Parameter Values for Glass Waste

\begin{tabular}{|c|c|c|c|c|c|c|}
\hline$\rho_{\mathbf{p}}\left(\mathrm{g} / \mathrm{cm}^{\mathbf{3}}\right)$ & $\rho_{\mathbf{b}}\left(\mathrm{g} / \mathrm{cm}^{\mathbf{3}}\right)$ & $\theta_{\mathbf{s}}$ & $\theta_{\mathbf{r}}$ & $\alpha\left(\mathrm{cm}^{-1}\right)$ & $\mathbf{n}$ & $\mathbf{K}_{\mathbf{s}}(\mathrm{cm} / \mathbf{s})$ \\
\hline \hline 2.68 & 2.63 & 0.02 & 0.00 & 0.2 & 3 & 0.01 \\
\hline
\end{tabular}

\subsection{Diversion Layer Materials}

A diversion layer consisting of a sand drainage layer over a gravel capillary barrier is not a component of the current conceptual design of the new ILAW disposal facility as described in PHMC (1998). It is under active consideration, however, and may be included in the final design as a replacement for, or in addition to, the asphaltic concrete layer. Specifications for the hydraulic properties of the sand and gravel

1. Fayer, M.J. and C.T. Kincaid. 1998. Simulations to Guide Measurements of Near-Field Hydraulic Parameters. Letter Report to Fluor Daniel Hanford, Inc., September 30, 1998, Pacific Northwest National Laboratory, Richland, Washington. 
materials will depend on the required performance of the diversion layer and on the particular design of the layer in terms of its dimensions and slope. The materials will need to be chosen to achieve satisfactory hydraulic performance and long-term stability. Nichols and Meyer (1996) performed detailed, two- and three-dimensional simulations of capillary barrier performance for three sand/gravel combinations and three values of slope. Until further analysis is carried out to define the diversion layer materials for the ILAW facilities, hydraulic properties for the materials of the diversion layer are assumed equal to those of materials used in the simulations of Nichols and Meyer (1996) that resulted in the best performance.

\subsubsection{Sand Drainage Layer}

The best-estimate parameters of the sand drainage layer are those estimated by Rockhold et al. (1993) for a backfill sample. This sample was obtained from the excavation spoil pile of the existing disposal facility. The material was sieved to remove particles greater than $2 \mathrm{~mm}$. The resulting material was $91 \%$ sand, $3 \%$ silt, and $6 \%$ clay. These parameter values were also used by Nichols and Meyer (1996) for the sand component of the best-performing capillary barrier they simulated. The parameter values are given in Table 4.15 .

Table 4.15. Best-Estimate Parameter Values for Sand Drainage Layer

\begin{tabular}{|c|c|c|c|c|c|c|}
\hline \hline$\rho_{\mathbf{p}}\left(\mathrm{g} / \mathrm{cm}^{3}\right)$ & $\rho_{\mathbf{b}}\left(\mathrm{g} / \mathrm{cm}^{3}\right)$ & $\theta_{\mathbf{s}}$ & $\theta_{\mathbf{r}}$ & $\alpha\left(\mathrm{cm}^{-1}\right)$ & $\mathbf{n}$ & $\mathbf{K}_{\mathbf{s}}(\mathrm{cm} / \mathbf{s})$ \\
\hline \hline 2.8 & 1.65 & 0.371 & 0.045 & 0.0683 & 2.08 & $3.00 \times 10^{-2}$ \\
\hline
\end{tabular}

\subsubsection{Gravel Capillary Barrier Layer}

The best-estimate parameter values of the gravel capillary barrier layer are those estimated by Rockhold et al. (1993) for a gravel sample. This sample had particle sizes in the range of 4 to $8 \mathrm{~mm}$. These parameters were also used by Nichols and Meyer (1996) for the gravel component of the best-performing capillary barrier they simulated. The parameter values are given in Table 4.16.

Table 4.16. Best-Estimate Parameter Values for Gravel Capillary Barrier Layer

\begin{tabular}{|c|c|c|c|c|c|c|}
\hline$\rho_{\mathbf{p}}\left(\mathrm{g} / \mathrm{cm}^{\mathbf{3}}\right)$ & $\rho_{\mathbf{b}}\left(\mathrm{g} / \mathrm{cm}^{3}\right)$ & $\theta_{\mathbf{s}}$ & $\theta_{\mathbf{r}}$ & $\alpha\left(\mathrm{cm}^{-1}\right)$ & $\mathbf{n}$ & $\mathbf{K}_{\mathbf{s}}(\mathbf{c m} / \mathbf{s})$ \\
\hline \hline 2.8 & 1.38 & 0.518 & 0.014 & 3.54 & 2.66 & 1.85 \\
\hline
\end{tabular}




\subsection{Other Materials}

\subsubsection{Backfill Material}

Kaplan et al. (1998) report measurements made on a backfill sample composited from archived samples collected from 200 East Area boreholes ( 85 individual samples obtained at depths of 3 to $17 \mathrm{~m}$ were composited). This material was $92.5 \%$ sand, $2.5 \%$ silt, and $5 \%$ clay. The sand component had particle size fractions of $11.8 \%$ between 1 and $2 \mathrm{~mm}, 33.8 \%$ between 0.5 and $1 \mathrm{~mm}, 30 \%$ between 0.25 and 0.5 $\mathrm{mm}, 13.5 \%$ between 0.1 and $0.25 \mathrm{~mm}$, and $3.3 \%$ between 0.075 and $0.1 \mathrm{~mm}$. Reported bulk density and porosity were $1.79 \mathrm{~g} / \mathrm{cm}^{3}$ and 0.29 , respectively. Saturated hydraulic conductivity and water retention measurements were made. The van Genuchten function was fit to the water retention data reported by Kaplan et al. (1998) resulting in the following parameters for the composite backfill material:

$$
\theta_{\mathrm{s}}=0.34, \theta_{\mathrm{r}}=0.025, \alpha=0.04 \mathrm{~cm}^{-1}, \mathrm{n}=1.49 \text {, and } \mathrm{K}_{\mathrm{s}}=0.0022 \mathrm{~cm} / \mathrm{s} \text {. }
$$

Note that the fitted saturated water content is greater than the reported porosity. As with the quartz sand measurements discussed in Section 4.2.2, the matric potentials used by Kaplan et al. (1998) in their water retention measurements do not adequately delineate the water retention curve. As a result, the fitted parameters are not reliable.

The same composite backfill material was also evaluated more recently using the multistep outflow method of Eching et al. (1994). A sample of the material was packed to a bulk density of $1.889 \mathrm{~g} / \mathrm{cm}^{3}$; average particle density was measured at $2.762 \mathrm{~g} / \mathrm{cm}^{3}$. This resulted in a porosity of 0.316 . Estimated water retention and hydraulic conductivity parameter values from the multistep outflow experiment are given in Table 4.17. These values are the best-estimate parameter values for the backfill material.

Table 4.17. Best-Estimate Parameter Values for Backfill

\begin{tabular}{|c|c|c|c|c|c|c|}
\hline$\rho_{\mathbf{p}}\left(\mathbf{g} / \mathbf{c m}^{3}\right)$ & $\rho_{\mathbf{b}}\left(\mathbf{g} / \mathbf{c m}^{3}\right)$ & $\theta_{\mathbf{s}}$ & $\theta_{\mathbf{r}}$ & $\alpha\left(\mathbf{c m}^{-1}\right)$ & $\mathbf{n}$ & $\mathbf{K}_{\mathbf{s}}(\mathbf{c m} / \mathbf{s})$ \\
\hline \hline 2.76 & 1.89 & 0.316 & 0.049 & 0.035 & 1.72 & $1.91 \times 10^{-3}$ \\
\hline
\end{tabular}

\subsubsection{Water Conditioning Layer}

Quartz sand and crushed glass are being considered for the material of the water conditioning layer. The best-estimate values for the water conditioning layer are the parameter values obtained for the quartz sand sample discussed in Section 4.2.2. These parameter values are repeated here in Table 4.18. 
Table 4.18. Best-Estimate Parameter Values for Water Conditioning Layer

\begin{tabular}{|c|c|c|c|c|c|c|}
\hline$\rho_{\mathbf{p}}\left(\mathbf{g} / \mathbf{c m}^{\mathbf{3}}\right)$ & $\rho_{\mathbf{b}}\left(\mathbf{g} / \mathbf{c m}^{\mathbf{3}}\right)$ & $\theta_{\mathbf{s}}$ & $\theta_{\mathbf{r}}$ & $\alpha\left(\mathbf{c m}^{-1}\right)$ & $\mathbf{n}$ & $\mathbf{K}_{\mathbf{s}}(\mathbf{c m} / \mathbf{s})$ \\
\hline \hline 2.63 & 1.59 & 0.397 & 0.005 & 0.106 & 4.26 & $3.79 \times 10^{-2}$ \\
\hline
\end{tabular}

\subsection{Summary}

The best-estimate water retention and hydraulic conductivity functions for the near-field materials of the ILAW disposal facilities are displayed in Figure 4.1. These functions use the best-estimate parameters given in this chapter. The best-estimate parameter values are also collected together in Table 4.19. 
Table 4.19. Summary of Best-Estimate Parameter Values for Near-Field Materials

\begin{tabular}{|c|c|c|c|c|c|c|c|c||}
\hline Material & $\rho_{\mathbf{p}}\left(\mathrm{g} / \mathrm{cm}^{3}\right)$ & $\rho_{\mathbf{b}}\left(\mathrm{g} / \mathrm{cm}^{3}\right)$ & $\theta_{\mathbf{s}}$ & $\theta_{\mathbf{r}}$ & $\alpha\left(\mathrm{cm}^{-1}\right)$ & $\mathbf{n}$ & $\mathbf{K}_{\mathbf{s}}(\mathbf{c m} / \mathbf{s})$ \\
\hline \hline Silt Loam-Gravel Admix & 2.72 & 1.48 & 0.456 & 0.0045 & 0.0163 & 1.37 & $8.4 \times 10^{-5}$ \\
\hline Compacted Silt Loam & 2.72 & 1.76 & 0.353 & 0.0035 & 0.0121 & 1.37 & $1.8 \times 10^{-6}$ \\
\hline Sand Filter & 2.755 & 1.88 & 0.318 & 0.030 & 0.538 & 1.68 & $8.58 \times 10^{-5}$ \\
\hline Gravel Filter & 2.725 & 1.935 & 0.290 & 0.026 & 8.10 & 1.78 & $1.39 \times 10^{-2}$ \\
\hline Gravel Drainage & 2.725 & 1.935 & 0.290 & 0.006 & 17.8 & 4.84 & 2.0 \\
\hline Asphaltic Concrete & 2.63 & 2.52 & 0.04 & 0.000 & $1.0 \times 10^{-7}$ & 2.0 & $1.0 \times 10^{-11}$ \\
\hline Vault Concrete & 2.63 & 2.46 & 0.067 & 0.00 & $3.87 \times 10^{-5}$ & 1.29 & $1.33 \times 10^{-9}$ \\
\hline Vault Filler & 2.63 & 1.59 & 0.397 & 0.005 & 0.106 & 4.26 & $3.79 \times 10^{-2}$ \\
\hline Glass Waste & 2.68 & 2.63 & 0.02 & 0.00 & 0.2 & 3 & 0.01 \\
\hline Diversion Layer Sand & 2.8 & 1.65 & 0.371 & 0.045 & 0.0683 & 2.08 & $3.00 \times 10^{-2}$ \\
\hline Diversion Layer Gravel & 2.8 & 1.38 & 0.518 & 0.014 & 3.54 & 2.66 & 1.85 \\
\hline Backfill & 2.76 & 1.89 & 0.316 & 0.049 & 0.035 & 1.72 & $1.91 \times 10^{-3}$ \\
\hline Conditioning Layer & 2.63 & 1.59 & 0.397 & 0.005 & 0.106 & 4.26 & $3.79 \times 10^{-2}$ \\
\hline
\end{tabular}



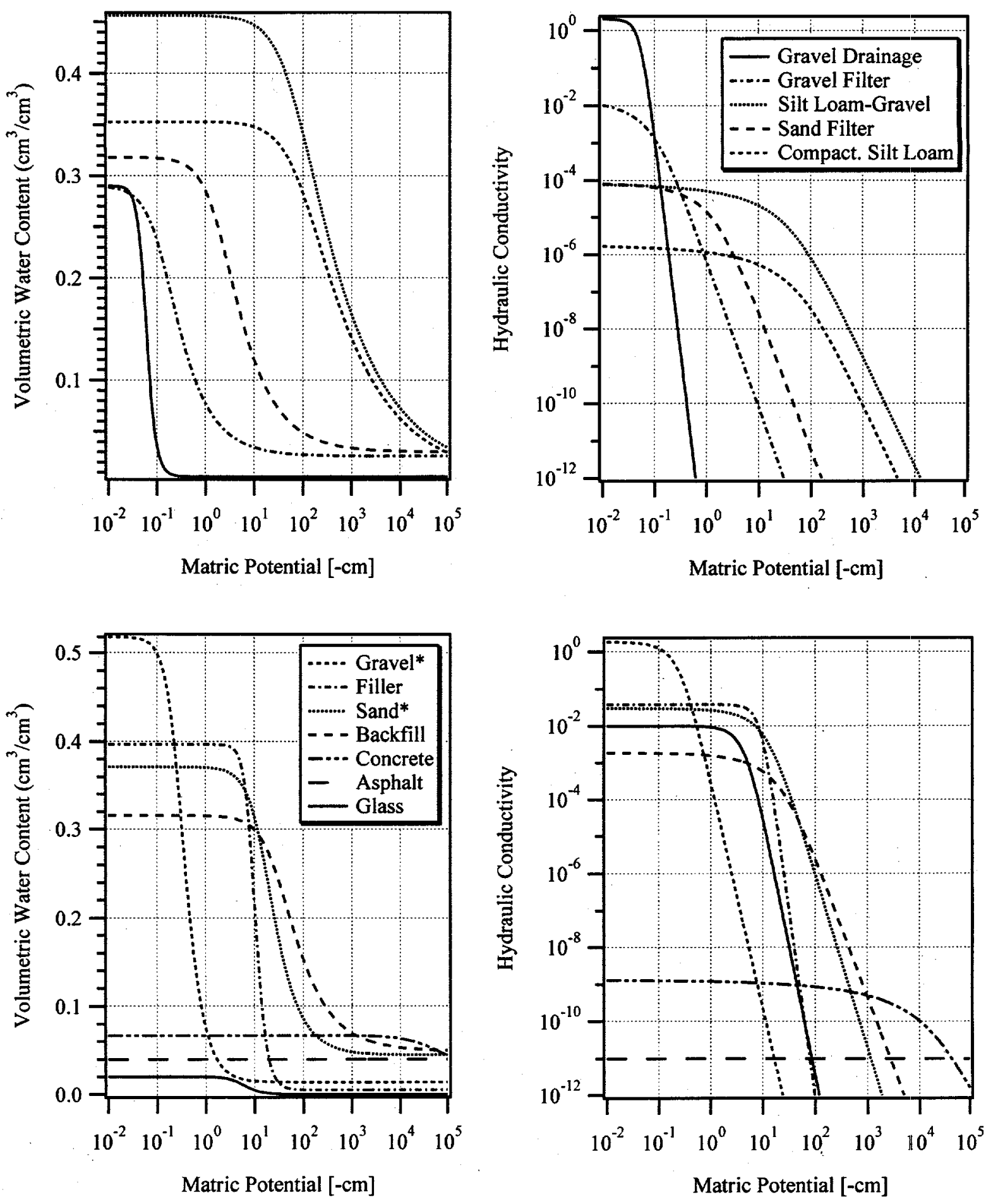

Figure 4.1. Water Retention and Hydraulic Conductivity Functions for Near-Field Materialls Using the Best-Estimate Parameters (*component of diversion layer). Note, best-estimate conditioning layer parameters are identical to those of the filler material. 


\subsection{Best-Estimate Values for Transport Parameters of Near-Field Materials}

This chapter presents the best-estimate values for the transport parameters of the near-field materials. Transport parameter values for the materials of the surface cover are not discussed, however, because contaminants are expected to travel primarily out and down from the concrete vaults. Although diffusion has been shown to be the primary means of transport in simulations of the ILAW disposal facilities, the small flux of water through the surface cover has been sufficient to prevent upward transport from the vaults. ${ }^{1}$ If the simulations carried out for the 2001 ILAW PA behave differently, the effect of transport parameters in the surface cover materials may become more important.

Consideration of transport parameters here is also limited to dispersivity and diffusion coefficients. Parameters governing the chemistry of the near-field materials (e.g., adsorption distribution coefficients and solid phase solubility controls) can be found in other data packages (McGrail et al., 1999; Kaplan and Serne, 1999).

\subsection{Dispersivity}

Transport in the near-field is expected to take place within the materials of the vault and within the backfill. Thus, the discussion will be limited to those materials. Khaleel (1999) provides a discussion of dispersion in the naturally occurring sediments beneath the excavated areas of the ILAW facilities.

Mechanical dispersion is not expected to be a significant factor in transport at the ILAW disposal facilities. Fayer et al. (1997) performed a cursory sensitivity analysis of dispersivity using a waste-formalone simulation of the ILAW disposal (i.e., no vault) and found that the value of the dispersivity had little effect on the contaminant transport results. Although these results applied to transport from the waste-form to the groundwater, they are expected to hold for near-field simulations as well. The transport flux in the near-field materials due to mechanical dispersion is expected to be small for a number of reasons.

- The scale of transport is limited to the extent of the near field. This limited scale tends to result in small values of dispersivity (Gelhar et al., 1992).

- The near-field materials are relatively homogeneous - the vault materials because they are constructed to be homogeneous and the backfill material because of mixing by construction equipment. This homogeneity will tend to reduce dispersivity (Gelhar, 1986).

- Pore water velocities in the near field are expected to be small due to the low water flux through the surface barrier. Such low pore water velocities decrease the magnitude of the dispersive flux relative to the diffusive flux.

1. Fayer, M.J. and C.T. Kincaid. 1998. Simulations to Guide Measurements of Near-Field Hydraulic Parameters. Letter Report to Fluor Daniel Hanford, September 30, 1998, Pacific Northwest National Laboratory, Richland, Washington. 
Measurements of dispersion in unsaturated field soils are rare. Indirect evidence suggests that the dispersivities in the backfill soil at the ILAW facilities will be on the order of a few centimeters. Rockhold et al. (1996) modeled a detailed tracer-infiltration experiment in heterogeneous sandy soils in New Mexico. The scale of the model was $7 \mathrm{~m}$ deep, comparable to the scale of the near-field depth at the ILAW disposal facilities. Excellent predictive results were obtained by Rockhold et al. (1996) using a dispersivity value of $3 \mathrm{~cm}$.

Recently, Ward et al. (1998) ${ }^{1}$ conducted a pair of tracer-infiltration tests in the 200 East Area of the Hanford Site, on the new ILAW disposal site. The first test measured field-scale flow and transport properties in the naturally occurring surface soils. After excavating to a depth of $1.5 \mathrm{~m}$, the experiment was repeated. The scale of each experiment was approximately $1 \mathrm{~m}$ by $6 \mathrm{~m}$ in plan and $1.5 \mathrm{~m}$ deep (thus the second experiment sampled sediments $3 \mathrm{~m}$ below the surface). Dispersivities estimated from the experimental results of the second test increased with scale, but appeared to approach an asymptotic value of about $7 \mathrm{~cm}$ at a scale of about $1 \mathrm{~m}$.

Many numerical methods for simulating contaminant transport in the subsurface have difficulty when dispersivity is significantly less than the dimension of the numerical grid. As a result, dispersivity values have often been selected to satisfy numerical restrictions. In the simulation of Rockhold et al. (1996) this problem was avoided by using a numerical grid size of $10 \mathrm{~cm}$, sufficiently small to avoid numerical difficulties with the dispersivity of $3 \mathrm{~cm}$ they used. (This dispersivity value was based on tracer measurements.) The observations of Ward et al. (1998) and the expected conditions at the site suggest that, for the ILAW PA, longitudinal dispersivity in the near-field materials should be small. A value of $10 \mathrm{~cm}$ is recommended. If numerical requirements dictate that a larger dispersivity be used in the near-field, the effect of this choice should be investigated and estimated.

\subsection{Apparent Diffusion Coefficients through Concrete}

\subsubsection{Conceptual Model of Diffusion through Cement}

Atkinson (1983), Atkinson et al. (1986), and Atkinson and Nickerson (1988) present a useful conceptual model for describing the transport of contaminants through cement. The authors consider that the transport is a combination of both physical processes such as diffusion and chemical processes such as precipitation/dissolution and adsorption/desorption. The first two articles discuss diffusion-controlled release (leaching) of a contaminant out of cement while the latter article discusses how to evaluate the diffusion of

1. Ward, A.L., R.E. Clayton and J.S. Ritter. 1998. Hanford Low-Activity Tank Waste Performance Assessment Activity: Determination of In Situ Hydraulic Parameters of the Upper Hanford Formation. Letter Report to Fluor Daniel Hanford, Inc., December 31, 1998, Pacific Northwest National Laboratory, Richland, Washington. 
a contaminant through a slab of cement or into a thick slab of cement. All three articles are limited to water-saturated cement.

The model used by Atkinson and colleagues for the apparent diffusion coefficient was presented previously as Equation 3.5.

$$
\mathrm{D}_{\mathrm{a}}=\mathrm{D}_{\mathrm{i}} / \alpha^{\prime}=\mathrm{D}_{\mathrm{f}} \delta \phi /\left(\tau \alpha^{\prime}\right)
$$

Recall that in this equation the term $\mathrm{D}_{\mathrm{i}}$ contains all the physical aspects of diffusional transport and the term $\alpha^{\prime}$ contains all the chemical aspects. Several experimental approaches can be used to measure these two parameters and, by observation, Atkinson et al. (1986) and Atkinson and Nickerson (1988) have determined which experimental techniques give the best results for various contaminants under various geochemical conditions.

\subsubsection{Measurement of Diffusion Coefficients}

Atkinson et al. (1986) suggest that classical leach tests of spiked cement solids (saturated with aqueous solution) that use the intermittent solution exchange method such as the ISO and ANSI/ANS-16.1 tests (see ISO, 1979; Mendel, 1982; and ANS, 1986), and the purely static leach test, can be used in concert to calculate $\mathrm{D}_{\mathrm{a}}$ and $\alpha^{\prime}$, respectively. Using the combination of two leach test methods, one can get fairly accurate values for the physical and chemical parameters of interest.

At long time periods, the static leach test provides a good estimate of the ultimate amount of contaminant that can leave the solid waste and go into solution for scenarios with limited water flux, such as is expected in the ILAW disposal facilities. From knowledge of the starting inventory in the waste, $A_{s}(t=0)$, one can determine the final inventory left in the solid, $A_{s}(t=\infty)$, which represents equilibrium between the solid and solution phases. From knowledge of the volumes of solution and the volume of the solid present in the static test, one can calculate $\alpha^{\prime}$ from Equation 5.2:

$$
\alpha^{\prime}=A_{s}(\infty) V_{L} /\left(A_{L}(\infty) V_{s}\right)
$$

where $\quad A_{s}=$ amount of contaminant in solid, per volume, at end of test

$A_{L}=$ amount of contaminant in solution, per volume, at end of test

$\mathrm{V}_{\mathrm{L}}=$ volume of liquid used in static test

$\mathrm{V}_{\mathrm{S}}=$ volume of solid used in static test.

After $\alpha^{\prime}$ has been calculated, Equation 3.11 and known solid characteristics of porosity and dry bulk density can be used to estimate the $K_{d}$ value. The intermittent solution exchange leach tests previously mentioned give a direct measurement of $\mathrm{D}_{\mathrm{a}}$. (Note that $\mathrm{D}_{\mathrm{a}}$ is also referred to as the effective diffusion coefficient, $D_{\text {eff }}$, in the leaching literature.) Given that the apparent diffusion coefficient is related to the intrinsic diffusion coefficient of the porous media, $D_{i}$, by Equation 5.1 , one can calculate $D_{i}$ for each contaminant from its value of $D_{a}$ (obtained from the intermittent leach test) and its value of $\alpha^{\prime}$ (obtained from the static leach test). 
Alternatively, one can make some other contaminant measurements and estimate $D_{i}$ and $\alpha^{\prime}$ for a given cement type and particular contaminant solely from the intermittent leach tests as follows. If one believes that there is a constituent that does not interact with the cement chemically, then it can be used to measure the intrinsic diffusion coefficient directly because $\alpha^{\prime}$ will be equal to the porosity (because the $\mathrm{K}_{\mathrm{d}}$ for a non-reacting constituent is zero, see Equation 3.11). Some researchers have assumed that nitrate, tritium, chloride, sodium, or potassium are non-reactive constituents in concrete or cement leach tests. If so, then the measured $\mathrm{D}_{\mathrm{a}}$ can be used to estimate the intrinsic diffusion coefficient for the particular cement by multiplying it by the cement porosity (see Equations 3.10 and 3.11). In this instance, $D_{i}$ is assumed to be a property solely of the cement and not the contaminants within the cement. Once $D_{i}$ is established, then the other leach data for reactive constituents within the cement give a measure of their unique $D_{a}$, from which the individual values of $\alpha^{\prime}$ can be calculated. In addition, from knowledge of the porosity and dry bulk density, the value of $\mathrm{K}_{d}$ for an individual contaminant can be estimated. Atkinson et al. (1986) suggest that such an approach should provide an estimate of $\alpha^{\prime}$ that is within one order of magnitude for a contaminant with a large $K_{d}$ and should provide a much better estimate for a contaminant with a small $K_{d}$. Measurements used as the basis for the best-estimate diffusion coefficients reported in later in this chapter have used nitrate as the noninteracting chemical.

\subsubsection{Through-Diffusion Test}

There are numerous through-diffusion and diffusion penetration profile experiments that have been performed by the nuclear waste community to evaluate contaminant fate. These data can also be used to estimate the two basic parameters in Atkinson and Nickerson's conceptual model, $D_{i}$ and $\alpha^{\prime}$, from which the $K_{d}$ value can be obtained. We have found by analysis of many experiments that $D_{j}$ is most accurately measured using the through-diffusion type of test where a thin slab of porous media is mounted between two reservoirs of liquid. In one reservoir the solution is devoid of the contaminant of interest, and in the other, the solution chemical composition is the same except that the contaminant is present. The "hot" reservoir is connected to a large recirculating reservoir such that there is no drop in the contaminant concentration throughout the test. The build-up of the contaminant in the initially "cold" reservoir is monitored until it reaches a steady state. Steady state is reached when a plot of $\mathrm{C} / \mathrm{C}_{0}$ on the Y-axis and time on the Xaxis (the breakthrough curve) culminates in a straight line. $D_{i}$ is related to the slope of such a plot by the constant factor $(\phi \mathrm{VL} / \mathrm{A})$

where $\quad \mathrm{V}=$ volume of solution in the initially "cold" reservoir (no contaminant present)

$\mathrm{L}=$ thickness of the porous slab or disk

$\mathrm{A}=$ geometric surface area of the porous slab or disk

$\mathrm{C}=$ concentration of the contaminant in the "cold" reservoir at time $t$

$\mathrm{C}_{\mathrm{o}}=$ concentration in the "hot" reservoir at all times (must be kept constant).

If the experiment is performed correctly the chemical term $\alpha^{\prime}$ can also be estimated from the equation 


$$
\alpha^{\prime}=6 D_{i} t_{o} / L^{2}
$$

where $t_{0}=$ the intercept of the slope of the above mentioned plot with zero breakthrough (the amount of time delay before contaminant starts to appear in the cold reservoir under steady state conditions).

Atkinson and Nickerson (1988) suggested that through-diffusion tests give an accurate measure of $D_{i}$ but they felt that the estimate of $\alpha^{\prime}$ was not as accurate because there appear to be two types of porosity in cement. Dual porosity causes the estimates of $\alpha^{\prime}$ to be smaller than they really are.

One type of porosity makes up a small percentage of the total porosity and is conceptualized as well-connected pores allowing fast transport and relatively lower chemical capacity (adsorption). The second type of porosity makes up the bulk of the total porosity and allows slow transport because of constrictions/tortuosity in the pore "connectiveness." Because this second type of porosity makes up most of the total porosity it also can adsorb (chemically react) more than the first type of porosity and thus it exhibits a higher chemical capacity factor, $\alpha^{\prime}$.

One drawback to the through-diffusion testing is that highly adsorbing contaminants take long time periods to show up in the cold reservoir. Also, for concretes with large aggregate, one must make the slabs or disks thicker to prevent short circuits around the individual grain boundaries of the large aggregates.

\subsubsection{Penetration Profile Test}

A second experimental approach generally referred to as the penetration profile test utilizes a slab of porous medium that has all but one side blocked off to solution penetration (e.g., by being cast in an epoxy mold or embedded in hydrophobic plastic or wax). If the slab is assumed to be semi-infinitely thick, then at any given time the penetration profile of a contaminant that is in contact with the surface $(x=0)$ of the slab is related to the physical aspects of diffusion, $D_{i}$, and the chemical capacity factor, $\alpha^{\prime}$, through the complementary error function.

$$
\frac{C_{s}(x)}{C_{L}}=\alpha^{\prime} \operatorname{erfc}\left\{\sqrt{\frac{\alpha^{\prime} x^{2}}{4 D_{i} t}}\right\}
$$

where $\quad \mathrm{C}_{\mathrm{s}}=$ concentration of contaminant on solid at depth $\mathrm{x}$ and time $\mathrm{t}$

$\mathrm{C}_{\mathrm{L}}=$ concentration in liquid at time $\mathrm{t}$

Brown et al. (1964; 1969), Phillips and Brown (1964), and Relyea et al. (1986) describe a convenient data reduction scheme that transforms the contaminant penetration profile into the cement or other porous medium as a probit probability distribution. One takes the breakthrough profile, determined as the concentration of the contaminant in cement at depth $\mathrm{x}$ and time $\mathrm{t}$ divided by the concentration of the contaminant in the face of the cement at $\mathrm{x}=0$ and $\mathrm{t}=0$, and after calculating this ratio (as a percentage) one looks up the equivalent probit value for all the data points between $5 \%$ and $95 \%$ using the probit table in Finney (1971) or equivalent tables of mathematical functions. The probit data are then plotted on the Y- 
axis and the depth of penetration is plotted on the X-axis. Such plots should generate a straight line as opposed to the sigmoidal curve that is the outcome of Equation 5.4. Thus the probit transformation curve is easier to interpret. The apparent diffusion coefficient, $D_{a}$, is related to the slope, $\Delta$, of the line formed by the data through the following equation.

$$
D_{a}=\left(2 \Delta^{2} t\right)^{-1}
$$

Again by using several tracers or contaminants and having one that is considered a non-reactive constituent (perhaps nitrate, tritium or chloride), one can estimate $K_{d}$ values for the other reactive constituents using Equations 3.10 and 3.11. This goes back to the original conceptual model that breaks transport into a purely physical term, $\mathrm{D}_{\mathrm{i}}$, and a purely chemical term $\alpha^{\prime}$. Because $\mathrm{D}_{\mathrm{i}}$ is a property of the porous medium, it is the same for all the tracers or contaminants moving through a given cement. When one knows that a particular contaminant is non-reactive then its measured apparent diffusion coefficient, $\mathrm{D}_{\mathrm{a}}$, is equivalent to $D_{i} / \phi$ because the $K_{d}$ of the non-reactive contaminant is zero. Once $D_{i}$ is known, $\alpha^{\prime}$ for each reactive contaminant can be calculated from its measured apparent diffusion coefficient, $D_{a}$, and the measured value of the cement's intrinsic diffusion coefficient, $D_{i}$, can be determined from the non-reactive contaminant. When $\alpha^{\prime}$ has been determined for each reactive contaminant, then $\mathrm{K}_{d}$ can be estimated from Equation 3.10 and the known porosity and dry bulk density of the cement.

Application of these conceptual models and mathematical techniques to diffusion and leach data in the literature could increase the available estimates of $\mathrm{K}_{d}$ values for important contaminants, given that there are many more waste-form leach tests and diffusion tests for cement in the literature than there are well implemented adsorption tests. We have not pursued this approach for this data package, however. Instead, we have tabulated the apparent diffusion coefficients, $D_{a}$, directly without trying to separate the physical and chemical reaction components. For the next data package we will try to see if the leach and diffusion data in the literature are, in fact, readily converted and whether the calculated $\alpha^{\prime}$ values seem plausible in comparison to direct $\mathrm{K}_{\mathrm{d}}$ measurements on concrete/cement.

\subsubsection{Best-Estimate Diffusion Coefficients}

Tests using both the through-diffusion concrete slab test and the penetration profile test are currently underway as part of the ILAW PA project. In both cases we are studying the diffusion of $\mathrm{I}^{-}$and $\mathrm{TcO}_{4}{ }^{-}$ through concrete. The first results should be available in January 2000 , but the through-diffusion test will likely require another year to reach steady state.

In the through-diffusion test, a 2-cm-thick slab of concrete with the composition shown in Table 5.1 is mounted between two reservoirs of liquid. In one reservoir the solution is devoid of the contaminant of interest and in the other (much larger reservoir) the chemical composition is the same except the contaminants are present. It was hoped that the reservoir was large enough that there would be no significant drop in the contaminant concentration throughout the test. Preliminary results suggest that the concentration of contaminants in the "hot" reservoir is decreasing with time. A more sophisticated mathematical algorithm 
to analyze diffusion data has recently been published (Moridis, 1999). This algorithm can analyze data for which the concentration of contaminant in the hot reservoir decreases over time.

Table 5.1. The Composition of ILAW Concrete Used in Diffusion Testing

\begin{tabular}{|c|c|c||}
\hline Material & Design Mix & Material Details \\
\hline \hline Cement & 0.27 & Portland Type I \& II \\
\hline Fly Ash & 0.04 & $\begin{array}{c}\text { Class F fly ash; 20\% of } \\
\text { cement volume }\end{array}$ \\
\hline Coarse Aggregate & 0.04 & $\begin{array}{c}\text { Particle size } 2.83 \mathrm{~mm} \text { to } 2 \mathrm{~mm} \\
\text { (ASTM sieve }-7 \text { to }+10 \text { ) }\end{array}$ \\
\hline Fine Aggregate & 0.48 & $\begin{array}{c}\text { Sand particle size }<2 \mathrm{~mm} \\
\text { (ASTM sieve -10) }\end{array}$ \\
\hline Water & 0.13 & Water-to-cement ratio: 0.5 \\
\hline Steel Fiber & 0.04 & $\begin{array}{c}\text { Deformed, nominal length } \\
\text { 8 mm (0.32 in.) }\end{array}$ \\
\hline Polyheed 997 & $3.75 \mathrm{e}-3$ & \\
\hline Air Content & $4.5 \%$ & \\
\hline
\end{tabular}

In the penetration profile test, two cells, one containing Hanford sediment and one consisting of a plug of concrete, are butted up to each other in a cylindrical half-cell arrangement. The soil cell is a typical Hanford sand soil (4 cm diameter and $25 \mathrm{~cm}$ long) while the concrete monolith (4 cm in diameter and $4 \mathrm{~cm}$ long) is spiked with $0.5 \mathrm{mCi} / 1$ of ${ }^{125} \mathrm{I}, 0.05 \mathrm{mCi} / 1$ of ${ }^{99} \mathrm{Tc}$ and $20 \mathrm{mg} / 1$ of $\mathrm{U}$. Preliminary results of the penetration of the isotopes into the Hanford soil are expected in January 2000. Identical half-cells with spiked and unspiked Hanford sediment are used to differentiate the diffusion of contaminants out of the concrete and into the sediment.

Apparent diffusion coefficients for constituents migrating through cement are shown in Table 5.2. Sources for the diffusion coefficient data presented in Table 5.2 are Serne (1990), Serne et al. (1987), Serne et al. (1989a), Serne et al. (1989b), Serne et al. (1992), Serne et al. (1995), and Krupka and Serne (1996) and are predominantly from grouts and solidified cementitious waste forms without any aggregate present. We have found one recent article on the diffusion of $\mathrm{Cl}^{-}$, considered a non-reactive species, through various concretes. The median value obtained was $8 \times 10^{-8} \mathrm{~cm}^{2} / \mathrm{s}$ (Bretton et al., 1992). This value can be compared to the apparent diffusion coefficients of several nonreactive constituents in grouts and cement (no aggregate present) from Table 5.2. The grout/cement diffusion values for nonreactive tracers are consistently $\sim 5 \times 10^{-8} \mathrm{~cm}^{2} / \mathrm{s}$. The slightly higher apparent diffusion coefficient in concrete may be attributable to the presence of aggregate and the relatively higher porosity around the aggregate/cement paste interfaces. 
Table 5.2. Best-Estimate Apparent Diffusion Coefficients for Constituents Migrating through Cement

\begin{tabular}{|c|c|c|}
\hline Contaminant & $\begin{array}{l}\text { Apparent Diffusion } \\
\text { Coefficients }\left(\mathrm{cm}^{2} / \mathrm{s}\right)\end{array}$ & Comment \\
\hline $\mathrm{Ac}$ & $5 \times 10^{-11}$ & \\
\hline $\mathrm{Am}$ & $5 \times 10^{-13}$ & \\
\hline $\mathrm{Sb}$ & $2 \times 10^{-10}$ & \\
\hline As & $5 \times 10^{-10}$ & \\
\hline $\mathrm{Ba}$ & $5 \times 10^{-11}$ & \\
\hline $\mathrm{Bi}$ & $5 \times 10^{-8}$ & \\
\hline C-14 as carbonate & $1 \times 10^{-12}$ & \\
\hline $\mathrm{Cd}$ & $5 \times 10^{-10}$ & \\
\hline $\mathrm{Ce}$ & $5 \times 10^{-11}$ & \\
\hline Cr(III) & $5 \times 10^{-10}$ & \\
\hline $\mathrm{Cr}(\mathrm{VI})$ & $1 \times 10^{-10}$ & \\
\hline $\mathrm{Cm}$ & $5 \times 10^{-11}$ & \\
\hline $\mathrm{Co}$ & $5 \times 10^{-11}$ & \\
\hline Cs & $5 \times 10^{-10}$ & \\
\hline $\mathrm{CN}^{-}$ & $5 \times 10^{-8}$ & \\
\hline $\mathrm{Eu}$ & $5 \times 10^{-11}$ & \\
\hline $\mathrm{Fe}$ & $5 \times 10^{-11}$ & \\
\hline $\mathrm{H}^{3}$ (tritium) & $5 \times 10^{-8}$ & \\
\hline$I^{-}$(iodide) & $5 \times 10^{-8}$ & \\
\hline $\mathrm{Pb}$ & $1 \times 10^{-11}$ & \\
\hline $\mathrm{Hg}$ & $5 \times 10^{-11}$ & \\
\hline $\mathrm{Mn}$ & $5 \times 10^{-11}$ & \\
\hline $\mathrm{Nb}$ & $5 \times 10^{-11}$ & \\
\hline $\mathrm{Ni}$ & $5 \times 10^{-10}$ & \\
\hline $\mathrm{NO}_{3}^{-}$ & $5 \times 10^{-8}$ & \\
\hline $\mathrm{Np}(\mathrm{V})$ & $5 \times 10^{-10}$ & \\
\hline $\mathrm{Pa}$ & $5 \times 10^{-8}$ & conservative guess \\
\hline $\mathrm{Pd}$ & $5 \times 10^{-11}$ & \\
\hline $\mathrm{Pm}$ & $5 \times 10^{-10}$ & \\
\hline Po & $5 \times 10^{-11}$ & \\
\hline
\end{tabular}


Table 5.2. Best-Estimate Apparent Diffusion Coefficients for Constituents Migrating through Cement (Continued)

\begin{tabular}{|c|c|c||}
\hline Contaminant & $\begin{array}{c}\text { Apparent Diffusion } \\
\text { Coefficients }\left(\mathrm{cm}^{2} / \mathbf{s}\right)\end{array}$ & Comment \\
\hline \hline $\mathrm{Pu}$ & $5 \times 10^{-11}$ & \\
\hline $\mathrm{Ra}$ & $5 \times 10^{-11}$ & guess \\
\hline $\mathrm{Rn}$ & $5 \times 10^{-8}$ & \\
\hline $\mathrm{Ru}$ & $5 \times 10^{-10}$ & \\
\hline $\mathrm{Se}$ & $2 \times 10^{-10}$ & \\
\hline $\mathrm{Ag}$ & $5 \times 10^{-11}$ & \\
\hline $\mathrm{Sm}$ & $5 \times 10^{-11}$ & \\
\hline $\mathrm{Sn}$ & $1 \times 10^{-11}$ & \\
\hline $\mathrm{Sr}$ & $5 \times 10^{-11}$ & \\
\hline $\mathrm{Tc}$ & $1 \times 10^{-8}$ & \\
\hline $\mathrm{Th}$ & $1 \times 10^{-12}$ & \\
\hline $\mathrm{Tl}$ & $5 \times 10^{-10}$ & \\
\hline $\mathrm{U}$ & $1 \times 10^{-12}$ & \\
\hline $\mathrm{Y}$ & $5 \times 10^{-11}$ & \\
\hline $\mathrm{Zn}$ & $5 \times 10^{-10}$ & guess \\
\hline
\end{tabular}

For the ILAW PA simulations, the values in Table 5.2 should be used directly if possible. In the event that the simulation codes cannot directly use the apparent diffusion coefficients, the free-water diffusion coefficients and capacity factors for the potential ILAW contaminants are given in Table 5.3. The freewater diffusion values were taken from Robinson and Stokes (1959). The values presented are for $25^{\circ} \mathrm{C}$ and should be adjusted for other temperatures by multiplying by the ratio of the viscosity of water at $25^{\circ} \mathrm{C}$ to the viscosity at the desired temperature. For example, at $15^{\circ} \mathrm{C}$ the $\mathrm{D}_{\mathrm{f}}$ values in Table 5.3 should be multiplied by 0.782 to correct for the lower temperature. The capacity factors in Table 5.3 were calculated by taking the measured (or estimated) values of the apparent diffusion coefficients from Table 5.2 and assuming that nitrate has no interaction with the cements/grouts and thus has a capacity factor of one. The intrinsic diffusion coefficient, which represents the physical aspects of the grout/cement/concrete, therefore becomes $5 \times 10^{-8} \mathrm{~cm}^{2} / \mathrm{s}$ for all constituents. The estimated capacity factors are thus the intrinsic diffusion coefficient $\left(5 \times 10^{-8}\right)$ divided by each reactive constituent's apparent diffusion coefficient (see Equation 5.1). 
Table 5.3. Best-Estimate Free-Water Diffusion Coefficients and Capacity Factors for Constituents Migrating through Concrete

\begin{tabular}{|c|c|c|c|}
\hline Contaminant & $\begin{array}{c}\text { Free-Water } \\
\text { Diffusion } \\
\text { Coefficient }\left[\mathrm{cm}^{2} / \mathrm{s}\right]\end{array}$ & $\begin{array}{c}\text { Capacity Factor } \\
\text { [unitless] }^{3}\end{array}$ & Comment \\
\hline Ac & $6 \times 10^{-6}$ & 1,000 & $\mathrm{D}_{\mathrm{f}}$ assumed to be $\mathrm{La}$ \\
\hline $\mathrm{Am}$ & $6 \times 10^{-6}$ & 100,000 & $D_{\mathrm{f}}$ assumed to be $\mathrm{La}$ \\
\hline $\mathrm{Sb}$ & $1 \times 10^{-5}$ & 250 & $D_{f}$ conservative estimate \\
\hline As & $1 \times 10^{-5}$ & 100 & $D_{f}$ conservative estimate \\
\hline $\mathrm{Ba}$ & $8.5 \times 10^{-6}$ & 1000 & Both measured \\
\hline $\mathrm{Bi}$ & $1 \times 10^{-5}$ & 1 & $D_{\mathrm{f}}$ and $\alpha^{\prime}$ conservative estimates \\
\hline C-14 [bicarbonate] & $1.1 \times 10^{-5}$ & 50,000 & Both measured \\
\hline $\mathrm{Cd}$ & $7 \times 10^{-6}$ & 100 & $D_{\mathrm{f}}$ assumed to be $\mathrm{Zn}$ \\
\hline $\mathrm{Ce}$ & $6 \times 10^{-6}$ & 1000 & $D_{f}$ assumed to be La \\
\hline Cr(III) & $7 \times 10^{-6}$ & 1000 & $D_{\mathrm{f}}$ assumed to be $\mathrm{Zn}$ \\
\hline $\mathrm{Cr}(\mathrm{VI})$ & $1 \times 10^{-5}$ & 500 & $D_{f}$ conservative estimate \\
\hline $\mathrm{Cm}$ & $6 \times 10^{-6}$ & 1000 & $\mathrm{D}_{\mathrm{f}}$ assumed to be $\mathrm{La}$ \\
\hline $\mathrm{Co}$ & $7 \times 10^{-6}$ & 1000 & $\mathrm{D}_{\mathrm{f}}$ assumed to be $\mathrm{Zn}$ \\
\hline Cs & $2.1 \times 10^{-5}$ & 100 & Both measured \\
\hline $\mathrm{CN}^{-}$ & $2 \times 10^{-5}$ & 1 & $D_{f}$ and $\alpha^{\prime}$ conservative estimates \\
\hline $\mathrm{Eu}$ & $6 \times 10^{-6}$ & 1000 & $\mathrm{D}_{\mathrm{f}}$ assumed to be $\mathrm{La}$ \\
\hline $\mathrm{Fe}$ & $6 \times 10^{-6}$ & 1000 & $D_{\mathrm{f}}$ assumed to be $\mathrm{Zn}$ \\
\hline $\mathrm{H}^{3}$ (as $\left.\mathrm{OH}^{-}\right)$ & $6 \times 10^{-5}$ & 1 & Both measured \\
\hline$I^{-}$ & $2 \times 10^{-5}$ & 1 & Both measured \\
\hline $\mathrm{Pb}$ & $9 \times 10^{-6}$ & 5000 & Both measured \\
\hline $\mathrm{Hg}$ & $8 \times 10^{-6}$ & 1000 & $D_{f}$ conservative estimate \\
\hline $\mathrm{Mn}$ & $7 \times 10^{-6}$ & 1000 & $\mathrm{D}_{\mathrm{f}}$ assumed to be $\mathrm{Zn}$ \\
\hline $\mathrm{Nb}$ & $2 \times 10^{-5}$ & 1000 & $D_{f}$ conservative estimate \\
\hline $\mathrm{Ni}$ & $7 \times 10^{-6}$ & 100 & $\mathrm{D}_{\mathrm{f}}$ assumed to be $\mathrm{Zn}$ \\
\hline $\mathrm{NO}_{3}^{-}$ & $1.8 \times 10^{-5}$ & 1 & Both measured \\
\hline $\mathrm{Np}(\mathrm{V})$ & $2 \times 10^{-5}$ & 100 & $D_{\mathrm{f}}$ conservative estimate \\
\hline $\mathrm{Pa}$ & $2 \times 10^{-5}$ & 1 & $D_{\mathrm{f}}$ and $\alpha^{\prime}$ conservative estimates \\
\hline $\mathrm{Pd}$ & $2 \times 10^{-5}$ & 1000 & $D_{\mathrm{f}}$ conservative estimate \\
\hline $\mathrm{Pm}$ & $6 \times 10^{-6}$ & 100 & $\mathrm{D}_{\mathrm{f}}$ assumed to be $\mathrm{La}$ \\
\hline Po & $2 \times 10^{-5}$ & 1000 & $D_{f}$ conservative estimate \\
\hline $\mathrm{Pu}(\mathrm{V}, \mathrm{VI})$ & $2 \times 10^{-5}$ & 100 & $D_{f}$ conservative estimate \\
\hline
\end{tabular}


Table 5.3. Best-Estimate Free-Water Diffusion Coefficients and Capacity Factors for Constituents Migrating through Concrete (Continued)

\begin{tabular}{|c|c|c|c||}
\hline $\mathrm{Pu}(\mathrm{III}, \mathrm{IV})$ & $6 \times 10^{-6}$ & 1000 & $\mathrm{D}_{\mathrm{f}}$ assumed to be La \\
\hline $\mathrm{Ra}$ & $8 \times 10^{-6}$ & 1000 & $\mathrm{D}_{\mathrm{f}}$ assumed to be Ba \\
\hline $\mathrm{Rn}$ & $1 \times 10^{-4}$ & 1 & $\mathrm{D}_{\mathrm{f}}$ and $\alpha^{\prime}$ conservative estimates \\
\hline $\mathrm{Ru}$ & $2 \times 10^{-5}$ & 100 & $\mathrm{D}_{\mathrm{f}}$ conservative estimate \\
\hline $\mathrm{Se}$ & $2 \times 10^{-5}$ & 250 & $\mathrm{D}_{\mathrm{f}}$ conservative estimate \\
\hline $\mathrm{Ag}$ & $2 \times 10^{-5}$ & 1000 & Both measured \\
\hline $\mathrm{Sm}$ & $6 \times 10^{-6}$ & 1000 & $\mathrm{D}_{\mathrm{f}}$ assumed to be La \\
\hline $\mathrm{Sn}$ & $2 \times 10^{-5}$ & 5000 & $\mathrm{D}_{\mathrm{f}}$ conservative estimate \\
\hline $\mathrm{Sr}$ & $8 \times 10^{-6}$ & 1000 & Both measured \\
\hline $\mathrm{Tc}$ & $2 \times 10^{-5}$ & 1 & $\mathrm{D}_{\mathrm{f}}$ conservative estimate \\
\hline $\mathrm{Th}$ & $6 \times 10^{-6}$ & 50,000 & $\mathrm{D}_{\mathrm{f}}$ assumed to be La \\
\hline $\mathrm{Tl}$ & $2 \times 10^{-5}$ & 100 & $\mathrm{D}_{\mathrm{f}}$ conservative estimate \\
\hline $\mathrm{U}(\mathrm{VI})$ & $2 \times 10^{-5}$ & 100 & $\mathrm{D}_{\mathrm{f}}$ conservative estimate \\
\hline $\mathrm{U}(\mathrm{IV})$ & $6 \times 10^{-6}$ & 50,000 & $\mathrm{D}_{\mathrm{f}}$ assumed to be La \\
\hline $\mathrm{Y}$ & $2 \times 10^{-5}$ & 1000 & $\mathrm{D}_{\mathrm{f}}$ conservative estimate \\
\hline $\mathrm{Zn}$ & $7 \times 10^{-6}$ & 100 & Both measured \\
\hline
\end{tabular}

\subsection{Apparent Diffusion Coefficients in Backfill and Glass Waste}

For nonreactive solutes diffusing through unsaturated sediments, one of the empirical relationships discussed in Section 3.9 can be used. Measurements of intrinsic diffusion coefficients were reported in Conca and Wright (1990 and 1991) for a variety of materials, including sediments from the Hanford Site. The results obtained by Conca and Wright suggest that the model of Kemper and Van Schaik (1966) (Equation 3.9) is inappropriate and may significantly overestimate the intrinsic diffusion coefficients at low water contents. The models of Millington (1959) and Campbell (1985) (Equations 3.7 and 3.8) are more representative of the relationship between the intrinsic diffusion coefficient and volumetric water content observed by Conca and Wright. It was also observed that the $D_{i}(\theta)$ relationship (for a chemically nonreactive solute) was remarkably similar for the variety of materials reported in Conca and Wright (1991), which included porous and nonporous tuff gravels, bentonite clays, Hanford sandy soils and gravels, and whole rock cores of non-welded tuff. This result suggests that the aqueous intrinsic diffusion coefficient may not depend strongly on the porosity of the material and that the model of Millington (Equation 3.7) may not be the most appropriate model for the ILAW PA. An informal comparison of the results presented in Conca and Wright (1991) and the diffusion models represented by Equations 3.7 and 3.8 suggest that a slightly modified version of the model of Campbell (1985) appears to fit the data of Conca and Wright (1991) reasonably well. This model has the form 


$$
\mathrm{D}_{\mathrm{i}}=2.8 \mathrm{D}_{\mathrm{f}} \theta^{2.3}
$$

which is Equation 3.8, with a slightly smaller exponent. Equation 5.6 can be used in the ILAW PA simulations to model diffusion of nonreactive constituents in the non-cementitious materials of the near field. The free-water diffusion coefficients, $D_{f}$, for individual contaminants can be selected from Table 5.3 or calculated using one of the available equations (see Grathwohl, 1998).

To estimate the effect of chemical interactions on the diffusion coefficients, the retardation factor can be used. Combining Equations 3.10 and 3.12, the apparent diffusion coefficient (which includes the chemical effects) can be obtained from the intrinsic diffusion coefficient (which includes only physical effects of the porous medium).

$$
\mathrm{D}_{\mathrm{a}}=\mathrm{D}_{\mathrm{i}} / \mathrm{R} \theta
$$

The porosity in Equation 3.12 is replaced by the water content for unsaturated media. Estimated values for the $\mathrm{K}_{\mathrm{d}}$ of a given constituent and sediment (required to calculate the retardation coefficient) can be obtained from the geochemistry data package (Kaplan and Serne, 1999). 


\subsection{Uncertainty and Other Issues Affecting Parameter Values}

The best-estimate parameter values discussed in Chapters 4 and 5 are not the only values required for the 2001 ILAW PA. The PA must consider uncertainty in its predictions of facility performance and this uncertainty is due, in part, to uncertainty in the hydraulic and transport parameters of the near-field materials. In addition, the long time-frame of the PA analysis requires that potential changes over time in the near-field materials and their properties be considered. This chapter discusses the currently available information regarding near-field hydraulic and transport parameter uncertainty and changes in near-field material parameter values over time.

The issue of effective parameter values is also briefly discussed here. Effective parameter values are required when the scale of material heterogeneity represented in simulations is larger than the scale of that heterogeneity in the actual system being modeled. This issue is particularly important for the naturally occurring sediments beneath the excavated areas of the ILAW disposal facilities (and is discussed in Khaleel [1999]), but it is also relevant in the near-field simulations where the materials of the vault (concrete, glass waste, filler material, and steel corrosion products) are not likely to be represented in detail.

The materials of the surface barrier, except for the asphaltic concrete, are not discussed here. Fayer (1999) discusses the uncertainty in the recharge rate allowed through the surface barrier and the manner in which the recharge rate is expected to change over time as a result of changes in the surface barrier.

\subsection{Uncertainty in Parameter Values}

The best-estimate parameter values discussed in Chapter 4 are uncertain because they are based on limited data, they use indirect methods to estimate parameters (such as the Arya and Paris [1981] method), or they use data from existing materials that are not expected to be identical to the materials used in the ILAW facilities (such as the concrete). In addition, material properties are expected to vary spatially and the small-scale measurements obtained in the laboratory may not represent the large-scale behavior in the field. Improving the available data on critical materials and planning for construction of a test pad to make field-scale measurements are anticipated to be subjects of further investigation by the ILAW PA project in FY 2000. Available information concerning the uncertainty of the near-field material properties is discussed in this section.

This discussion of uncertainty is framed in terms of reasonable bounding cases that should be considered in the 2001 ILAW PA. As a result, the bounding parameter values provided in this section represent reasonable bounds on the average properties of each material. It is not unreasonable to expect that spatial heterogeneity in material properties may result in point measurements that are outside these bounding values.

In an uncertainty analysis, it is generally not necessary to consider all the parameters used in the simulation models. The input parameters that are most important to the uncertainty in the output of the 
models (e.g., predictions of dose or contaminant concentrations) are those parameters that simultaneously possess two characteristics.

1. The uncertainty (or variability) of the parameter is significant. The parameter uncertainty can be represented by its coefficient of variation, which is the standard deviation of the parameter divided by its mean value. This can be estimated from measured data and/or from expert judgement and experience.

2. The sensitivity of the simulation model results to the value of the parameter is significant. The relative sensitivity of a model to its parameter values is measured by systematically or randomly varying parameter values and calculating the resulting changes in model output. It should be noted that the typical procedure of varying parameters individually ignores parameter correlation and the potential dependence of sensitivity on the values of other parameters.

It is worthwhile to note that significant parameter variability does not always mean large parameter variability. If simulation model results are very sensitive to a particular parameter, the variability of that parameter value may not need to be very large in order to be significant.

In evaluating parameters with respect to the two characteristics above for application to the ILAW PA, the authors have relied primarily on expert judgement and experience because there is currently no comprehensive sensitivity analysis of the ILAW disposal facilities and there is insufficient data to calculate parameter uncertainty in most cases.

\subsubsection{Asphaltic Concrete}

Although the water retention parameters of the asphaltic concrete layer are highly uncertain (because there are no known measurements of water retention on this material), these parameters are not anticipated to greatly affect the performance of this low permeability layer. This is because the asphaltic concrete is expected to remain saturated over a very wide range of matric potentials (see Figure 4.1). The hydraulic parameter expected to most significantly impact the performance of the asphaltic concrete is the saturated hydraulic conductivity. In addition, the porosity may be of secondary importance.

Several studies of the hydraulic conductivity of asphalt or asphaltic concrete conducted as part of the development of the Hanford Barrier were discussed in Section 4.1.6. Lacking other information, these studies form the basis of the reasonable bounds on the saturated hydraulic conductivity of the asphaltic concrete layer of the ILAW disposal facilities. The asphalt measurements of Clemmer et al. (1992) represent the lower bound on hydraulic conductivity $\left(10^{-13} \mathrm{~cm} / \mathrm{s}\right)$ and porosity $(0.03)$. The in-field measurements of asphaltic concrete hydraulic conductivity reported in DOE-RL (1993) represent the upper bound $\left(10^{-7} \mathrm{~cm} / \mathrm{s}\right)$. This upper bound represents the potential for the in-field value to be significantly larger than the small-scale laboratory measurements and assumes that the asphalt coating fails to perform as designed or is not used. The upper bound porosity is taken from the largest porosities measured in the concrete cores obtained from the $213 \mathrm{~J}$ bunker on the Hanford Site $(0.08)$. Reasonable bounding values are given in Table 6.1. 
Table 6.1. Reasonable Bounding Values for Critical Asphaltic Concrete Parameters. Best-Estimate Values Shown for Comparison

\begin{tabular}{|c|c|c|c|}
\hline Parameter & Lower Bound & Best Estimate & Upper Bound \\
\hline \hline $\mathbf{K}_{\mathbf{s}}(\mathbf{c m} / \mathbf{s})$ & $1.0 \times 10^{-13}$ & $1.0 \times 10^{-11}$ & $1.0 \times 10^{-7}$ \\
\hline$\phi\left(=\theta_{\mathbf{s}}\right)$ & 0.03 & 0.04 & 0.08 \\
\hline
\end{tabular}

\subsubsection{Concrete}

Because the concrete functions hydraulically as a low permeability layer, like the asphaltic concrete, the hydraulic parameter expected to most significantly impact concrete behavior is the saturated hydraulic conductivity. Water retention measurements on concrete are rare. However, the measurements on the cores obtained from the 213J vault on the Hanford Site are available to estimate potential variability in these parameters. These measurements and literature values are available to estimate potential variability in concrete saturated hydraulic conductivity.

The saturated hydraulic conductivity of concrete is known to vary significantly with the water/ cement ratio, additives such as slag or fly ash, and the curing conditions (Whiting and Walitt, 1988). In addition, the hydraulic conductivity of concrete is typically greater than the hydraulic conductivity of the cement paste alone. Because of the difficulty in directly measuring hydraulic conductivity, gas permeability and electrical conductivity measurements are often used as indirect methods to estimate concrete hydraulic conductivity. Gas permeability measurements have been an unreliable estimator of water permeability and the electrical conductivity measurements appear to result in hydraulic conductivity estimates that are two orders of magnitude smaller than obtained with direct measurement (Tumidajski and Lin, 1998).

The concrete to be used in the new ILAW disposal facility has currently not been specified, but it is assumed here that it will be a standard concrete with no additives. The best-estimate value of saturated hydraulic conductivity is representative of the direct measurements on concrete that have appeared in the literature. This best estimate was based on measurements of a 50-year-old concrete with large aggregate. (The observed diameter of the aggregate was typically $2 \mathrm{~cm}$, but exceeding $4.5 \mathrm{~cm}$ in one of the cores.) For the six concrete samples from the $213 \mathrm{~J}$ vault, the measured hydraulic conductivity varied from $4.4 \times 10^{-10}$ to $5.9 \times 10^{-9} \mathrm{~cm} / \mathrm{s}$. Based on a survey of literature values, a reasonable lower bound for the saturated hydraulic conductivity of concrete is $5 \times 10^{-11} \mathrm{~cm} / \mathrm{s}$. Currently available data are based on measurements made on small samples. It is possible that large-scale field measurements of concrete hydraulic conductivity will be significantly larger, as reported in DOE-RL (1993) for the asphaltic concrete of the Hanford Barrier. Assuming this is the case, a reasonable upper bound on the saturated hydraulic conductivity of concrete is $1 \times 10^{-7} \mathrm{~cm} / \mathrm{s}$. 
Reasonable bounds on the variability of the water retention parameters for concrete were based on the measurements from the six core samples obtained from the $213 \mathrm{~J}$ vault on the Hanford Site. The lower and upper bounds were taken as the approximate 0.01 and 0.99 quantiles of the parameter distributions. A normal distribution was assumed for the saturated water content (porosity) and for the van Genuchten parameter, n. A lognormal distribution was assumed for the van Genuchten parameter, $\alpha$. The mean and variance of each distribution was assumed to be the sample mean and variance obtained from the six concrete samples. The resulting lower and upper bounds are given in Table 6.2 for the water retention parameters and the saturated hydraulic conductivity.

Table 6.2. Reasonable Bounding Values for Concrete Parameters. Best-Estimate Values Shown for Comparison

\begin{tabular}{|c|c|c|c|}
\hline Parameter & Lower Bound & Best Estimate & Upper Bound \\
\hline \hline $\mathbf{K}_{\mathbf{s}}(\mathbf{c m} / \mathbf{s})$ & $5.0 \times 10^{-11}$ & $1.33 \times 10^{-9}$ & $1.0 \times 10^{-7}$ \\
\hline$\phi\left(=\theta_{\mathbf{s}}\right)$ & 0.039 & 0.067 & 0.095 \\
\hline$\theta_{\mathbf{r}}$ & 0 & 0.00 & 0 \\
\hline$\alpha\left(\mathrm{cm}^{-1}\right)$ & $8.67 \times 10^{-6}$ & $3.87 \times 10^{-5}$ & $1.73 \times 10^{-4}$ \\
\hline $\mathbf{n}$ & 1.17 & 1.29 & 1.41 \\
\hline
\end{tabular}

\subsubsection{Glass Waste}

The best-estimate parameter values for the glass waste were based on qualitative information about the expected final form of the glass waste. Because there were no direct measurements on this expected material and there are no measurements in the literature on analogous materials, the best-estimate parameter values are very uncertain. Because of the lack of data, the reasonable lower and upper bounds for the glass waste are based on a judgement about what the nature of the fractures might be. The lower bound parameter values represent a case in which there are fewer fractures and the fracture apertures are very small. The glass waste behaves more like a fine sand in this case, albeit one with a very low porosity. The upper bound parameters represent a case in which the fracture apertures are much larger. The glass waste behaves more like a gravel in this case. The values given in Table 6.3 reflect these assumptions.

The bounding values for the glass waste assume that the waste is sufficiently fractured that it can be represented as a porous medium. If the actual glass waste violates this assumption, the hydraulic behavior of the glass waste may be quite different than the best-estimate and bounding values presented. The resultant uncertainty in contaminant fate and transport is a key issue, anticipated to be a subject of further investigation by the ILAW PA project in FY 2000. 
Table 6.3. Reasonable Bounding Values for Glass Waste Parameters. Best-Estimate Values Shown for Comparison

\begin{tabular}{|c|c|c|c|}
\hline Parameter & Lower Bound & Best Estimate & Upper Bound \\
\hline \hline$K_{\mathbf{s}}(\mathbf{c m} / \mathbf{s})$ & $1.0 \times 10^{-4}$ & 0.01 & 1.0 \\
\hline$\phi\left(=\theta_{\mathbf{s}}\right)$ & 0.01 & 0.02 & 0.05 \\
\hline$\theta_{\mathbf{r}}$ & 0 & 0.00 & 0 \\
\hline$\alpha\left(\mathrm{cm}^{-\mathbf{1}}\right)$ & 0.01 & 0.2 & 4 \\
\hline $\mathbf{n}$ & 1.5 & 3 & 5 \\
\hline
\end{tabular}

\subsubsection{Filler Material}

The best-estimate filler material parameters are based on a single measurement of a quartz sand. The actual material to be used, however, has not yet been specified, although it is likely to be a sediment with a sandy texture. Using regression techniques, Carsel and Parrish (1988) derived probability distributions for soil hydraulic parameters, classified by soil texture. Schaap and Leij (1998) calculated means and variances for hydraulic parameters obtained from fitting the van Genuchten water retention function to three large databases of water retention measurements. These results were also classified according to soil texture. These references, combined with the authors' judgement, form the basis of the reasonable upper and lower bounds for the hydraulic parameters of the filler material.

The lower and upper bounds for the saturated water content are the 0.10 and 0.90 quantiles of an assumed normal distribution for this parameter, with the mean and variance of the distribution taken from the sample statistics for sand soils presented by Schaap and Leij (1998) using all their data. The upper bound of the residual water content is calculated in the same manner. The lower bound for the residual water content is the best-estimate value, because this value is very low for a sand [lower than the 0.10 quantile from the statistics of Schaap and Leij (1998)]. The reasonable bounds for the van Genuchten parameters, $\alpha$ and $\mathbf{n}$, and for the saturated hydraulic conductivity were calculated in a similar manner, with the assumption that these parameters were lognormally distributed. Schaap and Leij (1998) presented statistics for $\log (\alpha), \log (n)$, and $\log \left(\mathrm{K}_{\mathrm{s}}\right)$, implying that their data exhibited skewed distributions. The upper bound for $\alpha$ is the mean sand value from Carsel and Parrish (1988). The best-estimate value was greater than the 0.90 quantile using the statistics of Schaap and Leij (1998).

The reasonable bounding values for the filler material parameters are given in Table 6.4. These values were based on an assumption that the material would have a sand texture. If the ultimate material used as the filler violates this assumption, these bounding values (and the best estimate) should be reevaluated. 
Table 6.4. Reasonable Bounding Values for Filler Material Parameters. Best-Estimate Values Shown for Comparison

\begin{tabular}{|c|c|c|c|}
\hline Parameter & Lower Bound & Best Estimate & Upper Bound \\
\hline \hline $\mathbf{K}_{\mathbf{s}}(\mathbf{c m} / \mathbf{s})$ & $1.3 \times 10^{-3}$ & $3.79 \times 10^{-2}$ & $4.3 \times 10^{-2}$ \\
\hline$\phi\left(=\theta_{\mathbf{s}}\right)$ & 0.30 & 0.397 & 0.45 \\
\hline$\theta_{\mathbf{r}}$ & 0.005 & 0.005 & 0.09 \\
\hline$\alpha\left(\mathrm{cm}^{-1}\right)$ & 0.017 & 0.106 & 0.15 \\
\hline $\mathbf{n}$ & 1.9 & 4.26 & 5.4 \\
\hline
\end{tabular}

\subsubsection{Backfill}

Reasonable bounding values for the backfill were based on the statistics presented in Khaleel and Freeman (1995) for the sediment samples they classified as gravelly sand. The sediment samples analyzed by Khaleel and Freeman (1995) were all obtained from boreholes located in the 200 Areas of the Hanford Site. Ten of the 183 samples included in the analysis were classified as gravelly sand. The gravelly sand classification was used for the backfill bounding values because the boreholes drilled at the new ILAW disposal facility indicated the presence of gravel in the near-surface sediments (see Figure 2.1) and the best-estimate parameter values for the backfill appeared to most closely match the mean parameters values for the gravelly sand class of Khaleel and Freeman (1995), with the exception of the saturated water content.

The reasonable bounding values for the backfill material were taken as the minimum and maximum values reported by Khaleel and Freeman (1995) for their 10 gravelly sand samples. These values bound the best-estimate values and are given in Table 6.5 .

Table 6.5. Reasonable Bounding Values for Backfill Parameters. Best-Estimate Values Shown for Comparison

\begin{tabular}{|c|c|c|c|}
\hline Parameter & Lower Bound & Best Estimate & Upper Bound \\
\hline \hline $\mathbf{K}_{\mathbf{s}}(\mathbf{c m} / \mathbf{s})$ & $5.4 \times 10^{-5}$ & $1.91 \times 10^{-3}$ & $8.0 \times 10^{-3}$ \\
\hline$\phi\left(=\theta_{\mathbf{s}}\right)$ & 0.20 & 0.316 & 0.33 \\
\hline$\theta_{\mathbf{r}}$ & 0.01 & 0.049 & 0.07 \\
\hline$\alpha\left(\mathbf{c m}^{-1}\right)$ & 0.004 & 0.035 & 0.074 \\
\hline $\mathbf{n}$ & 1.5 & 1.72 & 2.5 \\
\hline
\end{tabular}




\subsubsection{Diversion Layer Materials}

As discussed in Section 4.3, the performance of the diversion layer will depend critically on the hydraulic parameters of the sand drainage and gravel capillary barrier layer. Because the required performance of the diversion layer and the specification of the materials are unknown, it is difficult to set reasonable bounds on the hydraulic properties. In addition, it is the combination of the two materials and their hydraulic interaction under the particular conditions of the ILAW facilities that can result in poor performance. It is suggested here that the approach of Nichols and Meyer (1996) be used in the 2001 ILAW PA to examine uncertainty in the diversion layer performance. They identified three combinations of sand and gravel hydraulic properties that resulted in progressively better performance under the conditions they simulated. The best performing properties were assigned as the best-estimate parameter values for the diversion layer materials (see Tables 4.15 and 4.16). The poorest performing materials used by Nichols and Meyer (1996) and those that performed moderately well are listed in Table 6.6. These parameter values could serve as a starting point for the ILAW PA sensitivity simulations of the diversion layer.

Table 6.6. Diversion Layer Parameters Used by Nichols and Meyer (1996) for their Poorest and Moderate Performing Cases. Best-Estimate Values Shown for Comparison

\begin{tabular}{|c|c|c|c|c|c|c||}
\hline \multirow{2}{*}{ Parameter } & \multicolumn{2}{|c|}{ Poorest Performance } & \multicolumn{2}{c|}{ Moderate Performance } & \multicolumn{2}{c|}{ Best Estimate } \\
& Sand & Gravel & Sand & Gravel & Sand & Gravel \\
\hline \hline $\mathbf{K}_{\mathbf{s}}(\mathbf{c m} / \mathbf{s})$ & $1.0 \times 10^{-4}$ & $1.0 \times 10^{-2}$ & $3.0 \times 10^{-2}$ & 1.0 & $3.00 \times 10^{-2}$ & 1.85 \\
\hline$\theta_{\mathbf{s}}$ & 0.35 & 0.34 & 0.35 & 0.34 & 0.371 & 0.518 \\
\hline$\theta_{\mathbf{r}}$ & 0.01 & 0.02 & 0.01 & 0.02 & 0.045 & 0.014 \\
\hline$\alpha\left(\mathbf{c m}^{-1}\right)$ & 0.044 & 0.101 & 0.044 & 0.4 & 0.0683 & 3.54 \\
\hline $\mathbf{n}$ & 1.52 & 2.92 & 1.52 & 2.92 & 2.08 & 2.66 \\
\hline
\end{tabular}

\subsubsection{Diffusion Coefficient Uncertainty}

Regarding the uncertainty in apparent diffusion coefficients for solute transport through concrete we suggest that the values given in Table 5.2 be considered realistic estimates or best-estimate values. Based solely on expert judgement, we recommend that reasonable bounding values for the apparent diffusion coefficients in concrete be taken as as a factor of ten larger and smaller than the values from Table 5.2. For the diffusion coefficients in other materials calculated using Equation 5.7, the contribution to uncertainty should be considered to come primarily from the retardation coefficient and from any uncertainty in the water content. 


\subsection{Changes in Parameter Values over Time}

A number of the materials discussed in Section 2.2 may undergo significant changes over time, potentially affecting the performance of the disposal facilities. These changes will be caused by natural processes and in response to chemical changes in the near-field environment resulting from degradation of the glass waste. The materials for which hydraulic property changes over time are expected to most significantly impact the transport of contaminants are the asphaltic concrete of the surface barrier, the concrete vault, and the glass waste; corrosion of the steel waste containers is also expected to have a significant effect on contaminant transport. In addition, changes in backfill material, the filler material within the vaults, and the gravel capillary barrier material (if used as a component of the surface barrier) are potentially important. Potential changes in the hydraulic parameters of each of these materials as a function of time (material aging) is discussed below.

Changes in recharge through the surface cover either as a result of subsidence or in response to expansion of the waste containers due to steel corrosion are not discussed here. While these processes will not produce changes in the small-scale hydraulic properties of the surface cover materials (with the exception of the low-permeability asphaltic concrete layer), they may significantly affect the overall performance of the cover. Potential variations in the recharge rate over time as a result of changes in the volume of the waste are discussed in the recharge data package (Fayer et al., 1999).

\subsubsection{Asphaltic Concrete}

Changes to the hydraulic properties of the asphaltic concrete component of the surface barrier may increase the recharge rate reaching the concrete vaults. Because the upper layers of the surface barrier will protect the asphalt component from ultraviolet radiation and from extremes in temperature, the asphaltic concrete is expected to change little over the initial 500-year period from the time of construction. U.S. Nuclear Regulatory Commission (U.S. NRC) guidance for low-level waste disposal performance assessments recommends that the man-made components of the facility should be credited with a maximum of 500 years of as-built performance (NRC, 1997). Studies of naturally occurring asphalts, undertaken as part of the Hanford Barrier development (Waugh et al., 1994; Freeman and Romine, 1994), indicate that asphalt lifetimes under conditions expected in the ILAW disposal facilities are in excess of 500 years. One issue that has not been addressed, however, is the effect on asphalt of changes in pore water chemistry due to glass dissolution. Preliminary simulation studies of the near-field chemistry indicate that a high pH front may travel up towards the surface from the glass waste ${ }^{1}$. This issue will be given additional consideration before the disposal facility designs are finalized.

Given the current information, it is recommended that the best-estimate asphaltic concrete parameter values be assumed constant for a period of 500 years. The hydraulic properties of this barrier layer can

1. B.P. McGrail. June, 1999. Personal communication. 
be given the properties of the aggregate material of the concrete after the 500 -year period of performance. This is consistent with the assumptions of the recharge rate discussed in the recharge data package (Fayer et al., 1999) and with the approach used in the initial ILAW PA (Mann et al., 1998).

\subsubsection{Concrete}

The concrete vaults provide a low-permeability barrier to water intrusion and also influence the chemistry of the water reaching the glass waste. For the purpose of low-level waste disposal, NRC guidance recommends assuming a 500-year service life for man-made components unless justification for a longer service life can be made. The degradation of concrete in response to the chemical conditions to which it is exposed has been studied extensively (Clifton, 1993). Service life predictions can be based on a comparison of performance to existing concretes; accelerated testing using elevated temperature, pressure, and chemical conditions; and mathematical modeling.

Simulations by Fayer and Kincaid (1998) ${ }^{1}$ indicate that the presence of intact concrete may have either a relatively small effect on the peak dose from the ILAW facility or a fairly large effect, depending on the parameters assumed for the glass waste. In these simulations, various concrete hydraulic properties were assumed for intact, fractured, and degraded concrete. The peak dose over a 100,000-year period from a single vault was compared to the case where no concrete was used. Peak dose increased by $14 \%$ to $259 \%$ when no concrete was used as compared to the use of intact concrete. The wide range in the effect of the concrete was due to the particular model assumed for the glass waste. It must be pointed out that the hydraulic properties for the intact concrete and the glass waste were not the best-estimate values presented in Sections 4.2.1 and 4.2.3.

Sensitivity simulations for the 2001 ILAW PA should be carried out using (1) the intact properties of concrete given in Section 4.2.1 and (2) the backfill properties given in Section 4.4.1 in place of the concrete. This latter case represents an assumption that no concrete is used in the ILAW disposal facility. The two cases together serve to bound the importance of the concrete properties to the facility performance and consequently provide some guidance on the importance of modeling the degradation of concrete over time. If concrete degradation is to be modeled, the specific chemical conditions of the ILAW facilities should be included in the analysis. Available models such as described in Snyder and Clifton (1995), Berner (1992), Walton (1990), and Clifton and Knab (1989) may be useful in the estimation of concrete service life. An empirical approach, used in the Grouted Waste Disposal PA (Winkel, 1994), may also prove practical.

The volume occupied by the corrosion products of the steel waste containers is expected to be greater than the volume of the intact steel. Corrosion of the steel will thus result in additional stress on the

1. Fayer, M.J. and C.T. Kincaid. 1998. Simulations to Guide Measurements of Near-Field Hydraulic Parameters. Letter report to Fluor Daniel Hanford, Inc., Sept. 30, 1998, Pacific Northwest National Laboratory, Richland, Washington. 
concrete vault, potentially producing cracks in the concrete ${ }^{1}$. Stress fractures will increase the effective hydraulic conductivity of the concrete. Wang et al. (1997) provide laboratory measurements of the relationship between hydraulic conductivity and crack width for concrete that has undergone stress fracturing. Depending on final design decisions for the disposal facilities, the interaction between corrosion of the steel waste containers, geotechnical stability of the disposal facility, and the near-field hydrology may be a subject of further investigation by the ILAW PA project in the future.

If the degradation of the concrete vault is not modeled explicitly, there is no technical basis for assuming a transition in concrete properties between the best-estimate values and the fully degraded properties. In addition, the simulations conducted by Fayer and Kincaid $(1998)^{2}$ resulted in minor differences between the peak dose when using fractured concrete properties and that obtained when using their fully degraded concrete properties. We recommend that the best-estimate parameter values for concrete be used for the first 500 years of facility operation and that the fully degraded concrete parameter values be used for the remainder of the time. The fully degraded concrete parameter values should be assigned based on the expected composition of the concrete aggregate, which has not been specified for the new ILAW disposal facility. It is assumed here that the fully degraded concrete can be represented as a mixture of $60 \%$ of the backfill material (see Section 4.4.1) and $40 \%$ of a gravel with particle diameters distributed relatively uniformly between 2 and $10 \mathrm{~mm}$. The assumed particle size distribution for this material is given in Table 6.7.

Table 6.7. Assumed Particle Size Distribution for Fully Degraded Concrete

\begin{tabular}{|c|c|c|c|c|c|c|c|c|c|c|c|}
\hline Particle Size (mm) & 10 & 7 & 5 & 3 & 2 & 1 & 0.5 & 0.25 & 0.1 & 0.05 & 0.002 \\
\hline Percent Finer & 100 & 95 & 88 & 75 & 60 & 52.9 & 32.6 & 14.6 & 6.5 & 4.5 & 3 \\
\hline
\end{tabular}

The particle size distribution of Table 6.7 was used in the method of Arya and Paris (1981) to generate a set of sample water retention points for the fully degraded concrete. The bulk and particle densities were assumed to be the same as the best-estimate backfill values. Using the sample water retention points and the RETC code (van Genuchten et al., 1991), water retention parameters were estimated for the fully degraded concrete. Saturated hydraulic conductivity was estimated using the Kozeny-Carmen equation (Bear, 1972).

1. Nozaki, A., B.P. McGrail, M.J. Fayer, and K.M. Krupka. 1999. "Mechanical stability analysis for the immobilized low-activity waste (ILAW) disposal facility at the Hanford Site." Computers and Structures, in review.

2. Fayer, M.J. and C.T. Kincaid. 1998. Simulations to Guide Measurements of Near-Field Hydraulic Parameters. Letter report to Fluor Daniel Hanford, Inc., Sept. 30, 1998, Pacific Northwest National Laboratory, Richland, Washington. 


$$
\mathrm{K}_{\mathrm{s}}=\frac{\rho \mathrm{g}}{\mu} \cdot \frac{\phi^{3}}{(1-\phi)^{2}} \cdot \frac{\mathrm{d}_{\mathrm{m}}^{2}}{180}
$$

where $\rho$ and $\mu$ are the density and viscosity of water, respectively, $g$ is the acceleration due to gravity, and $d_{m}$ is a mean particle diameter. Density and viscosity were specified at $15^{\circ} \mathrm{C}$. Porosity was assumed to be equal to the saturated water content. The mean particle diameter of $2.1 \mathrm{~mm}$ was calculated as the average of the particle size fractions defined in Table 6.7 weighted by the percent in each fraction. Parameter values for the fully degraded concrete are given in Table 6.8 .

Table 6.8. Parameter Values for Fully Degraded Concrete

\begin{tabular}{|c|c|c|c|c|c|c|}
\hline$\rho_{\mathbf{p}}\left(\mathrm{g} / \mathrm{cm}^{3}\right)$ & $\rho_{\mathbf{b}}\left(\mathrm{g} / \mathrm{cm}^{3}\right)$ & $\theta_{\mathbf{s}}$ & $\theta_{\mathbf{r}}$ & $\alpha\left(\mathrm{cm}^{-1}\right)$ & $\mathbf{n}$ & $\mathbf{K}_{\mathbf{s}}(\mathbf{c m} / \mathbf{s})$ \\
\hline \hline 2.76 & 1.89 & 0.313 & 0.0 & 2.43 & 1.41 & $1.34 \times 10^{-3}$ \\
\hline
\end{tabular}

\subsubsection{Glass Waste}

The hydraulic properties of the fractured glass waste are expected to undergo changes over time in response to chemical reactions between the glass waste and the water moving through the waste. Corrosion testing of potential low-activity waste glasses is discussed in McGrail et al. (1998). As discussed in Section 4.2.3, this testing was performed on crushed glass samples, whereas the actual glass waste form is expected to be a highly fractured material. As discussed in McGrail et al. (1998), corrosion of their crushed glass sample resulted in pronounced changes in the sample's water retention characteristic. The changes appeared to be related to the onset of precipitation of zeolitic alteration phases. Scanning electron microscope pictures revealed that the originally pristine fracture surfaces of the grains had a relatively thick coating of alteration phases.

The effect of the alteration phases coating the glass particle surfaces was to increase the water content of the sample at a given matric potential. Although a water retention model was not fit to the data observed by McGrail et al. (1998), the alteration phase coating apparently resulted in a sizeable decrease in the values of the $\alpha$ and $n$ parameters in the van Genuchten water retention function. That is, the crushed glass sample behaved less like a coarse sand and more like a loamy-textured soil. Little change in the porosity or the saturated hydraulic conductivity was observed during the test conducted by McGrail et al. (1998), although this was attributed to the relatively short duration of the test.

The changes in the surfaces of the glass grains observed by McGrail et al. (1998) are expected to occur on the fracture surfaces of the ILAW glass waste and should produce similar changes in the hydraulic parameters of the glass waste, that is, a decrease in the $\alpha$ and $n$ parameters in the van Genuchten water retention function. The magnitude of these changes are currently unknown and are anticipated to be a subject of further investigation by the ILAW PA project in FY 2000. 


\subsubsection{Steel Container Corrosion}

The steel containers holding the glass waste are expected to be impermeable to water when initially put into the concrete vaults, but they are expected to corrode over time. The nature of the corrosion process and the consequent changes in the permeability of the steel and the ability of contaminants to be transported out of the steel containers has not been a subject of investigation. It is assumed here that the steel will eventually be converted completely to products of its corrosion. The hydraulic properties of these corrosion products is the subject of this section.

The specific products of steel or stainless steel corrosion depend on the unique environmental conditions within which corrosion takes place. Studies of steel exposed to the atmosphere, in non-polluted sea water, and in concrete have shown the iron oxides goethite $(\alpha-\mathrm{FeOOH})$ and lepidocrocite $(\gamma-\mathrm{FeOOH})$ to be the dominant corrosion products. Schwertmann and Cornell (1991) describe the formation and transformation pathways of iron corrosion products. Under oxidizing conditions and with $\mathrm{pH}$ in the range of 5-7, the transformations lead from $\mathrm{Fe}^{2+}$ to goethite and lepidocrocite. Transformation of these phases to hematite depends on the environmental conditions (Cornell and Schwertmann, 1996). With $\mathrm{pH}>8, \mathrm{Fe}^{2+}$ will oxidize directly to magnetite, maghemite, and hematite (Schwertmann and Cornell, 1991).

Based on studies for disposal of high-level radioactive waste at Yucca Mountain and on modeling studies for the ILAW PA project ${ }^{1}$, the dominant steel corrosion products in the ILAW disposal facilities are expected to be goethite and hematite. Although goethite is expected to transform to hematite, the reaction rate is expected to be slow enough that significant goethite will be present for a long period. (Actual corrosion transformation rates are unknown.)

Naturally occurring rock samples of hematite, goethite, and lepidocrocite were obtained to serve as surrogate materials for the steel corrosion products. The rocks were crushed in the laboratory to prepare samples for hydraulic property measurements. The crushed samples were hand-sieved using 2-mm (No. 10), 0.125-mm (No. 120), and 0.075-mm (No. 200) sieves to provide a general separation of particle sizes, but not a complete separation. Coarse-textured and fine-textured samples of crushed hematite and goethite were analyzed for physical and hydraulic properties (four samples total). A centrifuge method was used to measure water retention and unsaturated hydraulic conductivity ${ }^{2}$.

Average particle densities of the goethite and hematite samples were 3.82 and $4.50 \mathrm{~g} / \mathrm{cm}^{3}$, respectively. Average bulk densities were 2.05 and $2.78 \mathrm{~g} / \mathrm{cm}^{3}$, respectively, for the goethite and hematite samples. Hydraulic parameters were fit to each sample using RETC (van Genuchten et al., 1991). A simultaneous fit to the water retention and hydraulic conductivity data was performed with all parameters

1. B.P. McGrail, April, 1999, Personal communication.

2. Meyer, P.D. 1999. Hydraulic Parameters of Aged Near-Field Materials of the Immobilized Low-Activity Waste Disposal Facility, Letter Report to Fluor Daniel Northwest, Inc., August 30, 1999, Pacific Northwest National Laboratory, Richland, Washington. 
being fit $^{1}$. Note that compaction of the fine-textured hematite sample during the centrifuge measurements and the relative difficulty of fitting unsaturated hydraulic conductivity data resulted in a variable quality of fit for each sample. Other than the particle and bulk densities, the texture of the samples (coarse or fine) seemed to have a greater influence on the parameter values than the mineral type. The average parameters of the fine goethite and hematite samples are given in Table 6.9. Arithmetic averages were used except for $\alpha$ and $\mathrm{K}_{\mathrm{s}}$, for which geometric averages are given. These parameters may be representative of the fully corroded steel containers. Average grain size measurements for the fine samples were $96 \%$ finer than 0.125 $\mathrm{mm}, 50 \%$ finer than $0.063 \mathrm{~mm}$, and $36 \%$ finer than $0.045 \mathrm{~mm}$.

Table 6.9. Representative Parameter Values for the Fully Corroded Steel Containers

\begin{tabular}{|c|c|c|c|c|c|c|}
\hline$\rho_{\mathbf{p}}\left(\mathrm{g} / \mathrm{cm}^{3}\right)$ & $\rho_{\mathbf{b}}\left(\mathrm{g} / \mathrm{cm}^{3}\right)$ & $\theta_{\mathbf{s}}$ & $\theta_{\mathbf{r}}$ & $\alpha\left(\mathrm{cm}^{-1}\right)$ & $\mathbf{n}$ & $\mathbf{K}_{\mathbf{s}}(\mathbf{c m} / \mathbf{s})$ \\
\hline \hline 4.16 & 2.30 & 0.39 & 0.04 & 0.0008 & 1.77 & $2.2 \times 10^{-6}$ \\
\hline
\end{tabular}

\subsubsection{Backfill and Filler Material between Waste Packages}

The backfill and filler material within the vault may undergo changes in their hydraulic properties due to the high pH conditions expected within and around the vault. Kaplan et al. (1998) report on a series of experiments in which the quartz sand and backfill materials discussed in Sections 4.2.2 and 4.4.1 were exposed to $\mathrm{NaOH}$ solutions. $\mathrm{NaOH}$ was chosen as the experimental solution because its ions in solution are expected to be prevalent in the near-field pore water resulting from dissolution of the glass waste. Kaplan et al. (1998) performed batch and column experiments using 0.5, 1.0, 2.0, and 3.0 M solutions of $\mathrm{NaOH}$ with contact time of up to 10 months. No systematic changes in hydraulic properties were observed for either material. Results remained inconclusive, however, because biological growth was observed to occur in all samples. These experiments are currently being repeated on sediments that have been irradiated to sterilize them and minimize biological growth. Results will be available in FY 2000.

\subsubsection{Gravel Capillary Barrier Layer}

One of the changes suggested to occur from the degradation of the glass waste is the migration of a high $\mathrm{pH}$ front upward from the vault. If the diversion layer is used as a component of the surface barrier, the migration of a high $\mathrm{pH}$ front into the gravel capillary layer may produce mineral precipitation that could change the gravel hydraulic properties and potentially affect the performance of the diversion layer. Precipitation on the gravel grains would cause the hydraulic behavior of the gravel to become more like a sand; that is, the $\alpha$ and $\mathrm{n}$ parameters of the van Genuchten water retention function, and potentially the sat-

1. Meyer, P.D. 1999. Hydraulic Parameters of Aged Near-Field Materials of the Immobilized Low-Activity Waste Disposal Facility. Letter Report to Fluor Daniel Northwest, Inc., August 30, 1999, Pacific Northwest National Laboratory, Richland, Washington. 
urated hydraulic conductivity as well, would be reduced. Potential rates of mineral precipitation and resulting changes in hydraulic properties have not been quantified, but are anticipated to be a subject of further investigation by the ILAW PA project in FY 2000-2001.

\subsection{Comments on Effective Parameter Values}

Physical heterogeneity is widespread in natural porous media, and can be manifest on a hierarchy of scales from the sub-pore (microns) to the field (meters or more) (e.g., Cushman 1997; Whitaker 1999). A number of approaches have been proposed for deriving effective parameters when the scale of the heterogeneity is not explicitly represented in simulation models (Renard and de Marsily, 1997; Dagan, 1997). Although the near-field materials are not naturally occurring, there is nonetheless potentially significant physical heterogeneity due to the use of different materials over a fairly small scale, particularly within the vaults where concrete, glass waste, filler material, and steel corrosion products are all present. Nonuniform changes in material properties over time may also result in increasing heterogeneity of near-field materials. The methods developed for deriving the effective properties of naturally heterogeneous materials should also apply in simulations of the near-field materials.

Volume averaging is one approach that has been successfully used to formally account for the effects of subsurface heterogeneity on flow and transport. In volume averaging approaches, one seeks to describe the behavior of a system averaged over a volume of a porous medium. The approach can be applied in two distinct modes.

In the first mode, volume averaging is used to upscale random heterogeneous structures. Often, the problem that heterogeneity poses is that there exist structures in the porous medium that cannot be fully characterized deterministically because such a characterization is either impractical or impossible. For such cases, methods have been developed that use statistical information for developing the upscaled conservation equations and for determination of the effective parameters that appear in the conservation equation.

In the second mode, the method is used to upscale deterministic structure. Such upscaling may be necessary, for example, when one has available a high-resolution model (such as a geologic process model) of the heterogeneous porous media (Ahmadi and Quintard 1996). Under these circumstances, although the deterministic structure is available, it may be impractical to solve flow and transport equations in such a system because of computational limitations. This may be the case in near-field simulations, particularly because of the complex chemical reactions being modeled. In some instances, however, the domain can be re-discretized at a coarser scale by developing upscaled flow and transport equations (via volume averaging), and then calculating the associated effective parameters for each coarse grid block. Such a re-sampled system could then be solved with much less computational effort. Such approaches have been successfully employed to upscale deterministic structure in saturated systems (e.g., Ahmadi et 
al., 1998), but have not yet been applied to the problems of identification of effective parameters for unsaturated systems.

Using an effective parameter value to represent a large volume of heterogeneous material assumes that the nature of the heterogeneity (whether random or deterministic) can be determined. If the degree of heterogeneity is underestimated, the derived effective parameter values may provide a poor representation of the actual flow and transport. Such difficulties can arise, for example, under conditions that produce preferential flow. Because the ILAW near-field materials are engineered, they are likely to be less heterogeneous than the far-field materials. In addition, a properly functioning surface cover will not only lower the water content in those materials beneath the cover, but it will also reduce temporal variations in flow. These conditions reduce the potential for significant preferential flow. With the larger water flux from a degraded cover and increasing heterogeneity from material degradation, preferential flow may become more important. This possibility can be examined in future work. 


\subsection{Conclusions}

This report has discussed issues related to the appropriate hydraulic and transport parameters to use in simulations of the ILAW disposal facilities for the 2001 ILAW PA. This report is limited to those materials, both natural and man-made, that will be used within the excavated zone of the ILAW disposal facilities. Values for physical, hydraulic, and transport parameters are provided, although the transport parameters are limited to dispersivity and apparent diffusion coefficients. The apparent diffusion coefficients lump physical and chemical effects together. The current best-estimate parameter values are given along with a justification for their selection. In addition, the uncertainty of these parameters is discussed and reasonable upper and lower bounds are given for many of the parameters. These bounding values and the uncertainty information provided may prove useful in sensitivity or uncertainty analyses carried out as part of the 2001 ILAW PA. The report also includes a discussion of changes in material properties over time and how these changes are expected to affect the parameter values.

The parameter values provided in this report provide a starting point for the PA simulations. Changes in facility design, additional information and data that may become available, and unanticipated considerations may require that these parameter values be altered in the PA simulations. If this occurs, the new parameter values should be justified and the issues related to uncertainty and changes over time should be addressed for the new parameter values. Related parameters may also be used in other data packages being assembled for the 2001 ILAW PA. These data packages have not all been reviewed for consistency with this report.

Studies are ongoing as part of the ILAW PA project to better define the parameters of the near-field materials and to improve the analyses needed for completion of the PA. The PA will use the most current information available, which may supersede the contents of this report. This data package will be updated to collect all new information in a single source for use in future PAs. 


\subsection{References}

Ahmadi, A., M. Quintard, and S. Whitaker. 1998. "Transport in chemically and mechanically heterogeneous porous media, V, Two-equation model for solute transport with adsorption." Adv. Water Resour., 22:59-86.

Ahmadi, A. and M. Quintard. 1996. "Large-scale properties for two-phase flow in random porous media." J. Hydrol., 183:69-99.

American Nuclear Society (ANS). 1986. Measurement of the Leachability of Solidified Low-Level Radioactive Wastes by a Short-Term Test Procedure. ANSI/ANS-16.1-1986, American Nuclear Society, La Grange Park, Illinois.

Arya and Paris. 1981. "A Physicoempirical Model to Predict the Soil Moisture Characteristic from Particle-Size Distribution and Bulk Density Data." Soil Sci. Soc. Am. J., 45:1023-1030.

ASTM D422-63. Standard test method for particle-size analysis of soils. American Society of Testing and Materials, Philadelphia, Pennsylvania.

Atkinson, A. 1983. "Mathematical Modeling of Leaching From Porous Nuclear Waste-Forms." Radioactive Waste Management and the Nuclear Fuel Cycle, 3:371-386.

Atkinson, A. and Nickerson. 1988. "Diffusion and sorption of cesium, strontium, and iodine in water-saturated cement." Nuclear Technology, 81:100-113.

Atkinson, A. , K. Nelson, and T. M. Valentine. 1986. "Leach Test Characterisation of Cement-Based Nuclear Waste Forms." Nuclear and Chemical Waste Manaagement, 6:241-253.

Bear, J. 1972. Dynamics of Fluids in Porous Media. American Elsevier, New York.

Berner, U.R. 1992. "Evolution of pore water chemistry during degradation of cement in a radioactive waste repository environment." Waste Management, 12:201-219.

Blake, G.R. and K.H. Hartge. 1986a "Bulk Density". In Methods of Soil Analysis, Part 1, Physical and Mineralogical Methods, A. Klute (ed.), pp. 363-375, American Society of Agronomy, Madison, Wiscon$\sin$.

Blake, G.R: and K.H. Hartge. 1986b. "Particle Density." In Methods of Soil Analysis, Part 1, Physical and Mineralogical Methods, A. Klute (ed.), pp. 377-382, American Society of Agronomy, Madison, Wisconsin.

Bouwer, H. and R.C. Rice. 1983. "Effect of stones on hydraulic properties of vadose zones." In Proceedings of the characterization and monitoring of the vadose (unsaturated) zone. National Water Well Association, Worthington, Ohio.

Bretton, D., J.-P. Ollivier, and G. Ballivy. 1992. "Diffusivite des ions chlore dans la zone de transition entre pate ciment et roche granitue. pp 269-278, in Interfaces in Cementitious Composites, J. C. Maso (ed.), E\&FN Spon, an Imprint of Chapman \& Hall, London, England.

Brooks, R. H. and A. T. Corey. 1966. "Properties of porous media affecting fluid flow." J. Irrig. Drainage Div. Proc. Am Soc. Civ. Eng., 92:62-88. 
Brown, D. A., B. E. Fulton, and R. E. Phillips. 1964. "Ion Diffusion: I. A Quick-Freeze Method for the Measurement of Ion Diffusion in Soil and Clay Systems." Soil Sci. Soc. Am. Proc., 28:628-632.

Brown, D. A., J. E. Dunn and B. Fuqua. 1969. "Multiple-Ion Diffusion-I. Techniques for Measuring and Calculating Apparent Self-diffusion Coefficients in Heteroionic Systems." Clay and Clay Minerals 17:271-277.

Buckingham, E. 1904. Contributions to Our Knowledge of the Aeration of Soils. Bulletin 25. U.S. Department of Agriculture Bureau of Soils, Washington, D. C.

Buckmaster, M.A. 1993. Engineering Report for Prototype Surface Barrier of 200-BP-1 Operable Unit, Project W-263. WHC-SD-EN-TI-142, Rev. 0, Westinghouse Hanford Company, Richland, Washington.

Burbank, D.A. and T.M. Hohl. 1999. Reanalysis of Alternatives for Immobilized Low-Activity Waste Disposal. HNF-4003, Lockheed Martin Hanford Co., Richland, Washington.

Campbell, G.S. 1985. "Soil Physics with BASIC.” In Developments in Soil Science 14, Elsevier Science Publishers B.V., New York, New York.

Carsel, R.F. and R.S. Parrish. "Developing joint probability distributions of soil water retention characteristics." Wat. Resour. Res., 24(5):755-769.

Cedergren, H.R. 1989. Seepage, Drainage, and Flow Nets. Third Edition. John Wiley and Sons, Inc., New York, New York.

Clemmer, R.G., R.P. Allen, and L.K. Fetrow. 1992. Hydrogen Permeation of Asphalt Test Results - FY 1992. HGTP392-0605-02, Hanford Grout Technology Program, Pacific Northwest Laboratory, Richland, Washington.

Clifton, J.R. 1993. "Predicting the service life of concrete." ACI Materials Journal, 90(6):611-617.

Clifton, J.R. and L.I. Knab. 1989. Service Life of Concrete. NUREG/CR-5466 (also NISTIR 89-4086), U.S. Nuclear Regulatory Commission, Washington, D. C.

Conca, J.L. and J.V. Wright. 1990. "Diffusion coefficients in gravel under unsaturated conditions." Wat. Resour. Res., 26(5):1055-1066.

Conca, J.L. and J.V. Wright. 1991. "Aqueous diffusion coefficients in unsaturated materials." Mat. Res. Soc. Symp. Proc., Vol. 212, pp. 879-884.

Conca, J.L. and J.V. Wright. 1992. "Diffusion and flow in gravel, soil, and whole rock." Appied Hydrogeology, 1:5-24.

Cornell, R. M. and U. Schwertmann 1996. The Iron Oxides: Structure, Properties, Reactions, Occurrence, and Uses. VCH, Weinheim, Germany (also New York), 573 pp.

Cushman, J. H. 1997. The Physics of Fluids in Hierarchical Porous Media: Angstroms to Miles. Kluwer, Dordrecht.

Dagan, G. 1997. "Stochastic modeling of flow and transport: the broad perspective," in Subsurface Flow and Transport: A Stochastic Approach, G. Dagan and S. P. Neuman (eds.), Cambridge University Press, Cambridge, United Kingdom. 
Danielson, R.E. and P.L. Sutherland. 1986. "Porosity." In Methods of Soil Analysis, Part 1, Physical and Mineralogical Methods, A. Klute (ed.), pp. 443-461, American Society of Agronomy, Madison, Wiscon$\sin$.

DOE-RL. 1993. Focused Feasibility Study of Engineered Barriers for Waste Management Units in the 200 Areas. DOE/RL-93-33, Rev. 1, U.S. Department of Energy, Richland Operations Office, Richland, Washington.

DOE-RL. 1994. Constructibility Report for the 200-BP-1 Prototype Surface Barrier. DOE/RL-94-76, Draft A, U.S. Department of Energy, Richland Operations Office, Richland, Washington.

DOE-RL. 1999. 200-BP-1 Prototype Barrier Treatability Test Report. DOE/RL-99-11, Rev. 0, U.S. Department of Energy, Richland Operations Office, Richland, Washington.

Eching, S.O. and J.W. Hopmans. 1993. "Optimization of hydraulic functions from transient outflow and soil water pressure data." Soil Sci. Soc. of Am. J., 57(5):1167-1175.

Eching, S.O., J.W. Hopmans, and O. Wendroth. 1994 . "Unsaturated hydraulic conductivity from transient multistep outflow and soil water pressure data.." Soil Sci. Soc. of Am. J., 58(3):687-.

Ecology. 1987. Solid Waste Landfill Design Manual. No. 87-13, Parametrix, Inc., Bellevue, WA, for Washington State Department of Ecology, Olympia, Washington.

Environmental Protection Agency (EPA). 1989. Technical Guidance Document: Final Covers on Hazardous Waste Landfills and Surface Impoundments. EPA 530-SW-89-047, U.S. Environmental Protection Agency, Washington, D. C.

Fayer, M.J., E.M. Murphy, J.L. Downs, F.O. Khan, C.W. Lindenmeier, and B.N. Bjornstad. 1999. Recharge Data Package for the Immobilized Low-Activity Waste 2001 Performance Assessment. PNNL13033, Pacific Northwest National Laboratory, Richland, Washington.

Fayer, M.J. and C.S. Simmons. 1995. "Modified soil water retention functions for all matric suctions." Wat. Resour. Res., 31(5)1233-1238.

Fayer, M.J. and T.B. Walters. 1995. Estimated Recharge Rates at the Hanford Site. PNL-10285, Pacific Northwest Laboratory, Richland, Washington.

Fayer, M.J., M.D. White, and C.T. Kincaid. 1997. Sensitivity Tests of the Waste-Form-Alone Design for the Low-Activity-Waste Disposal System. PNNL-11717, Pacific Northwest National Laboratory, Richland, Washington.

Finney, D. J. 1971. Probit Analysis, 3rd edition. Cambridge University Press, New York, New York.

Freeman, H.D. and R.A. Romine. 1994. Hanford Permanent Isolation Barrier Program: Asphalt Technology Test Plan. PNL-9336, Pacific Northwest Laboratory, Richland, Washington.

Freeman, H.D., R.A. Romine, and A.H. Zacher. 1994. Hanford Permanent Isolation Barrier Program: Asphalt Technology Data and Status Report - FY 1994. PNL-10194, Pacific Northwest Laboratory, Richland, WA.

Gardner, W.H. 1986. "Water Content." In Methods of Soil Analysis, Part 1, Physical and Mineralogical Methods, A. Klute (ed.), pp. 493-544, American Society of Agronomy, Madison, Wisconsin. 
Gee, G.W. and J.W. Bauder. 1986. "Particle Size Analysis." In Methods of Soil Analysis, Part 1, Physical and Mineralogical Methods, A. Klute (ed.), pp. 383-409, American Society of Agronomy, Madison, Wisconsin.

Gee, G.W., R.R. Kirkham, J.L. Downs, M.D. Campbell. 1989. The Field Lysimeter Test Facility (FLTF) at the Hanford Site: Installation and Initial Tests. PNL-6810, Pacific Northwest Laboratory, Richland, Washington.

Gelhar, L.W. 1986. "Stochastic subsurface hydrology from theory to applications." Wat. Resour. Res., 22(9):135S-145S.

Gelhar, L.W., C. Welty, and K.R. Rehfeldt. 1992. "A critical review of data on field-scale dispersion in aquifers." Wat. Resour. Res., 28(7):1955-1974.

Grathwohl, P. 1998. Diffusion in Natural Porous Media: Contaminant Transport, Sorption/Desorption and Dissolution Kinetics, Kluwer Academic Publishers, Boston, Massachusetts.

Hajek, B.F. 1966. Soil Survey Hanford Project in Benton County Washington. BNWL-243, Pacific Northwest Laboratory, Richland, Washington.

Hillel, D. 1980. Applications of Soil Physics. Academic Press, San Diego, California, 385 pp.

Hoitink, D.J., K.W. Burk, and J.V. Ramsdell. 1999. Hanford Site Climatological Data Summary, 1998 with Historical Data. PNNL-12087, Pacific Northwest National Laboratory, Richland, Washington.

International Standards Organization (ISO). 1979. Draft International Standard on Long-Term Leach Testing of Radioactive Waste Solidification Products. ISO/DIS 6961, International Atomic Energy Agency, Vienna, Austria.

Kaplan, D. I., K.E. Parker, and J.C. Ritter. 1998. Effects of Aging Quartz Sand and Hanford Site Sediment. with Sodium Hydrolxide on Radionuclide Sorption Coefficients and Sediment Physical and Hydrologic Properties: Final Report for Subtask 2a. PNNL-11965, Pacific Northwest National Laboratory, Richland, Washington.

Kaplan, D. I. and R.J. Serne. 1999. Geochemical Data Package for the Hanford Immobilized Low-Activity Tank Waste Performance Assessment. PNNL-13037, Pacific Northwest National Laboratory, Richland, Washington.

Kemper, W. D. 1986. "Solute Diffusivity." In Methods of Soil Analysis, Part 1, Physical and Mineralogical Methods, A. Klute (ed.), pp. 1007-1024, American Society of Agronomy, Madison, Wisconsin.

Kemper, W. D. and J.C. van Schaik. 1966. "Diffusion of salts in clay-water systems." Soil Sci. Soc. Amer. Proc., 30:534-540.

Khaleel, R. 1999. Far-Field Hydrology Data Package for Immobilized Low-Activity Tank Waste Performance Assessment. HNF-4769, Rev. 1, Fluor Daniel Northwest, Inc., Richland, Washington.

Khaleel, R. and E.J. Freeman. 1995. Variability and Scaling of Hydraulic Properties for 200 Area Soils, Hanford Site. WHC-EP-0883, Westinghouse Hanford Company, Richland, Washington.

Khaleel, R., J.F. Relyea, and J.L. Conca. 1995. "Evaluation of van Genuchten-Mualem relationships to estimate unsaturated hydraulic conductivity at low water contents." Wat. Resour. Res., 31(11):2659-2668. 
Kincaid, C.T., J.W. Shade, G.A. Whyatt, M.G. Piepho, K. Rhoads, J.A. Voogd, J. H. Westsik, Jr., M.D. Freshley, K.A. Blanchard, and B.G. Lauzon. 1995. Performance Assessment of Grouted Double-Shell Tank Waste Disposal at Hanford. WHC-SD-WM-EE-004, Rev. 1, Vol. 1, Westinghouse Hanford Company, Richland, Washington.

Klute, A. 1986. "Water Retention: Laboratory Methods." In Methods of Soil Analysis, Part 1, Physical and In Mineralogical Methods. A. Klute (ed.), pp. 635-660, American Society of Agronomy, Madison, Wisconsin.

Klute, A. and C. Dirksen. 1986. "Hydraulic Conductivity and Diffusivity: Laboratory Methods." In Methods of Soil Analysis, Part 1, Physical and Mineralogical Methods, A. Klute (ed.), pp. 687-732, American Society of Agronomy, Madison, Wisconsin.

Krupka, K. M. and R. J. Serne. 1996. Performance Assessment of Low-Level Radioactive Waste Disposal Facilities: Effects on Radionuclide Concentrations by Cement/Ground-Water Interactions. NUREG/CR6377, U. S. Nuclear Regulatory Commission, Washington, D. C.

LMHC. 1998. Statements of Work for FY 1999 to 2004 for the Hanford Low-Activity Tank Waste Performance Assessment Program. HNF-SD-WM-PAP-062, Rev. 3, Lockheed Martin Hanford Company, Richland, Washington.

Luckner, L., M.Th. van Genuchten, and D.R. Nielsen. 1991. "Reply." Wat. Resour. Res., 27(4):663-664.

Mann, F.M. 1999a. Performance Objectives for the Hanford Immobilized Low-Activity Waste (ILAW) Performance Assessment. HNF-EP-0826, Rev. 2, Fluor Daniel Northwest, Inc., Richland, Washington.

Mann, F.M. 1999b. Scenarios for the Hanford Immobilized Low-Activity Waste (ILAW) Performance Assessment. HNF-EP-0828, Rev. 2, Fluor Daniel Northwest, Inc., Richland, Washington.

Mann, F.M., C.R. Eiholzer, A.H. Lu, P.D. Rittmann, N.W. Kline, Y. Chen, B.P. McGrail, G.F. Williamsion, N.R. Brown, and L.A. LaMont. 1997. Hanford Low-Level Tank Waste Interim Performance Assessment, WHC-EP-0884, Rev. 1, Westinghouse Hanford Company, Richland, Washington.

Mann, F.M., R.J. Puigh II, P.D. Rittmann, N.W. Kline, J.A. Voogd, Y. Chen, C.R. Eiholzer, C.T. Knicaid, B.P. McGrail, A.H. Lu, G.F. Williamson, N.R. Brown, and L.E. LaMont. 1998. Hanford Immobilized LowActivity Tank Waste Performance Assessment, DOE/RL-97-69, U.S. Department of Energy, Richland Operations Office, Richland, Washington.

McGrail, B.P., D. H. Bacon, J. P. Icenhower, W. L. Ebert, P. F. Martin, H. T. Schaef, and E. A. Rodriguez. 1999. Waste Form Release Data Package for the 2001 Immobilized Low-Activity Waste Performance Assessment. PNNL-13043, Pacific Northwest National Laboratory, Richland, Washington.

McGrail, B.P., C.W. Lindenmeier, P.F. Martin, and H.T. Schaef. 1998. Corrosion Testing of Low-Activity Waste Glasses, Fiscal Year 1998 Summary Report. PNNL-12014, Pacific Northwest National Laboratory, Richland, Washington.

Mendel, J. E. 1982. "The Measurement of Leach Rates: A Review." Nuclear and Chemical Waste Manaagement, 3:117-123.

Millington, R.J. 1959. "Gas diffusion in porous media." Science, 130:100-102.

Millington, R.J. and J.P. Quirk. 1959. "Permeability of porous media." Nature, 183:387-388. 
Millington, R.J. and J.P. Quirk. 1961. "Permeability of porous solids." Trans. Faraday Soc., 57:12001207.

Moridis, G.J. 1999. "Semianalytical solutions for parameter estimation in diffusion cell experiments." Wat. Resour. Res., 35(6):1729-1740.

Mualem, Y. 1976. "A new model for predicting the hydraulic conductivity of unsaturated porous media." Wat. Resour. Res., 12(3):513-522.

Mualem, Y. 1986. "Hydraulic Conductivity of Unsaturated Soils: Prediction and Formulas." In Methods of Soil Analysis, Part 1, Physical and Mineralogical Methods, A. Klute (ed.), pp. 799-823, American Society of Agronomy, Madison, Wisconsin.

Neitzel, D.A. (ed.). 1998. Hanford Site National Environmental Policy Act (NEPA) Characterization. PNNL-6415, Rev. 10, Pacific Northwest National Laboratory, Richland, Washington.

Nichols, W.E. and P.D. Meyer. 1996. "Multidimensional water flow in a low-level waste isolation barrier." Ground Water, 34(4):659-665.

Nimmo, J.R., J. Rubin, and D.P. Hammermeister. 1987. "Unsaturated flow in a centrifugal field: Measurement of hydraulic conductivity and testing of Darcy's Law." Wat. Resour. Res., 23(1):124-134.

Nimmo, J.R. 1990. "Experimental testing of transient unsaturated flow theory at low water content in a centrifugal field." Wat. Resour. Res., 26(9):1951-1960.

Nimmo, J.R. 1991. "Comment on the treatment of residual water content in "A consistent set of parametric models for the two-phase flow of immiscible fluids in the subsurface' by L. Luckner et al." Wat. Resour. Res., 27(4):661-662.

NRC. 1997. Branch Technical Position on a Performance Assessment Methodology for Low-Level Radioactive Waste Disposal Facilities. NUREG-1573 (Draft for Public Comment, May, 1997), U.S. Nuclear Regulatory Commission, Washington, D. C.

Olsen, S.R. W.D. Kemper, and J.C. van Schaik. 1965. "Self-diffusion coefficients of phosphorus in soil measured by transient and steady-state methods." Soil Sci. Am Proc., 29:154-158.

Olsen, S.R. and W.D. Kemper. 1968. "Movement of nutrients to plant roots." Adv. Agron., 30:91-151.

Papendick, R. I. and G. S. Campbell. 1980. "Theory and Measurement of Water Potential." in Water Potential Relations in Soil Microbiology, Am. Soc. of Agron. Spec. Publication No. 9, Soil Science Society of America, Madison, Wisconsin, pp. 1-22.

Phillips, R. E. and D. A. Brown. 1964. "Ion Diffusion: Il. Comparison of Apparent Self and Counter Diffusion Coefficients." Soil Sci. Soc. Am. Proc., 28:758-763.

PHMC. 1998. Conceptual Design Report, Immobilized Low-Activity Waste Disposal Facility, Project W520. HNF-3013, Rev. 0 Draft, Project Hanford Management Contractor, Richland, Washington.

PNL. 1973. A Study of Soil Matric Potential and Temperature in Hanford Soils. BNWL-1712, Pacific Northwest Laboratory, Richland, Washington. 
Porter, L.K., W.D. Kemper, R.D. Jackson, and B.C. Stewart. 1960. "Chloride diffusion in soils as influenced by moisture content." Soil Sci. Soc. Am. Proc., 24:460-463.

Puigh, R. 1999. Disposal Facility Data for the Hanford Immobilized Low-Activity Tank Waste. HNF-4950, Rev. 1, Fluor Daniel Northwest, Inc., Richland, Washington.

Rawlins, S.L. and G.S. Campbell. 1986. "Water Potential: Thermocouple Psychrometry." In Methods of Soil Analysis, Part 1, Physical and Mineralogical Methods, A. Klute (ed.), pp. 597-617, American Society of Agronomy, Madison, WI.

Reidel, S.P. and D.G. Horton. 1999. Geology Data Package for 2001 Immobilized Low-Activity Waste Performance Assessment. PNNL-12257, Pacific Northwest National Laboratory, Richland, Washington.

Reidel SP, and KD Reynolds. 1998. Characterization Plan for the Immobilized Low-Activity Waste Borehole. PNNL-11802, Pacific Northwest National Laboratory, Richland, Washington.

Reidel, S.P., K.D. Reynolds, and D.G. Horton. 1998. Immobilized Low-Activity Waste Site Borehole 299E17-21. PNNL-11957, Pacific Northwest National Laboratory, Richland, Washington.

Reitsma, S. and B. H. Kueper. 1994. "Laboratory measurement of capillary pressure-saturation relationships in a rock fracture." Wat. Resour. Res., 30(4):865-878.

Relyea, J. F., D. P. Trott, C. V. McIntyre and C. G. Rieger. 1986. "Diffusion of Tritiated Water and Chloride in Basalt-Bentonite Mixtures." Nuclear Technology, 74:317-323.

Renard, Ph. and G. de Marsily. 1997. "Calculating equivalent permeability: a review," Adv. Wat. Resour., 20(5-6):253-278.

Robinson, R. A. and R. H. Stokes. 1959. Electrolyte Solutions, 2nd Edition, Academic Press, New York, New York.

Rockhold, M.L., M.J. Fayer, and P.R. Heller, 1993. Physical and Hydraulic Properties of Sediments and Engineered Materials Associated with Grouted Double-Shell Tank Waste Disposal at Hanford. PNL-8813, Pacific Northwest National Laboratory, Richland, Washington.

Rockhold, M.L., R.E. Rossi, and R.G. Hills. 1996. "Application of similar media scaling and conditional simulation for modeling water flow and tritium transport at the Las Cruces Trench Site." Wat. Resour. Res., 32(3):595-609.

Rossi, C. and J. R. Nimmo. 1994. "Modeling of soil water retention from saturation to oven dryness." Wat. Resour. Res., 30(3):701-708.

Schaap, M.G. and F.J. Leij. 1998. "Database-related accuracy and uncertainty of pedotransfer functions." Soil Science, 163(10):765-779.

Schwertmann, U. and R. M. Cornell. 1991. Iron Oxides in the Laboratory: Preparation and Characterization. VCH, Weinheim, Germany (also New York), 137 pp.

Serne, R. J. 1990. "Grouted Waste Leach Tests: Pursuit of Mechanisms and Data for Long-Term Performance Assessment," in Scientific Basis for Nuclear Waste Management XIII, editors V. M. Oversby and P. W. Brown, Materials Research Society, Pittsburgh, Pennsylvania. Vol 176: 91-199. 
Serne, R. J., W. J. Martin, S. B. McLaurine, S. P. Airhart, V. L. LeGore and R. L. Treat. 1987. Laboratory Leach Tests of HFW Grout and Leachate Adsorption Tests Using Hanford Sediment. PNL-6019, Pacific Northwest Laboratory, Richland, Washington.

Serne, R. J., W. J. Martin, V. L. LeGore, C. W. Lindenmeier, S. B. McLaurine, P. F. C. Martin, R. O. Lokken. 1989a. Leach Tests on Grouts Made with Actual and Trace Metal-Spiked Synthetic Phosphate/ Sulfate Waste. PNL-7121. Pacific Northwest Laboratory, Richland, Washington.

Serne, R. J., W. J. Martin, R. O. Lokken, V. L. LeGore, C. W. Lindenmeier, P. F. C. Martin. 1989b. Leach and EP Toxicity Tests on Grouted Waste From Tank 106-AN. PNL-6960. Pacific Northwest Laboratory, Richland, Washington.

Serne, R. J., R. O. Lokken and L. J. Criscenti. 1992. "Characterization of Grouted LLW to Support Performance Assessment," Waste Management, Vol. 12, pp 271-287.

Serne, R. J., W. J. Martin and V. L. LeGore. 1995. Leach Test of Cladding Removal Waste Grout Using Hanford Groundwater. PNL-10745, Pacific Northwest Laboratory, Richland, Washington.

Shord, A.L. 1995. Tank Waste Remediation System Complex Site Evaluation Report. WHC-SD-WM-SE021, Rev. 0, Westinghouse Hanford Company, Richland, Washington.

Skelly, W.A. 1994. Material Properties Data and Volume Estimate of Silt Loam Soil at the NRDWL Reserve, McGee Ranch. WHC-SD-EN-TI-218, Westinghouse Hanford Company, Richland, Washington.

Snyder, K.A. and J.R. Clifton. 1995. 4SIGHT Manual: A Computer Program for Modelling Degradation of Underground Low Level Waste Concrete Vaults. NISTIR 5612, National Institute of Standards and Technology, Gaithersburg, Maryland.

Tumidajski, P.J. and B. Lin. 1998. "On the validity of the Katz-Thompson equation for permeabilities in concrete." Cement and Concrete Research, 28(5):643-647.

van Genuchten, M. Th. 1980. "A closed-form equation for predicting the hydraulic conductivity of unsaturated soils.” Soil Sci. Soc. Am. J., 44:892-898.

van Genuchten, M. Th., F. J. Leij, and S.R. Yates. 1991. The RETC Code for Quantifying the Hydraulic Functions of Unsaturated Soils. EPA/600/2-91/065, U.S. Environmental Protection Agency, Ada, Oklahoma.

Walton, J.C. 1990. Models for Estimation of Service Life of Concrete Barriers in Low-Level Radioactive Waste Disposal. NUREG/CR-5542, U.S. Nuclear Regulatory Commission, Washington, D. C.

Wang, K., D. C. Jansen, S.P. Shah, and A.F. Karr. 1997. "Permeability study of cracked concrete." Cement and Concrete Research, 27(3):381-393.

Washington Department of Transportation (WDOT). 1991. "Specification for Road, Bridge, and Municipal Construction." Washington Department of Transportation, Olympia, Washington.

Waugh, W.J., J.C. Chatters, G.V. Last, B.N. Bjornstad, S.O. Link, and C.R. Hunter. 1994. Barrier Analogs: Long-Term Performance Issues, Preliminary Studies, and Recommendations. PNL-9004, Pacific Northwest Laboratory, Richland, Washington.

Whitaker, S. 1999. The Method of Volume Averaging. Kluwer, Dordrecht. 
Whiting, D. and A. Walitt (eds.). 1988. Permeability of Concrete. American Concrete Institute, Detroit, Michigan.

Wierenga, P.J., M.H. Young, G.W. Gee, R.G. Hills, C.T. Kincaid, T.J. Nicholson, and R.E. Cady. 1993. Soil Characterization Methods for Unsaturated Low-Level Waste Sites. NUREG/CR-5988, U.S. Nuclear Regulatory Commission, Washington, D. C.

Wing N.R. 1993. The results of laboratory tests to determine the physical properties of various barrier construction materials. WHC-SD-ER-DP-006, Rev. 0, Westinghouse Hanford Company, Richland Washington.

Winkel, B.V. 1994. "Best estimate crack predictions for the grout vault engineered barriers." Appendix Q in Kincaid et al., Performance Assessment of Grouted Double-Shell Tank Waste Disposal at Hanford, WHC-SD-WM-EE-004, Rev. 1, Westinghouse Hanford company, Richland, Washington.

Wright, J.V., J.L. Conca, and X.Chen. 1994. Hydrostratigraphy and Recharge Distributions from Direct Measurements of Hydraulic Conductivity Using the UFA ${ }^{T M}$ Method. PNL-9424, Pacific Northwest Laboratory, Richland, Washington. 


\section{Appendix A: Quality Assurance and Safety}

All laboratory and field experiments are conducted under PNNL quality assurance (QA) requirements as described in the guidance provided in PNNL's Standards Based Management System (SBMS) and as specified in the Project QA Plan. Significant modifications to the QA plan are made in accordance with the guidance in the SBMS.

Project staff members are qualified and receive any training needed to carry out their assigned responsibilities.

Staff use equipment of known accuracy for data collection. For measurements necessary to substantiate test results, staff ensure that standards used for calibration are traceable to nationally recognized standards. Measuring and Test Equipment (M\&TE) lists are generated by each task and maintained in the project files applicable to the specific task. M\&TE used is identified in the laboratory record books or other data recording location to provide traceability to instrument calibrations.

Test procedures and methods are documented and deviations noted. New methods developed during the course of this work are documented and reviewed. All test procedures, data processing software, and supporting documentation undergo independent technical review by qualified PNNL staff.

Staff maintain records necessary to substantiate results and processes of research activities. After activities are completed, records are filed and maintained per the project Records Inventory and Disposition Schedule (RIDS).

All precautionary measures are taken in accordance with standard PNNL safety procedures to ensure that field work is conducted in a safe manner. No hazardous wastes have been generated during the conduct of work described in this report. 


\section{Distribution}

No. of

Copies

\section{OFFSITE}

D. I. Kaplan

Westinghouse Savannah River Company

Building 774-43A, Room 215

Aiken, SC 29808

J. Nimmo

U.S. Geological Survey

345 Middlefield Road, MS-421

Menlo Park, CA 94025

B. Scanlon

Texas Bureau of Economic Geology

University of Texas at Austin

University Station, Box X

Austin, TX 78713

\section{ONSITE}

\section{DOE, Office of River Protection}
C. A. Babel
H6-60
P. E. Lamont
H6-60

-3 Bechtel Hanford Inc.

B. H. Ford

H0-21

G. A. Jewel (2)

4 Fluor Daniel Northwest, Inc.

E. J. Freeman, Jr.

B4-43

R. Khaleel

B4-43

F. M. Mann

$\mathrm{H} 0-22$

R. J. Puigh II

B4-43
No. of

Copies

\section{Lockheed Martin Hanford Corporation}

D. A. Burbank, Jr.

S4-45

K. C. Burgard

S4-45

A. J. Knepp

$\mathrm{H} 0-22$

R. W. Root, Jr.

R2-53

\section{Washington State University}
A. P. Gamerdinger

K6-81

\section{Pacific Northwest National Laboratory}

D. H. Bacon

K9-33

R. W. Bryce

K6-75

M. J. Fayer

K9-33

G. W. Gee

K9-33

C. T. Kincaid

K9-33

C. W. Lindenmeier

K6-81

S. V. Mattigod

K6-81

B. P. McGrail

K6-81

P. D. Meyer (5)

S8-09

S. P. Reidel

K6-81

K. P. Saripalli

K6-81

R. J. Serne (3)

K6-81

G. P. Streile

K9-33

A. L. Ward

K9-33

Information Release Office (7)

Distr. 1 